\title{
Avaliação de políticas de substituição de objetos em CACHES na WEB
}

\author{
João Carlos Pinheiro
}

Orientadora:

Profa. Dra. Regina Helena Carlucci Santana

Dissertação apresentada ao Instituto de Ciências Matemáticas e de Computação ICMC-USP, como parte dos requisitos para obtenção do titulo de Mestre em Ciências de Computação e Matemática Computacional.

\section{USP - São Carlos \\ Dezembro/2001}

Data da Defesa:

$04 / 12 / 2001$

Visto do Orientador: Re rive Aanlefe

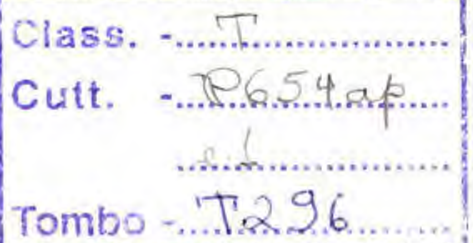


Dedico esta dissertação a minha mãe, Maria do Socorro, pelo exemplo de vida, apoio e dedicação. 


\section{Agradecimentos}

A Deus por sempre me mostrar o caminho.

A minha orientadora, Prof ${ }^{\mathrm{a}}$. Dr ${ }^{\mathrm{a}}$. Regina Helena Carlucci Santana, pela orientação e, principalmente, pela oportunidade e pelos conhecimentos transmitidos durante o mestrado.

Ao Prof. Dr. Marcos José Santana, pelas criticas sempre construtivas, pelos ensinamentos e, principalmente, pelos divertidos churrascos.

À minha mãe Maria do Socorro, pelo carinho, incentivo, confiança, pelos conselhos sempre valiosos.

À Tânia Sena Batalha (minha princesa), pelo apoio, compreensão, confiança e carinho.

Aos amigos da colônia maranhense Renato Bulcão, Mário Meireles e Érika pelos inúmeros momentos agradáveis, pelo apoio e companheirismo fundamentais em todos os momentos e pelas críticas e sugestões indispensáveis para este trabalho.

À minha família: Maria do Socorro, Ozino, Jean, Daniel e Lia Raquel.

Aos amigos e companheiros do LASDPC: Álvaro, Arion, Célia, Daniel Lobato, Douglas, Edmilson, Hermes, Kalinka, Jorge, Luis Fernando, Mara, Mário, Márcio, Naninha, Omar, Paulo Sérgio, Renata, Roberta, Renato Francês, Ricardo, Sarita, Tatiana, Tomas, Vera e muitos outros, que de uma maneira ou de outra contribuíram para realização deste trabalho.

Ao $\mathrm{CNPq}$, pelo apoio financeiro parcial. 


\section{ÍNDICE}

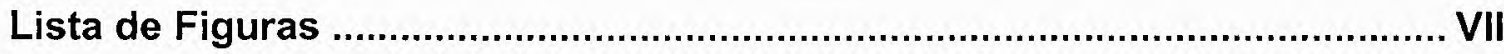

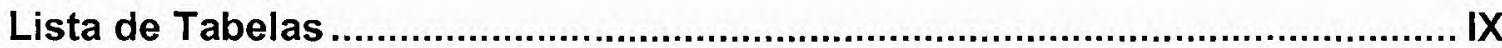

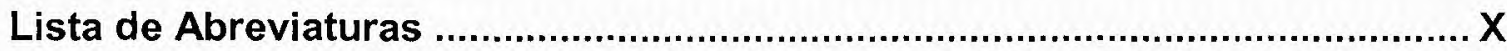

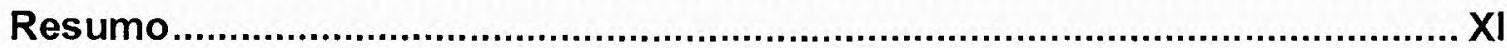

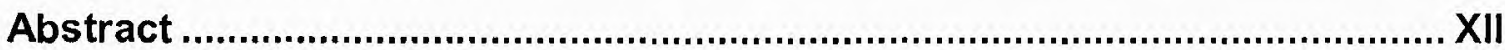

1 INTRODUÇÃO

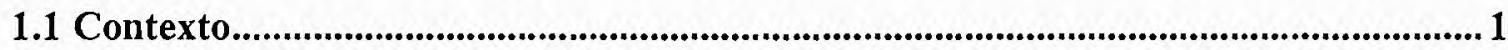

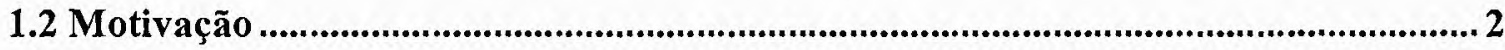

1.3 Objetivos................................................................................................................

1.4 Estrutura ............................................................................................................................

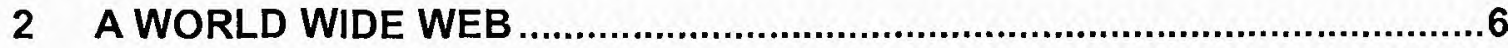

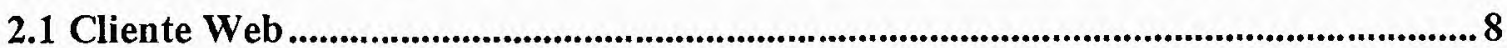

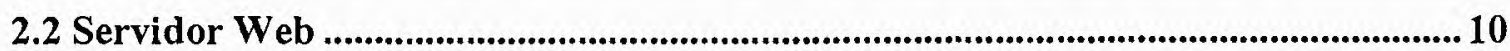

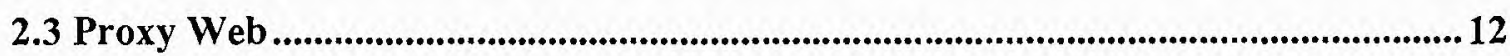

2.4 Considerações Finais .................................................................................................14

3 CACHES NA WEB

3.1 Caches Tradicionais ....................................................................................................16

3.2 Caches na Web............................................................................................................ 17

3.3 Consistência em Caches na Web ……..........................................................................22

3.4 Topologias de Caches na Web .......................................................................................23

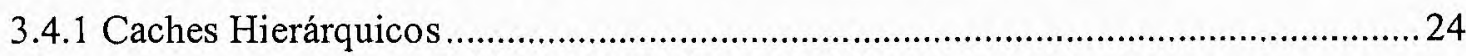

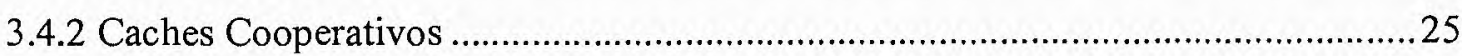

3.5 Políticas de Substituição de Objetos em Caches na Web.............................................26

3.5.1 Políticas que Consideram Somente um Parâmetro na Substituição ………………....27

3.5.2 Políticas que Consideram dois Parâmetros na Substituição ........................................29

3.5.3 Políticas que Consideram Múltiplos Parâmetros na Substituição ...............................33

3.6 Considerações Finais ..........................................................................................................34

4 CARACTERIZAÇÃO DE CARGA DE SERVIDORES PROXY COM

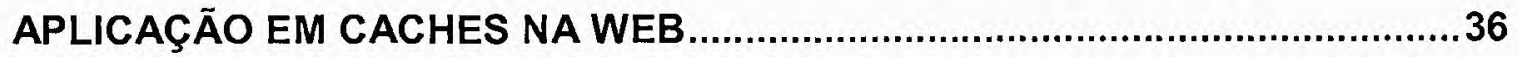




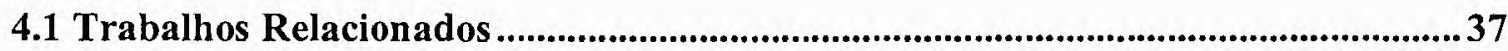

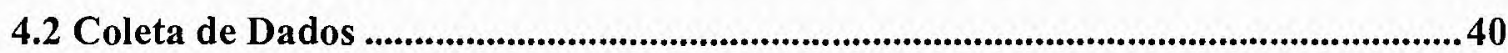

4.3 Análise dos Códigos de Status Retornados pelos Protocolos HTTP e ICP ..............43

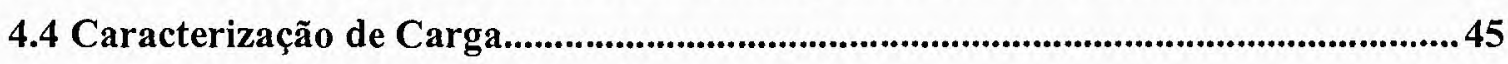

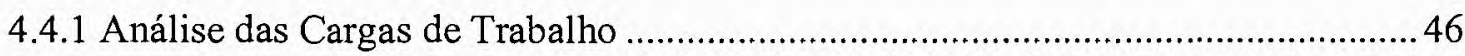

4.4.2 Caracterização de Requisições por Classe de Objetos ...........................................49

4.4.3 Caracterização das Requisições por Classes de Tamanho........................................52

4.4.4 Comparação entre Classes de Objetos e Tamanho ................................................5 54

4.5 Caracterização de Carga (Freqüência Acumulada)..................................................55

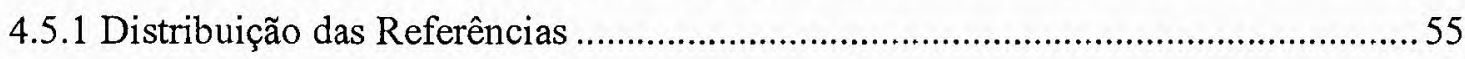

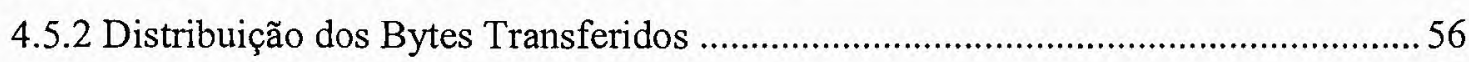

4.5.3 Distribuição das Referências Considerando o Tamanho dos Objetos..................... 57

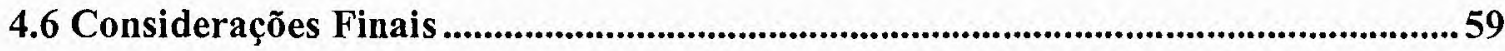

5 AVALIAÇÃO DE DESEMPENHO DE CACHES NA WEB...........................61

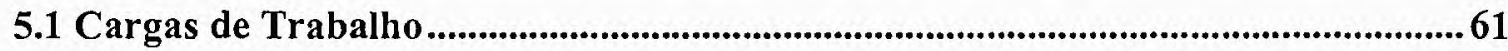

5.2 Estrutura e Funcionalidades do Simulador ........................................................62

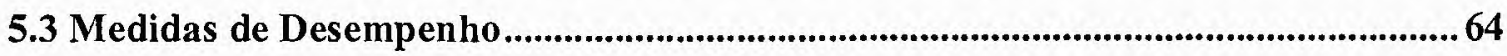

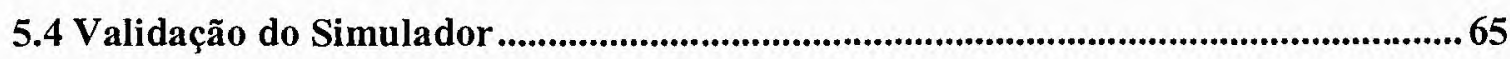

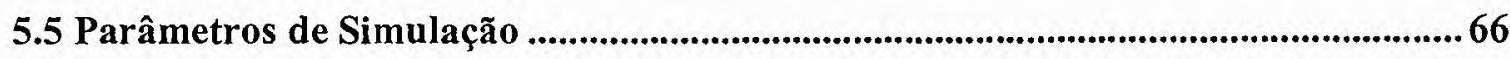

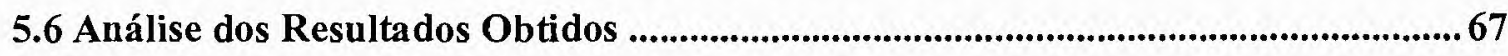

5.6.1 Determinação do Parâmetro $A_{\max }$ às Políticas LFU-Aging e LFU*-Aging ............ 68

5.6.2 Comparação das Políticas LFU, LFU*, LFU-Aging e LFU*-Aging ...................... 72

5.6.3 Uma Nova Política de Substituição: PESO …............................................................ 74

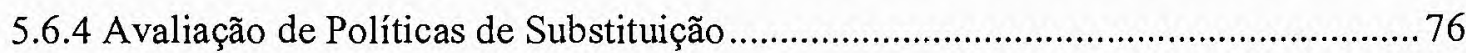

5.6.5 Limites Inferior e Superior aos Objetos Aceitos no Cache ................................... 78

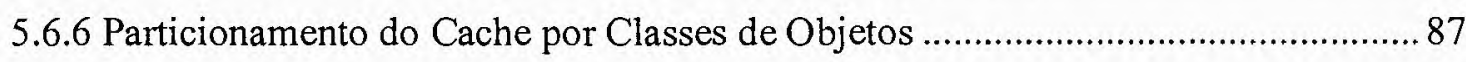

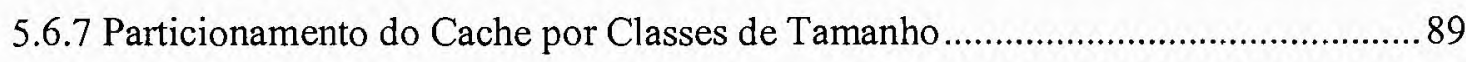

5.6.8 Comparação entre Caches não Particionado e Particionado por Classes de Objetos e

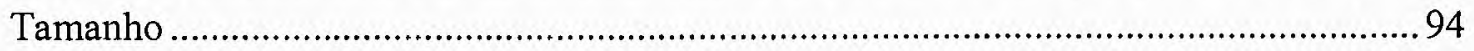

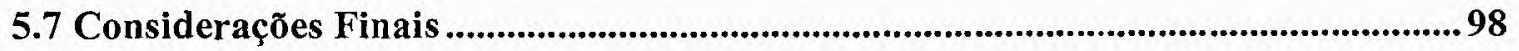




\section{CONCLUSÕES, CONTRIBUIÇÕES E PROPOSTAS PARA TRABALHOS}

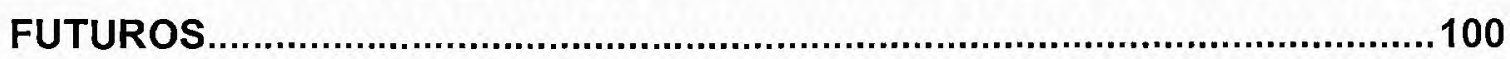

6.1 Considerações Sobre a Revisão Bibliográfica ........................................................... 100

6.2 Resultados, Contribuições e Conclusões........................................................................ 101

6.3 Trabalhos Futuros ..............................................................................................103

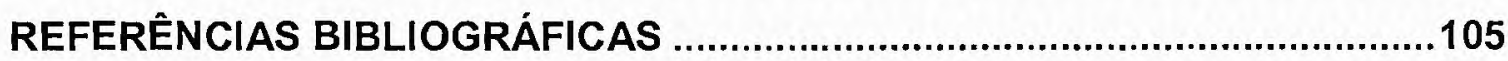




\section{Lista de Figuras}

FIGURA 2.1: Arquitetura cliente-servidor da Web. .................................................

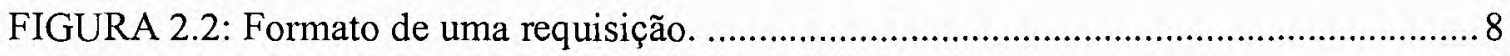

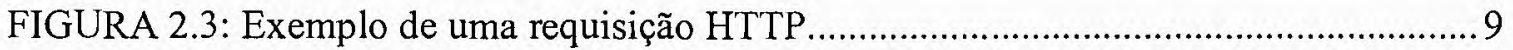

FIGURA 2.4: Formato de uma resposta HTTP..................................................................... 10

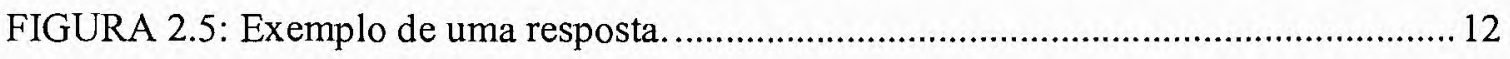

FIGURA 2.6: Exemplo de uma requisição através de um servidor proxy...........................13

FIGURA 3.1: Sistema de caches na Web.......................................................................... 19

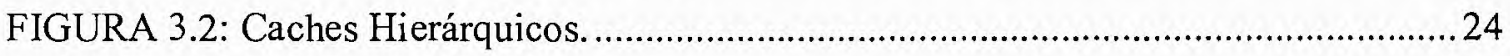

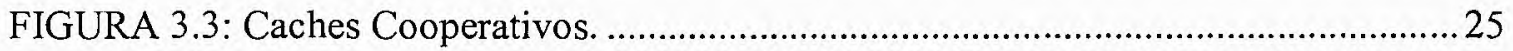

FIGURA 3.4: Organização das seções na política FBR …................................................... 31

FIGURA 3.5: Modelo da política de substituição dinâmica (Brandão \& Anido, 2001)...... 34

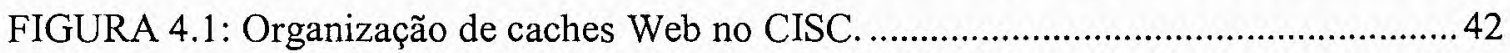

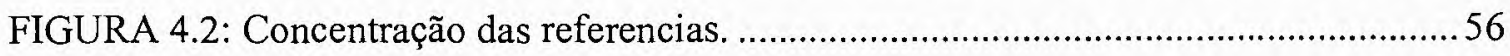

FIGURA 4.3: Concentração dos bytes transferidos ............................................................ 57

FIGURA 4.4: Freqüência acumulada ordenada pelo tamanho dos objetos...........................58

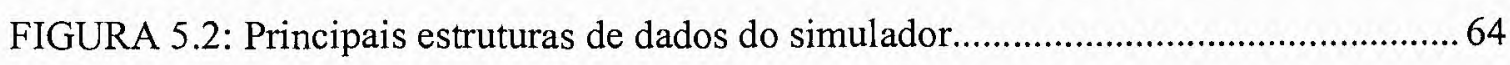

FIGURA 5.3: Comparação da HR para as políticas LFU, LFU*, LFU-Aging e LFU*_

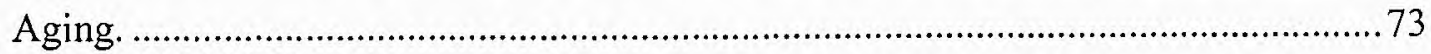

FIGURA 5.4: Comparação da BHR para as políticas LFU, LFU*, LFU-Aging e LFU*-

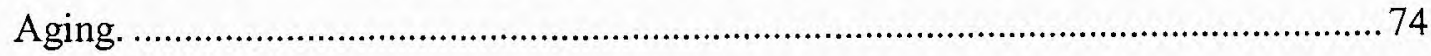

FIGURA 5.5: Comparação de políticas de substituição de objetos (CISC)........................... 77

FIGURA 5.6: Comparação de políticas de substituição de objetos. (BO2) ……................... 77

FIGURA 5.7: Comparação de políticas de substituição de objetos (PA).............................. 78

FIGURA 5.8: Comparação de políticas de substituição de objetos (SV)............................ 78

FIGURA 5.9: Comparação de políticas de substituição, considerando um limiar inferior e

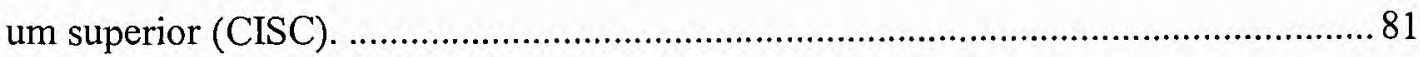

FIGURA 5.10: Comparação de politicas de substituição, considerando um limiar inferior e

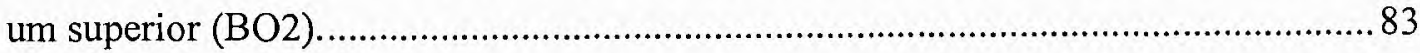


FIGURA 5.11: Comparação de políticas de substituição, considerando um limiar inferior e um superior (PA).

FIGURA 5.12: Comparação de políticas de substituição, considerando um limiar inferior e um superior (SV) 86

FIGURA 5.13: Comparação de políticas de substituição com 3 partições (CISC).............. 88

FIGURA 5.14: Comparação de políticas de substituição com 3 partições (BO2) ...............88

FIGURA 5.15: Comparação de políticas de substituição com 3 partições (PA)...................8 88

FIGURA 5.16: Comparação de políticas de substituição com 3 partições (SV)..................89

FIGURA 5.17: Comparação de políticas de substituição com 5 partições (CISC)...............91

FIGURA 5.18: Comparação de políticas de substituição com 5 partições (BO2)............... 91

FIGURA 5.19: Comparação de políticas de substituição com 5 partições (PA)................... 91

FIGURA 5.20: Comparação de políticas de substituição com 5 partições (SV)................... 92

FIGURA 5.21: Comparação de políticas de substituição de objetos na partição_1 1..............93

FIGURA 5.22: Comparação de políticas de substituição de objetos na partição_1 (BO2).. 93

FIGURA 5.23: Comparação de políticas de substituição de objetos na partição_3 (BO2)..93

FIGURA 5.24: Comparação de políticas de substituição de objetos na partição_4 (BO2).. 94

FIGURA 5.25: Comparação de políticas de substituição de objetos na partição_5 (BO2).. 94

FIGURA 5.26: Total de objetos armazenados no cache ao final da simulação. .................. 96

FIGURA 5.27: HR e BHR para quatro configurações no espaço de armazenamento dos

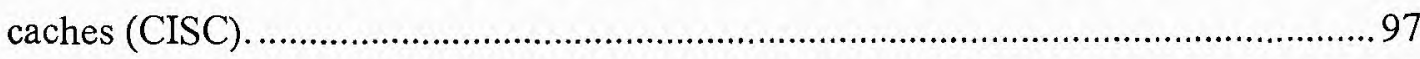

FIGURA 5.28: HR e BHR para quatro configurações no espaço de armazenamento dos

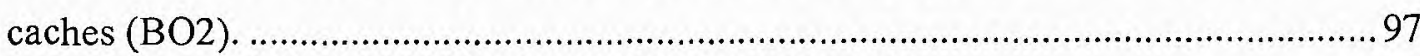

FIGURA 5.29: HR e BHR para quatro configurações no espaço de armazenamento dos

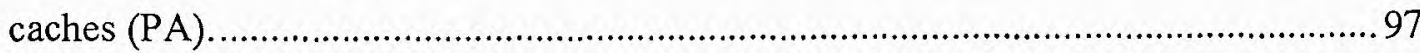

FIGURA 5.30: HR e BHR para quatro configurações no espaço de armazenamento dos caches (SV). 


\section{Lista de Tabelas}

TABELA 2.1: Métodos suportados pelo protocolo HTTP/1.1 ............................................ 9

TABELA 2.2: Classes de códigos de status HTTP............................................................ 11

TABELA 2.3: Código de status comumente retornado pelo servidor Web......................... 11

TABELA 4.1: Invariantes sobre o tráfego nos servidores Web.............................................. 38

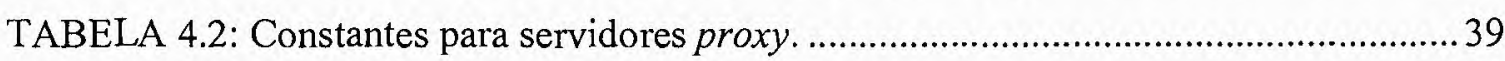

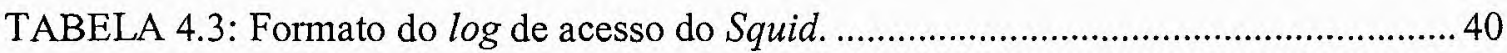

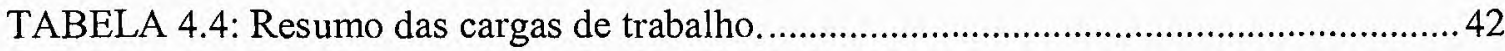

TABELA 4.5: Classes de respostas do protocolo HTTP e ICP. ............................................ 43

TABELA 4.6: Utilização dos métodos HTTP/1.1 e ICP........................................................4

TABELA 4.7: Análise das dos códigos de status mais observados nas cargas de trabalho. 45

TABELA 4.8: Características das quatro cargas de trabalhos analisadas. ............................46

TABELA 4.9: Características dos objetos distintos............................................................ 47

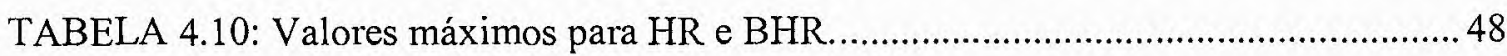

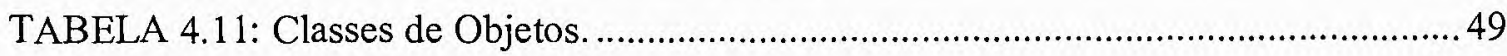

TABELA 4.12: Caracterização das requisições por classe de objetos...............................50

TABELA 4.13: Fração dos acessos únicos por classe de objetos. .......................................52

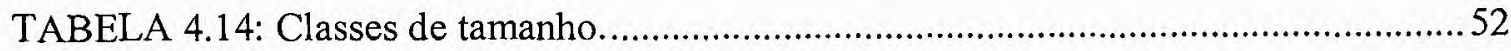

TABELA 4.15: Caracterização das requisições por classe de tamanho.............................. 53

TABELA 4.16: Fração dos acessos únicos por classes de tamanho. ..................................54

TABELA 5.1: Efeito do parâmetro $A_{\max }$ na política LFU-Aging.......................................69

TABELA 5.2: Efeito do parâmetro $A_{m a x}$ na política LFU*-Aging...................................... 71

TABELA 5.3: Definição dos parâmetros para caches com três partições..............................87

TABELA 5.4: Definição dos parâmetros para caches com cinco partições.......................... 89

TABELA 5.5: Definição dos parâmetros para caches com três partições.............................89 


\section{Lista de Abreviaturas}

ANSI American National Standards Institute

ASP Active Server Page

BHR Taxa de Acerto por Bytes

$\mathrm{BO} 2$ Boulder (Universidade do Colorado)

CGI Common Gateway Interface

CISC Centro de Informática de São Carlos

FBR Frequency-Based Replacement

HTML HyperText Markup Language

HTTP HyperText Transfer Protocol

HR Taxa de Acerto

ICP Internet Cache Protocol

ISP Internet Service Provider

LFU Least Frequently Used

LRU Least Recently Used

LRV Lowest Relative Value

MIME Multipurpose Internet Mail Extensions

NLANR National Laboratory for Applied Network Research

PA Palo Alto (California)

PDF Portable Document Format

PSS Pyramidal Selection Scheme

SV Vale do Silicio (California)

TCP Transmission Control Protocol

TTL Time-To-Live

URI Uniform Resource Identifiers

URL Uniform Resource Locator

XML Extensible Markup Language

WWW World Wide Web 


\section{Resumo}

Em qualquer sistema de cache real, o espaço de armazenamento é finito. Quando o cache estiver cheio e, for solicitado um objeto que não esteja presente no cache, será necessário definir o(s) objeto(s) que será(ão) retirado(s) do cache para ceder lugar ao objeto que está sendo inserido. Essa tarefa é cumprida pelas políticas de substituição de objetos. Um passo fundamental para melhorar o desempenho de caches na Web é identificar características comuns em suas cargas de trabalho para delinear diretrizes que buscam uma melhor parametrização das políticas de substituição e a organização do espaço de armazenamento de maneira eficaz. Este trabalho tem como propósito ponderar sobre o impacto provocado pelas políticas de substituição de objetos em caches na Web, por meio da investigação, avaliação de desempenho e comparação do uso destas políticas, considerando diversas configurações no espaço de armazenamento de caches. Foram implementadas e analisadas oito políticas, sendo duas delas tradicionais (LRU e LFU); uma política que implementa uma técnica de envelhecimento à política LFU (LFU-Aging); uma política que considera apenas o tamanho dos objetos para substituição (SIZE); duas que tratam de maneira direta os objetos com um único acesso (LFU* e LFU*-Aging); a política FBR, que divide o cache em três segmentos e; uma nova política proposta neste trabalho, denominada PESO. A avaliação é feita através de um simulador de caches para Web. 


\begin{abstract}
In any real caching system, storage space is finite. When the cache is full and an object which is not present in the cache is requested, it will be necessary to define the object that will be removed from the cache to give place to the one that is being inserted. Such task is accomplished by cache replacement policies. A fundamental step to improve the performance of caches in the Web is the identification of common characteristics in their workloads to provide guidelines that aim at a better parametrization of both substitution policies and storage space organization. This study aims to pondering on the impact caused by cache replacement policies in Web caches, through the investigation, performance analysis and comparison of the use of these policies by taking into account several storage space arrangements. Among the eight policies implemented and analyzed, two of them were traditional ones (LRU and LFU); one was implemented through the "aging" technique of the LFU policy (LFU-Aging); one considered only the size of the objects for substitution (SIZE); two dealt directly with single-accessed objects (LFU* and LFU*-Aging); one divided the cache into three segments (FBR) and, last but not least, a new policy was proposed in this study, called PESO. The evaluation is performed through a Web cache simulator.
\end{abstract}




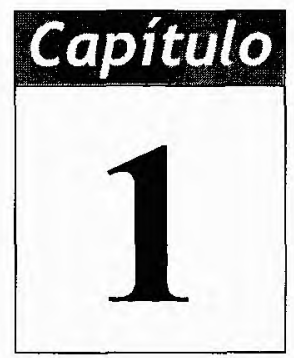

\section{Introdução}

\subsection{Contexto}

A crescente utilização da World Wide Web (WWW), ou simplesmente Web, tem provocado uma sobrecarga na Internet que pode ser percebida pelos altos tempos de recuperação dos objetos solicitados, bem como na degradação de desempenho em virtude do tráfego redundante. Uma das soluções para este problema é a utilização de caches para objetos Web.

A gerência de caches na Web é um problema com características diferentes dos sistemas de caches tradicionais encontrados em arquitetura de computadores, hierarquias de memória e sistemas operacionais (Murta \& Almeida, 2000). Por exemplo, enquanto que os caches tradicionais existentes nos sistemas de computação consistem de objetos de tamanho único, os sistemas de cache na Web operam com objetos de tamanhos muito variáveis. Outra característica que diferencia os dois tipos de caches é o tempo de recuperação dos objetos, que nos caches tradicionais são mais estáveis. As características peculiares a objetos da Web devem ser consideradas no projeto de políticas de substituição de objetos.

Uma vez que o espaço de um cache é finito, não há como armazenar indefinidamente todos os objetos lidos. Em algum momento será necessário retirar um ou mais objetos para armazenar novos objetos que não estão presentes no cache. A política de 
substituição de objetos decide qual ou quais objetos são retirados para ceder espaço a novos objetos.

\subsection{Motivação}

A Web se tornou o maior e mais acessado serviço de informação distribuído da Internet. Segundo as estatísticas da NSFNET, em janeiro de 1993, a Web ocupava a $127^{\mathrm{a}}$ posição dentre os serviços mais usados da Internet. Dois anos depois, a mesma já ocupava a primeira colocação, passando de $0,002 \%$ para $26,25 \%$ de todo o tráfego da Internet, ultrapassando, assim, os serviços de transferência remota de arquivos, fóruns de discussão, correio eletrônico e terminal remoto, os mais usados até então.

Esse desenvolvimento ocorreu de maneira espontânea. A facilidade de conexão à Web, tanto no lado cliente quanto no lado servidor, assim como o seu potencial econômico, são fatores que permitiram seu crescimento acelerado. A popularização da Web gerou sobrecarga na Internet e nos servidores, acarretando maiores tempos de resposta às requisições. Quando são feitos pedidos para servidores em links lentos, existe geralmente uma demora considerável na recuperação de objetos remotos. Além disso, a alta taxa de transferência de objetos pela rede leva a um aumento de tráfego que acaba reduzindo a largura de banda disponível e, também, introduzindo atrasos perceptíveis pelo usuário.

Uma premissa para melhorar o desempenho e a escalabilidade da Web é a compreensão de sua caracterização de carga, pois esta é fundamental para um bom planejamento e implementação de caches na Web. A utilização eficiente de caches proporciona o uso eficiente de largura de banda e reduzem a latência para recuperação dos objetos.

A utilização generalizada de caches em diversos pontos da rede no mundo, estimulado pela campanha Cache Now! (CacheNow, 2001), aliviou o problema de latências nas requisições e mostrou ser uma solução conveniente para a escalabilidade da Web. Wang (1999) e Murta e Almeida (1999) destacaram alguns benefícios apresentados pelos caches na Web: economia de largura de banda da rede, menor latência, redução de tráfego, redução na carga de servidores e maior disponibilidade. 
Segundo a Jupiter Media Metrix,

"quatro sites detêm 50\% do tempo dos americanos on-line. Os americanos passaram metade do tempo gasto em apenas 4 sites: AOL Time Warner, Microsoft, Yahoo! e Napster. Para se ter uma idéia da velocidade em que anda a consolidação dos sites, em março de 1999, eram 11 endereços que concentravam a metade do tempo on-line dos americanos. Um ano depois, eram 7. Já quando se fala de $60 \%$ do tempo gasto na internet, em março de 1999, eram 110 sites. Em março de 2000, 40. E no mesmo mês deste ano, apenas 14."

Fernanda Bottoni, de INFO Exame. 06/06/2000.

Percebe-se que poucos sites detêm a maioria dos acessos dos usuários, revelando a concentração de referências em um subconjunto pequeno de objetos e evidenciando a grande quantidade de tráfego redundante. Estas observações mostram, com clareza, que o uso de caches pode ser atrativo.

A utilização de políticas de substituição de objetos impõe novos desafios à seleção de objetos que são substituídos em caches, devido à diversidade de parâmetros envolvidos. Sendo assim, é importante que existam boas políticas para selecionar, de maneira conveniente que objetos devem ser removidos do cache, pois se a seleção não for adequada, a eficácia do uso de caches na Web pode ser comprometida.

\subsection{Objetivos}

Os objetivos deste trabalho são ponderar sobre o impacto provocado pelas políticas de substituição de objetos na taxa de acertos de caches na Web, assim como o seu desempenho, considerando-se diversas organizações de seu espaço de armazenamento. Estes objetivos serão alcançados por meio:

- da investigação e analise de políticas de substituição de objetos, assim como da proposta de uma nova política de substituição;

- caracterização das cargas de trabalho da Web visando a utilização dessas cargas na simulação de caches;

- avaliação do desempenho de políticas de substituição de objetos, através da simulação de caches para Web; 
- comparação da avaliação de desempenho de caches sem particionamento e com particionamento (por classes de objetos e por classes de tamanho).

\subsection{Estrutura}

Esta dissertação está dividida em três partes. A primeira parte apresenta uma revisão bibliográfica abordando os principais tópicos desta dissertação. A segunda apresenta um estudo de caracterização de carga da Web e, na terceira parte é apresentada uma avaliação de desempenho de políticas de substituição de objetos de caches na Web. Estas três partes estão organizadas em seis capítulos, conforme descritos a seguir.

No capítulo 2, faz-se uma revisão de alguns tópicos relacionados à Web, tais como, seu modelo cliente-servidor e o protocolo HTTP. Também são detalhados os principais componentes da Web: o cliente, o servidor e o proxy.

O capitulo 3 apresenta os principais conceitos envolvidos com caches na Web que estão relacionados ao tema deste trabalho, destacando-se as políticas de substituição de objetos em caches na Web. Primeiramente, faz-se uma revisão dos conceitos básicos de caches tradicionais e da Web, frisando suas principais diferenças. Ainda é abordado o problema de consistência em caches na Web, assim como dois tipos de organização de caches (hierárquico e cooperativo). Finalmente, são discutidas as principais políticas de substituição de objetos e apresentada a proposta de uma nova política.

No capítulo 4, apresentam-se vários estudos de caracterização de carga da Web. Também são detalhados os resultados do estudo de caracterização de carga desenvolvido neste trabalho. Este estudo tem o objetivo de prover um embasamento ao entendimento da caracterização de carga da Web, assim como validar as cargas que são utilizadas para avaliação de desempenho das políticas de substituição de objetos em caches na Web.

No capítulo 5, são analisados os resultados da avaliação de desempenho de várias políticas de substituição de objetos. Primeiramente, são apresentadas as principais características do simulador utilizado, e discutidos os parâmetros considerados na avaliação de desempenho. Em seguida, são apresentados os resultados da simulação e conclusões baseadas nestes resultados. 
No capítulo 6, chega-se à conclusão da dissertação, sendo destacadas suas contribuições mais importantes e apontados caminhos para melhoramentos e trabalhos futuros. 


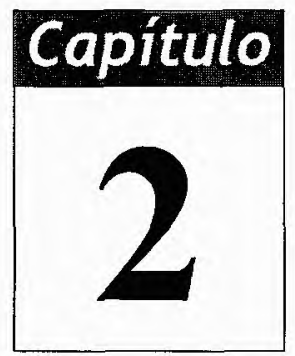

\section{A World Wide Web}

A Web tem apresentado um crescimento bastante acentuado. Sua expansão tem contribuído significativamente no volume do tráfego de rede na Internet. Em virtude disto, muitas pesquisas vêm sendo realizadas sobre desempenho e escalabilidade da Web.

A Web permite o acesso a objetos espalhados por um grande número de computadores na Internet. O princípio básico em que se baseia a Web é que as informações devem ser acessadas diretamente; o usuário tem a idéia de um repositório único no qual são armazenadas as informações. A Web pode ser vista como um sistema distribuído, cuja comunicação segue o modelo cliente-servidor e a rede de comunicação é a Internet (Figura 2.1). Do ponto de vista dos usuários, a Web é uma coleção de objetos, chamados de páginas, podendo cada uma destas conter links para outras páginas. Já do ponto de vista do servidor, a Web é um processo que "escuta" em uma porta específica (o padrão é a porta 80) até que um cliente solicite uma conexão. 


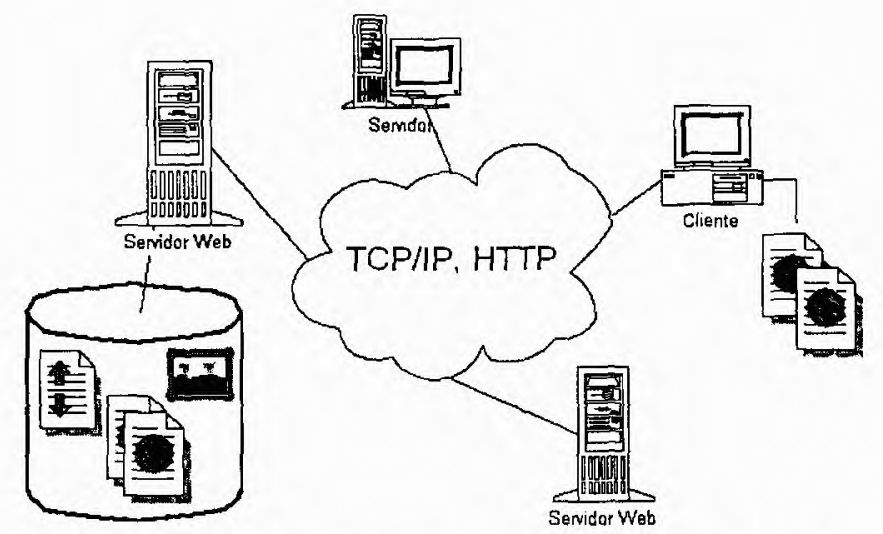

FIGURA 2.1: Arquitetura cliente-servidor da Web.

A Web utiliza a tecnologia de hipertexto para estruturação das informações (Berners-Lee et al., 1994a). Hipertexto é um texto com links (também conhecidos como hyperlinks) para outras informações, que podem ser textuais, gráfica, áudio ou vídeo. Objetos hipertexto são tipicamente escritos em HyperText Markup Language (HTML).

Para a comunicação pela rede é necessário um protocolo de comunicação comum a todos. A Web usa o protocolo HyperText Transfer Protocol (HTTP) para a comunicação cliente-servidor. O HTTP é um protocolo simples e orientado à conexão que funciona sobre o protocolo Transmission Control Protocol (TCP) (Tanenbaum, 1997), sendo seu principal objetivo gerenciar conexões e fornecer um canal de comunicação bidirecional e confiável entre o cliente e o servidor.

O HTTP é um protocolo do tipo requisição/resposta. A comunicação é iniciada pelo cliente na forma de uma requisição ao servidor; depois que um canal de comunicação é estabelecido pelo protocolo TCP, o cliente envia uma requisição ao servidor. O servidor analisa a requisição, e envia uma resposta ao cliente. Depois que o cliente recebe a resposta, a conexão é fechada pelo TCP. Cada página Web pode conter vários objetos, como imagens, sons e vídeos, e é necessário que o cliente estabeleça uma conexão diferente para o pedido de cada um destes objetos, ou seja, o pedido de uma página pelo usuário pode significar o estabelecimento de diversas conexões com o servidor. Isto fica transparente para o usuário, já que os pedidos dos objetos que estão no interior de uma página Web são automaticamente feitos pelo browser (seção 2.1). 
Neste capítulo, serão abordados alguns tópicos relacionados com a Web concernentes a este trabalho, tais como, sua apresentação como um sistema cliente-servidor e o protocolo HTTP, usado na comunicação entre o cliente e o servidor. Serão vistos, também, os seus principais componentes.

\subsection{Cliente Web}

Um cliente Web é uma aplicação (conhecida como navegador) que envia uma requisição de objetos Web localizados em um servidor, funcionando como uma interface entre os objetos pedidos pelos usuários e o servidor. Como exemplos de browsers, vale destacar o Netscape Communicator ${ }^{\circledR}$ e o Internet Explorer ${ }^{\circledR}$. Quando um usuário pressiona (clica) em um link ou solicita uma página, o browser cria uma requisição TCP que é enviada ao servidor no qual o objeto reside. Uma requisição típica tem o formato apresentado na Figura 2.2 (Fielding et al., 1998) e (Vass et al., 1998).

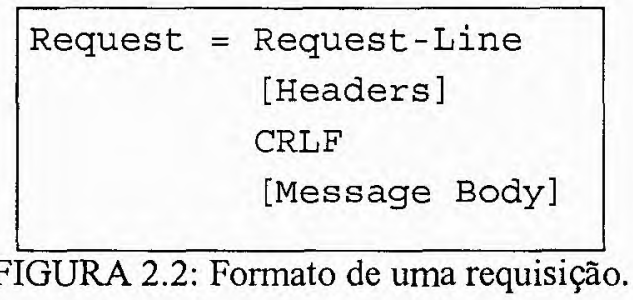

Request-Line especifica o método (operação requisitada), o nome do objeto Web representado por uma Universal Resource Locator (URL) (Berners-Lee et al., 1994b) e a versão do protocolo HTTP que está sendo utilizada. Os métodos suportados pelo HTTP versão 1.1 estão descritos na Tabela 2.1 .

O campo Header é opcional, podendo ser usado pelo cliente para passar informações adicionais ao servidor, tais como, o browser e a versão que está sendo utilizada. O campo CTRL (Carriage Return e Line feed) indica quebra de linha.

Um exemplo de uma requisição a um servidor Web é apresentado na Figura 2.3. Neste exemplo, o objeto / seminario/webCache.html do servidor lasdpc.icme. sc. usp.br é requisitado. 
GET /seminário/webCache.html HTTP/1.1

Accept: */*

If-Modified-Since: Wed, 23 Jul 2000 14:30:26 GMT

Referrer: http://lasdpc.icmc.sc.usp.br/seminario/webcache.html

User-Agent: Netscape/4.7

FIGURA 2.3: Exemplo de uma requisição HTTP.

Request-Line, por meio do método GET, indica que o cliente deseja obter o objeto /seminário/webCache.html usando a versão 1.1 do protocolo HTTP. O campo Accept significa que o cliente aceita qualquer tipo de objeto. O campo If Modified-Since informa ao servidor para enviar o objeto requisitado somente se ele foi modificado depois das 14:30:26 GMT do dia 23 de julho de 2000. Se o objeto não foi alterado antes do tempo especificado, o servidor envia ao cliente uma resposta indicando que ele tem uma cópia atualizada do objeto em seu cache, caso contrário, o objeto é transferido. O campo Referrer permite ao cliente especificar a URL de onde foi obtido um objeto. O campo User-Agent informa ao servidor que o cliente está usando o browser Netscape 4.7. O administrador do sistema pode utilizar estas informações para propósitos estatísticos.

Depois de enviar uma requisição ao servidor Web, o cliente fica aguardando uma resposta. De acordo com a resposta, o cliente pode fazer outra requisição ou exibir o objeto requisitado.

TABELA 2.1: Métodos implementados pelo protocolo HTTP/1.1.

\begin{tabular}{|c|l|}
\hline Método & \multicolumn{1}{|c|}{ Função } \\
\hline GET & $\begin{array}{l}\text { Solicita a leitura de um objeto Web. Quando o método GET for seguido de um } \\
\text { cabeçalho If-Modified-Since, o servidor só enviará os dados se eles tiverem sido } \\
\text { alterados. Isto é possível ao associar a solicitação à data de alteração do objeto }\end{array}$ \\
\hline HEAD & $\begin{array}{l}\text { Solicita o cabeçalho do objeto requisitado. Também serve para obter a data da última } \\
\text { modificação feita na página e testar a validade de uma URL }\end{array}$ \\
\hline POST & Envia dados ao servidor \\
\hline PUT & $\begin{array}{l}\text { Solicita o armazenamento de um objeto Web. Ao contrário do método GET, o } \\
\text { método PUT grava a página, possibilitando a criação de um conjunto de objetos em } \\
\text { um servidor remoto }\end{array}$ \\
\hline DELETE & $\begin{array}{l}\text { Apaga um objeto do servidor. O objeto a ser excluído pode ter um modo que proíba o } \\
\text { servidor HTTP de modificá-lo ou excluí-lo, por isso, deve-se ter uma permissão e } \\
\text { autenticação para garantir que o DELETE seja bem sucedido }\end{array}$ \\
\hline
\end{tabular}




\begin{tabular}{|c|l|}
\hline Método & \multicolumn{1}{|c|}{ Função } \\
\hline OPTIONS & $\begin{array}{l}\text { O método de OPÇÕES representa um pedido para informação sobre as opções de } \\
\text { comunicação disponível para uma URL. Este método permite ao cliente determinar as } \\
\text { opções associadas com um recurso, ou as capacidades de um servidor sem iniciar a } \\
\text { recuperação de um recurso. }\end{array}$ \\
\hline TRACE & $\begin{array}{l}\text { Este método é utilizado para gerar um loop-back. É utilizado para testes ou informações } \\
\text { de diagnósticos. }\end{array}$ \\
\hline
\end{tabular}

\subsection{Servidor Web}

O servidor Web é um programa que executa em um computador remoto, cuja finalidade é fornecer objetos solicitados pelos clientes. Exemplos de servidores Web são: Apache, CERN's "httpd" Server, Netscape Enterprise Server e Microsoft Information Server.

Servidores Web são projetados para mascarar detalhes de implementação do usuário. São responsáveis pelo mapeamento de uma URL fornecida, em um objeto ou em uma mensagem de erro. Este objeto pode ser um arquivo de texto HTML, uma imagem, um vídeo, um programa, ou ser construído dinamicamente como resultado de uma consulta a bancos de dados.

O servidor Web recebe as requisições de um cliente em uma porta específica (o padrão é a porta 80) (Fielding et al., 1998), para estabelecer uma conexão TCP com o cliente. O servidor envia uma resposta no formato apresentado na Figura 2.4 (Fielding et al., 1998) e (Vass et al., 1998):

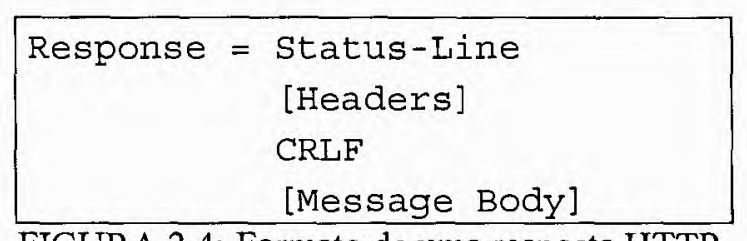

FIGURA 2.4: Formato de uma resposta HTTP.

O campo status-Line especifica a versão do protocolo e um código de status. $\mathrm{O}$ código de status é um número inteiro de três dígitos que descreve o resultado da solicitação do cliente. Os códigos de status existentes nos cabeçalhos de resposta informam ao cliente o grau de sucesso obtido quanto à solicitação de uma URL. 
O primeiro dígito do código de status define a classe de resposta. Os dígitos finais não possuem papel classificatório, servindo apenas para designar um identificador único para cada código de status. Há um total de cinco valores para o primeiro dígito conforme apresentado na Tabela 2.2 (Fielding et al., 1998).

TABELA 2.2: Classes de códigos de status HTTP.

\begin{tabular}{|l|l|}
\hline Classe & \multicolumn{1}{|c|}{ Descrição } \\
\hline $1 \mathrm{xx}$ & $\begin{array}{l}\text { É uma resposta temporal; indica que a requisição foi recebida e está atualmente sendo } \\
\text { processada. }\end{array}$ \\
\hline $2 \mathrm{xx}$ & Significa que a requisição foi recebida com sucesso, entendida e processada pelo servidor. \\
\hline $3 \mathrm{xx}$ & $\begin{array}{l}\text { Redireciona o cliente a outra URL. O Cliente deve executar outras ações para que a } \\
\text { requisição seja completada (por exemplo, requisitar uma outra URL). }\end{array}$ \\
\hline $4 \mathrm{xx}$ & $\begin{array}{l}\text { Indica que uma requisição inválida foi feita pelo cliente. A requisição contém erro de sintaxe } \\
\text { ou não pode ser atendida. }\end{array}$ \\
\hline $5 \mathrm{xx}$ & $\begin{array}{l}\text { Indica que, embora a requisição do cliente tenha sido válida, o servidor foi incapaz de } \\
\text { processa-la. Este erro ocorre enquanto a requisição está sendo processada. }\end{array}$ \\
\hline
\end{tabular}

A Tabela 2.3 indica os códigos de status geralmente utilizados (Fielding et al., 1998) e (Vass et al., 1998).

TABELA 2.3: Código de status comumente retornado pelo servidor Web.

\begin{tabular}{|l|l|}
\hline \multicolumn{1}{|c|}{ Código } & \multicolumn{1}{c|}{ Descrição } \\
\hline $200(\mathrm{OK})$ & Um objeto válido foi encontrado no servidor e retornado ao cliente. \\
\hline 202 Accepted & $\begin{array}{l}\text { A solicitação foi aceita para processamento, mas essa tarefa ainda não foi } \\
\text { terminada. }\end{array}$ \\
\hline 204 (No content) & $\begin{array}{l}\text { O servidor atendeu à solicitação, mas não há novas informações a serem } \\
\text { retornadas. }\end{array}$ \\
\hline 302 Moved Temporarily & O recurso solicitado utiliza temporariamente uma URL diferente \\
\hline 304 Not-Modiffied & $\begin{array}{l}\text { O cliente executou uma solicitação condicional com GET e o acesso foi } \\
\text { permitido, mas o objeto não foi modificado desde a data e hora especificados } \\
\text { no campo If-Modified-Since; o servidor responderá com esse código de status e } \\
\text { não enviará um cabeçalho Entity-Body ao cliente }\end{array}$ \\
\hline 400 Bad Request & O pedido não pôde ser entendido pelo servidor devido à sintaxe inválida. \\
\hline 403 Forbidden & O servidor entendeu a requisição, mas recusou completá-la. \\
\hline 404 Not Found & $\begin{array}{l}\text { O servidor não achou nada compativel com a URL solicitada. Este código de } \\
\text { estado é comumente usado quando o servidor não desejar revelar exatamente } \\
\text { por que o pedido foi recusado, ou quando nenhuma outra resposta é aplicável. }\end{array}$ \\
\hline $\begin{array}{l}500 \text { Internal Server } \\
\text { Error }\end{array}$ & $\begin{array}{l}\text { O servidor encontrou uma condição inesperada que impediu o atendimento da } \\
\text { solicitação. }\end{array}$ \\
\hline 504 Gateway timeout & $\begin{array}{l}\text { O servidor não recebeu uma resposta do gateasay ou do servidor superior dentro } \\
\text { do prazo permitido, quando feito um acesso para tentar completar a solicitação. }\end{array}$ \\
\hline
\end{tabular}


Uma possível resposta do servidor é apresentada na Figura 2.5.

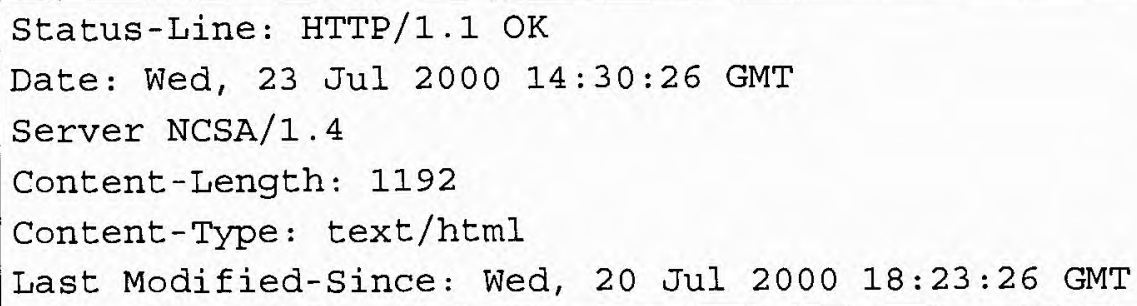

FIGURA 2.5: Exemplo de uma resposta.

Status-Line especifica que o servidor usa o protocolo HTTP/1.1 e que a solicitação foi completada com sucesso (status-code é 200). A data e a hora de resposta, assim como, o tipo de servidor são especificados (NCSA Server versão 1.4). ContentLenght especifica o tamanho do objeto em bytes que está sendo transferido. Content-Type descreve o formato do objeto usando o Multipurpose Internet Mail Extensions (MIME), neste caso, é um objeto do tipo HTML. O campo Last Modified informa a última vez em que o objeto requisitado foi atualizado. Esta informação pode ser usada pelo cliente através do método GET para verificar a validade do objeto no cache do cliente.

Freqüentemente, as requisições são feitas para objetos armazenados no servidor. Contudo, é possível que o servidor Web crie dinamicamente o objeto para o cliente. $\mathrm{O}$ Common Gateway Interface (CGI) é uma das tecnologias existentes que cumpre esse papel. No CGI, um servidor Web associa um programa a uma URL. Quando um cliente solicita uma URL, o servidor executa um programa associado a essa URL e envia a saída do programa ao cliente. Esses tipos de objetos são denominados objetos gerados dinamicamente.

\subsection{Proxy Web}

Um proxy $\mathrm{Web}^{1}$ é um programa de aplicação que recebe requisições de objetos de um conjunto de clientes, repassa estas requisições ao servidor apropriado e envia o objeto requisitado de volta para o cliente (Fielding et al., 1998). Cada resposta recebida é enviada de forma transparente ao cliente que originou a requisição.

\footnotetext{
${ }^{1}$ Ao longo deste trabalho, considerar-se-á o termo "proxy Web" unicamente como "proxy".
} 
Proxies foram inicialmente projetados para permitir que administradores de redes fossem capazes de controlar o acesso à Internet a partir de uma Intranet e proteger de intrusos a rede interna através de um firewall. Isto significa que a rede está logicamente separada do resto da Internet e que os usuários devem usar um servidor proxy, que é capaz de se conectar com a parte interna e externa da rede local. Contudo, notou-se que os proxies podem servir também como um repositório de objetos que são acessados freqüentemente. Esta função assumida pelo proxy o tornou bastante popular.

De um modo geral, um proxy funciona tanto como servidor quanto cliente (Fonseca et al., 1998). Quando estiver atendendo requisições de um cliente, o proxy funciona como servidor. Por outro lado, quando se conecta ao servidor remoto para requerer um objeto, o proxy funciona como cliente.

Para reduzir o tráfego de rede, o servidor proxy age como um repositório local de objetos. Assim que um objeto é carregado no browser através de um servidor proxy, o proxy salva uma cópia desta página (cache) (Figura 2.6). Desta forma, objetos requisitados freqüentemente por usuários na mesma rede local precisam ser transferidos para o proxy apenas uma vez. Futuras requisições para o mesmo objeto serão respondidas utilizando a cópia armazenada no seu cache local, ao invés de se conectar ao servidor Web de onde foi recuperado o objeto originalmente. Os clientes têm a ilusão de que estão recebendo os objetos diretamente do servidor remoto.

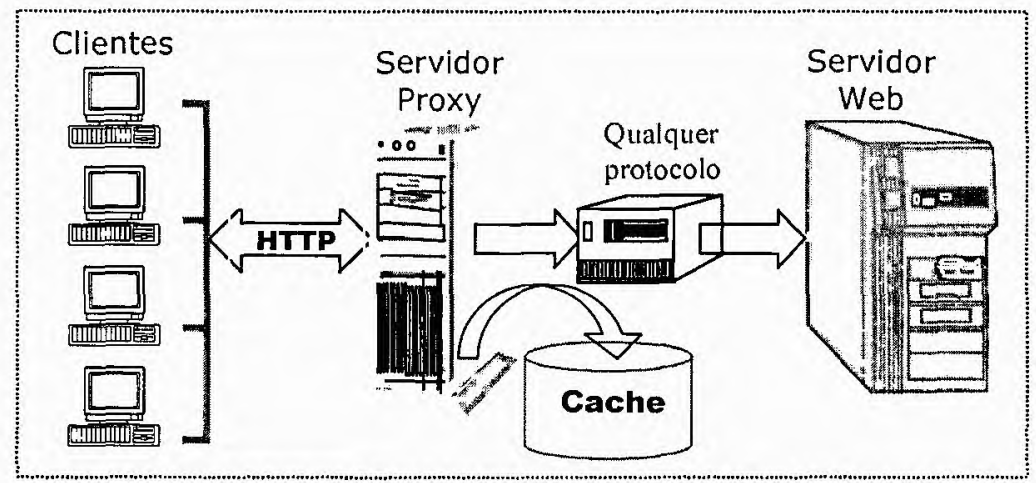

FIGURA 2.6: Exemplo de uma requisição através de um servidor proxy.

Servidores proxy são usados por uma comunidade com interesses semelhantes, como uma universidade ou uma empresa. Como exemplo, o servidor proxy de uma universidade serve a várias pessoas interessadas em tópicos comuns de pesquisa ou ensino, resultando em múltiplos acessos aos sites relacionados a esses tópicos (Fonseca et al., 
1998). Cesário et al. (1997), constataram que mais de $50 \%$ dos objetos requisitados ou das transferências de FTP já foram realizados por um outro usuário anteriormente.

\subsection{Considerações Finais}

$\mathrm{Na}$ primeira parte deste capítulo foi apresentado um panorama geral da Web, introduzindo-se a mesma como um sistema distribuído baseado no modelo de comunicação cliente-servidor, que usa hipertexto para estruturação das informações. Os principais componentes da Web - o cliente, o servidor e o proxy - foram considerados nas seções 2.1, 2.2 e 2.3. O próximo capítulo discute a utilização de caches na Web em maiores detalhes, por esse ser o tópico principal deste trabalho. 


\section{Caches na Web}

O crescimento da popularidade da Web está causando sérios problemas de desempenho nos acessos à Internet. Os principais motivos destes problemas são a facilidade de integração entre diversos servidores de informação (propiciada pelo protocolo HTTP), seu potencial econômico e a facilidade de uso de programas navegação (browsers).

A redução da latência nas requisições tem se tornado uma questão importante. A iniciativa de se implantar um sistema de cache na Web, que armazene localmente objetos ${ }^{1}$, pode melhorar a qualidade dos serviços fornecidos aos usuários e diminuir a sobrecarga presente nas redes atuais. A maioria dos sistemas de computadores modernos utiliza sistemas de cache em memória para melhorar o desempenho de processadores, aumentar a velocidade de acesso à memória principal e aumentar a velocidade de acesso ao disco.

Cache é, também, uma técnica bem conhecida para melhorar a escalabilidade e o desempenho de sistemas cliente-servidor, isto é, aumentar o número de clientes que podem ser atendidos, minimizando os pontos de contenção na rede ou no servidor. Arlitt e Williamson (1996a) mostraram que uma pequena fração dos objetos corresponde à maioria dos acessos ao servidor Web. Para evitar transferências repetidas no servidor do mesmo

\footnotetext{
'A palavra "objeto" será utilizada ao longo do texto para referenciar todos os arquivos que possam ser armazenados em caches.
} 
objeto através da rede, é necessário identificar estes objetos e copiá-los para um cache próximo aos clientes que os solicitam.

Neste capítulo são apresentadas algumas considerações sobre caches na Web, depois, faz-se uma revisão dos conceitos básicos de caches tradicionais e na Web, frisando suas principais diferenças. O problema de consistência, bem como duas organizações de caches na Web, é abordado. Finalmente, destacam-se as políticas de substituição de objetos existentes na literatura.

\subsection{Caches Tradicionais}

Quando a memória cache surgiu nos computadores monoprocessados, a preocupação com uso de caches não era tão evidente devido ao fato de o processador funcionar praticamente na mesma velocidade da memória principal. Com o surgimento de processadores mais velozes, a diferença de velocidade entre a memória principal e o processador tornou-se bastante acentuada, comprometendo o desempenho de novas gerações de computadores. Surgiu, então, a idéia de inserir uma pequena quantidade de memória, porém mais veloz, entre o processador e a memória principal para melhorar o tempo de acesso à memória. Essa pequena quantidade de memória passou a ser denominada memória cache, ou simplesmente cache (Stallings, 2000).

O uso de memória cache se tornou viável devido a dois princípios de acesso à memória: localidade temporal e localidade espacial (Tanenbaum, 1995). A localidade temporal indica que, se um processador acessa uma determinada posição de memória é muito provável que ele a acesse novamente em um curto espaço de tempo. A localidade espacial indica que, se um processador acessa uma determinada posição de memória, é muito provável que ele acesse posições adjacentes também em um curto espaço de tempo.

A memória cache de processador garante os princípios de localidade temporal ao armazenar cópias de posições de memória acessadas pelo processador, e de localidade espacial, ao buscar várias posições de memória de uma só vez. Toda vez que o processador solicitar um dado na memória, este poderá encontrá-lo na memória cache (cache hit) ou terá de buscá-lo diretamente na memória principal (cache miss). 
O gerenciamento de caches deve considerar diversos aspectos, tais como: quando atualizar o cache, quando atualizar a memória, tamanho do cache, tamanho dos objetos armazenados e as políticas de substituição.

De acordo com as formas de escrita na memória principal, os caches podem se comportar de duas maneiras: write-through, onde toda operação de escrita no cache é imediatamente realizada na memória principal, ou write-back, onde toda operação de escrita é feita primeiramente no cache para depois ser escrita na memória principal, quando a região do cache contendo as alterações for substituída (Stallings, 2000).

A memória cache é dividida em pequenas unidades de mesmo tamanho denominadas linhas de cache ou blocos. A unidade de transferência entre a memória principal e a memória cache é chamada de linha de cache.

A política de substituição define qual objeto deve ser retirado do cache para que seja armazenado um objeto que não se encontra no cache.

\subsection{Caches na Web}

Técnicas de caches na Web têm sido influenciadas consideravelmente por estudos de caches tradicionais, uma vez que ambas utilizam o mesmo princípio de funcionamento. Objetos requisitados são copiados em posições mais próximas do usuário, com o propósito de diminuir o tempo do próximo acesso ao objeto (Figura 3.1). Embora os conceitos sejam similares, há quatro diferenças básicas entre caches na Web e caches tradicionais:

- Tamanho dos objetos. Os caches tradicionais transferem objetos de tamanhos fixos, por exemplo, bloco ou linha, portanto, o número de bytes encontrados no cache em relação ao número de bytes requisitados é exatamente a taxa de acertos. Por outro lado, caches na $\mathrm{Web}^{3}$ envolvem objetos de tamanhos diversos, variando desde poucos bytes até megabytes. Isto implica dizer que o armazenamento de apenas um objeto grande no cache pode significar a retirada de dezenas, centenas ou milhares de objetos pequenos, alterando completamente o seu estado. Em caches na

\footnotetext{
${ }^{3}$ No decorrer deste trabalho a palavra cache será usada tendo o mesmo significado de cache na Web, e será empregada a expressão "caches tradicionais" em substituição aos diversos tipos de cache, tais como, caches de memória, caches de processador e de sistemas de arquivos distribuídos.
} 
Web, os objetos são transmitidos e armazenados na sua forma integral, não havendo o conceito de bloco. Como conseqüência, precisa-se trabalhar com duas métricas para medir o desempenho de sistemas de caches na Web: a fração de requisições atendidas pelo cache (Taxa de Acertos), e a fração de bytes requisitados atendidos pelo cache (Taxa de Acertos por Byte).

- Latência. Enquanto que em caches tradicionais o tempo de espera por uma requisição (latência) é muito próximo, os caches na Web podem ter diferentes tempos de acesso para objetos de mesmo tamanho cujos valores podem estar em escalas de tempo muito maiores. Esta diferença é influenciada por múltiplos fatores, como: largura de banda disponível, sobrecarga na rede, no servidor e sua localização em relação ao cliente.

- Carga de trabalho. Outra diferença é a carga de trabalho que cada uma evidencia. Murta e Almeida (2000) observaram que a Web apresenta duas características que desafiam a avaliação de desempenho e propostas de soluções para os seus problemas: larga escala e grande variabilidade. A Web possui muito mais usuários que um sistema distribuído de larga escala, como o Andrew File System (AFS), pois é composta por milhões de objetos, usuários e servidores espalhados pelo mundo.

- Operação de escrita. Não cabem aqui operações de escrita como em caches tradicionais; o sistema de caches na Web é basicamente para leitura.

Quando um cliente solicita um objeto, em primeiro lugar o cache é consultado (Figura 3.1). Se o objeto requisitado for encontrado no cache e o mesmo estiver atualizado, então será enviado de volta ao cliente diretamente, evitando um acesso ao servidor de origem. A isso se dá o nome de acerto no cache. Quanto mais o cache puder atender à solicitação dos clientes, maior será a taxa de acertos. 


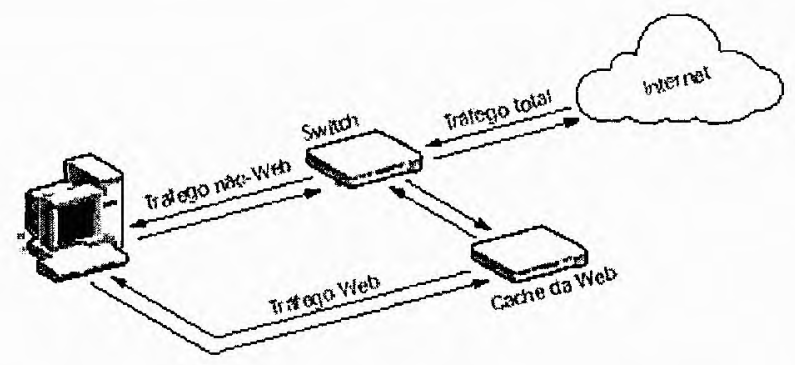

FIGURA 3.1: Sistema de caches na Web.

Há diversos locais diferentes em que se pode implantar caches na Web, a escolha de um local depende de qual será a sua função primária e o tipo de tráfego a ser gerenciado. De acordo com suas características, serviços de cache na Web podem ser implementados em várias localidades da rede, como:

- Cache de cliente. A maioria dos browsers possui um cache próprio, pois é bastante provável que um usuário acesse as mesmas páginas freqüentemente, ou muitas vezes em um mesmo dia. $\mathrm{O}$ cache de cliente possui a vantagem de evitar o acesso à rede, assim como recuperar o objeto em um tempo praticamente constante (somente o tempo de acessar a memória principal ou o disco local). No entanto, possui a desvantagem de não ser compartilhada entre diversos usuários, além da possibilidade de manter réplicas do mesmo objeto em vários clientes.

- Cache de servidor. Implementado na memória principal do servidor Web. O objetivo é deixar os objetos mais populares em memória principal, tornando o acesso mais rápido. Este cache está restrito ao conjunto de objetos presente no servidor.

- Cache de proxy. Implementado em pontos estratégicos da rede, entre os demais caches, geralmente fica em pontos mais próximos dos clientes, podendo ser acessado e compartilhado por muitos usuários. A aplicação proxy age como intermediária entre clientes e servidores Web. O servidor proxy procura pelo objeto solicitado, grava no disco e repassa para o usuário. Requisições subseqüentes de outros usuários vão recuperar o objeto que está gravado localmente. $\mathrm{O}$ objetivo de implementar caches em servidores proxy é atender a um conjunto de clientes que utilizam a mesma saida (backbone) para a Internet (Murta \& Almeida, 2000). Cache 
de proxy possui a vantagem de minimizar o espaço em disco utilizado, uma vez que é feita apenas uma cópia do objeto para vários usuários.

- Cache de proxy transparente (Barish \& Obraczka, 2000). Funciona interceptando requisições HTTP de maneira transparente e as redirecionando ao cache. São usados especialmente por provedores de acesso à Internet, pois não é necessária nenhuma configuração no lado cliente.

- Cache de proxy reverso (Barish \& Obraczka, 2000). Este cache é implantado próximo aos servidores originais interceptando requisições destinadas a um ou mais servidores Web. Esta solução é atrativa para servidores ou domínios bastante populares na Internet, com o objetivo de assegurar a qualidade do serviço prestado. Vale ressaltar que caches de proxy reverso são completamente independentes dos caches implantados próximos aos clientes, embora ambos caches podem coexistir e coletivamente trabalhar para melhorar o desempenho da Web.

Vale ressaltar que a utilização de caches na Web é limitada aos objetos estáticos, que são objetos atualizados apenas ocasionalmente. Objetos dinâmicos são aqueles atualizados a cada requisição, por exemplo, resultados de interações CGI (Common Gateway Interface), de uma consulta a bancos de dados, e páginas obtidas por HTTPs (HTTP seguro). Esses objetos geram páginas em função de parâmetros próprios definidos em cada requisição, portanto esses objetos não são armazenados em cache.

Sistemas de caches na Web trazem vários beneficios que justificam por que o seu uso os torna tão especiais e atrativos. Estes benefícios são destacados a seguir (Murta \& Almeida, 2000):

- Redução de tráfego. Menos requisições e respostas precisam trafegar na rede. Um objeto é recuperado do servidor somente uma vez, reduzindo a largura de banda usada pelo cliente. Devido à sobrecarga na Internet, a vantagem da redução de carga na rede passa a ser um objetivo dos caches na Web. Por meio da utilização de caches, pode-se aumentar a escalabilidade, reduzir a possibilidade de congestionamento e maximizar a utilização da infra-estrutura da Internet, minimizando a quantidade de tráfego redundante na Web. Reduzir o tráfego é especialmente interessante para administradores de rede e provedores 
de acesso e de serviços, que pagam por largura de banda. Por outro lado, reduzir o tempo de acesso é interessante para o usuário, que almeja ver a página solicitada o mais rápido possível.

- Redução na carga de servidores. Menos requisições para os servidores Web atenderem. Por exemplo, alguns sites ficam extremamente congestionados quando do lançamento de novos produtos. Com o uso de caches este problema pode ser minimizado.

- Redução de latência. As respostas de requisições a objetos que podem ser armazenados no cache são feitas a partir do cache local, e não pelo servidor Web original (a requisição e a resposta percorrem apenas o caminho entre o cliente e o cache). Dessa maneira, o acesso tende a ser bastante rápido.

- Possibilidade de acesso off-line. Considerando-se que o servidor Web de um endereço especificado em uma URL está inacessível (queda de enlace, servidor desligado), ou recebendo mais solicitações do que pode suportar, se o objeto estiver armazenado no cache será possível acessá-lo, embora não seja possível sua atualização.

Possíveis problemas que podem surgir com o uso de cache (Wang, 1999):

- Manter a consistência. Objetos podem não estar atualizados no cache. Nem sempre é fácil prever o tempo em que um objeto permanecerá válido. Vale destacar que este é um fator crítico de sucesso de caches na Web.

- Objeto requisitado não se encontra no cache (Miss). Caso ocorra muitas falhas, o tempo para recuperar um objeto aumenta devido ao tempo adicional para verificar se o objeto encontra-se no cache. Portanto, a Taxa de Acerto deve ser maximizada e o custo de uma falha deve ser minimizado durante o projeto de sistemas de cache.

- Gargalo no sistema. O cache pode se tornar um gargalo no sistema. Para que isto não ocorra, deve-se fixar o número máximo de clientes que um servidor proxy pode atender. O acesso aos caches deve ser, pelo menos, tão eficiente quanto o acesso ao servidor de origem. 
- Ponto de falha. Um cache implantado em um único servidor proxy, torna-se um único ponto de falha.

- Menos acesso ao servidor de origem. Com o uso de caches em servidores proxy é reduzida a quantidade de acessos aos servidores de origem, fazendo com que estes tenham uma estimativa irreal do total de acessos.

\subsection{Consistência em Caches na Web}

O uso de cache pode inserir inconsistências no sistema, pois se o objeto original for modificado depois que as cópias foram recuperadas, as cópias no cache tornam-se imediatamente desatualizadas. Este problema é conhecido como inconsistência de cache.

Para o armazenamento em cache ser efetivo, a consistência deve ser mantida, ou seja, as cópias nos caches devem ser atualizadas quando o objeto original for atualizado. Uma solução para o problema da inconsistência de cache seria checar todas as requisições para verificar se o objeto está desatualizado, porém em termos de desempenho esta abordagem se torna impraticável. Há vários mecanismos de consistência de cache propostos na literatura, como em (Gwertzman \& Seltzer, 1996): Time-To-Live (TTL), polling de cliente e o protocolo de invalidação pelo servidor.

TTL é uma estimativa do tempo de vida de um objeto. É utilizado para determinar quanto tempo um objeto permanecerá atualizado no cache. Para cada objeto é designado um tempo de vida (TTL), tal como dois dias ou doze horas. Se um cliente requisitar um objeto que ainda não expirou no cache, então o objeto é fornecido pelo cache sem precisar contatar o servidor. Contudo, se um cliente requisitar um objeto que expirou o seu tempo de vida, uma requisição condicional (If-Modified-Since) é feita ao servidor, que verifica se o objeto foi alterado. Caso verdadeiro, é retornado o novo objeto com o referente código de status; caso contrário, o servidor retorna um código de status, que informa ao cache que o objeto não foi modificado. TTLs são muito simples de implementar no protocolo HTTP, bastando usar o campo de cabeçalho expires que é opcional (Fielding et al., 1998).

Polling de cliente é uma técnica em que os clientes verificam periodicamente se um objeto no cache ainda está válido. A idéia de polling de cliente é baseada nas suposições de que os objetos novos são modificados com mais freqüência do que os objetos antigos. $\mathrm{O}$ 
cache associa um campo TTL que é expresso por uma porcentagem, conhecida como threshold ou limiar. Um objeto se torna inválido quando o tempo desde a última validação excede os tempos do limiar de atualização do objeto. Por exemplo, considere um objeto cuja idade são 20 dias e cuja validade foi checada um dia atrás. Se o limiar de atualização é de $10 \%$, então o objeto deveria ser marcado como inválido depois de dois dias. Quando for feita uma solicitação a este objeto e o mesmo se tornar inválido, o cache enviará um GET Condicional (código de status 304); caso o objeto tenha sido alterado será copiada a nova versão do objeto no servidor de origem. Esta estratégia possui a desvantagem de gerar muitas requisições condicionais ao servidor.

O protocolo de invalidação pelo servidor deve ser usado quando for necessário garantir uma consistência mais precisa. Nesta abordagem, cada vez que um objeto for modificado, o servidor notifica os caches de que suas cópias se tornaram inválidas. Um problema com este protocolo é que ele é computacionalmente caro. Servidores devem guardar um registro dos caches que armazenam seus objetos. Também deve lidar com clientes (caches) indisponíveis, pois se um cache não conseguiu ser notificado, o servidor deve continuar tentando notificá-lo, uma vez que o cache não saberá invalidar o objeto, a menos que seja notificado pelo servidor. O protocolo de invalidação requer modificação no servidor, enquanto que as outras abordagens TTL e polling de cliente podem ser implementadas em nível de proxy.

Uma comparação dessas abordagens de consistência em caches usando um simulador trace-driven é apresentada por Gwertzman \& Seltaer (1996). Esse estudo concluiu que, embora protocolos de invalidação sejam suficientes para fornecer uma perfeita consistência de cache, as outras abordagens podem reduzir o consumo de largura de banda, consideravelmente.

\subsection{Topologias de Caches na Web}

A forma como os caches estão organizados define uma topologia de cache particular. As duas organizações mais difundidas na literatura são: caches hierárquicos e caches cooperativos. No cache hierárquico a comunicação só é possível hierarquicamente, por conexões TCP; caches no mesmo nível não são acessíveis entre si. Nos caches 
cooperativos, todos os caches podem participar no processo de atendimento às requisições de usuários.

\subsubsection{Caches Hierárquicos}

Em um cache hierárquico, os servidores resolvem uma falha através de outros caches em níveis mais altos na hierarquia (Chankhunthod, et al., 1996). Caches em um mesmo nível não podem se comunicar (cooperar) para atender a uma requisição. Portanto, se o cache contatado não tiver o objeto solicitado, será contatado um cache de nível superior, ou o servidor de origem (Figura 3.2).

O armazenamento que ocorre próximo ao usuário da informação é geralmente mais efetivo, enquanto caches em camadas de níveis mais altos na hierarquia tendem a mostrar eficiências menores. Requisições para objetos que não são encontrados no cache propagam para os níveis superiores da hierarquia, e tipicamente o cache de maior nível tem que recuperar o objeto.

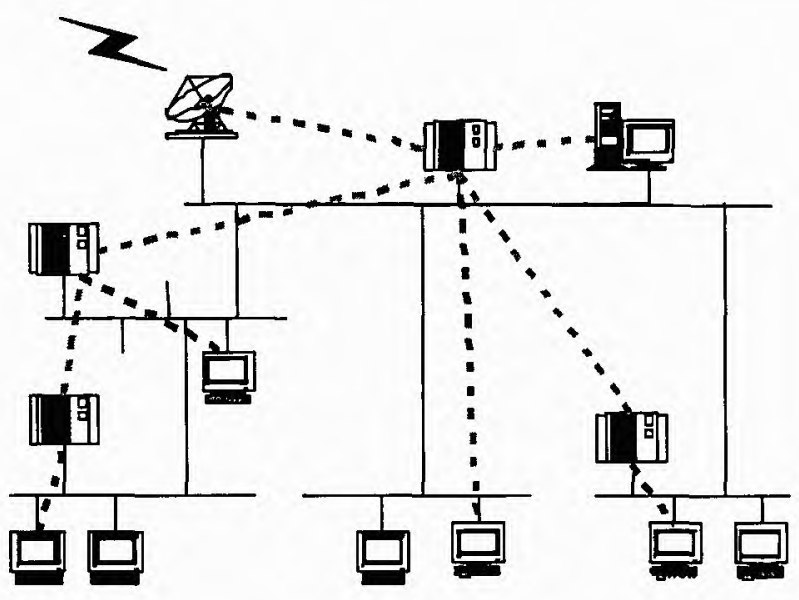

FIGURA 3.2: Caches Hierárquicos.

Uma desvantagem de caches hierárquicos é o aumento da latência de recuperação de um objeto. Caches em níveis mais altos na hierarquia devem suprir as falhas de seus filhos, sobrecarregando os caches de nível mais alto, podendo-se tornar um gargalo do sistema.

Caches hierárquicos não devem ter mais de dois niveis, porque um objeto recuperado do servidor de origem (ou de um cache de nível mais alto) será armazenado em 
todos os caches utilizados para transportar o objeto para o usuário. Isto significa que caches em níveis mais altos precisam de muito espaço em disco, caso contrário objetos serão descartados. Outra desvantagem de caches hierárquicos é a necessidade de uma conexão TCP que requer uma sobrecarga adicional no estabelecimento das conexões cada vez que se deseja carregar um objeto.

\subsubsection{Caches Cooperativos}

É um conjunto de caches que se comunicam servindo diferentes usuários. A comunicação pode ser feita usando diversos protocolos, como o Internet Cache Protocol (ICP) (Wessels \& Claffy, 1997).

Um cache cooperativo quando recebe uma requisição, verifica se o objeto requisitado se encontra em seu próprio cache. Caso não esteja, verifica se algum de seus irmãos tem o objeto armazenado. Se for verdadeiro, o objeto será requisitado (por exemplo, usando ICP). Vale destacar que a cópia não é armazenada caso tenha sido obtida de outro cache. Na Figura 3.3, observa-se que diversos caches cooperativos podem se comunicar para atender a uma requisição, diferentemente do cache hierárquico que pode contatar somente um cache de nível superior, ou o servidor de origem.

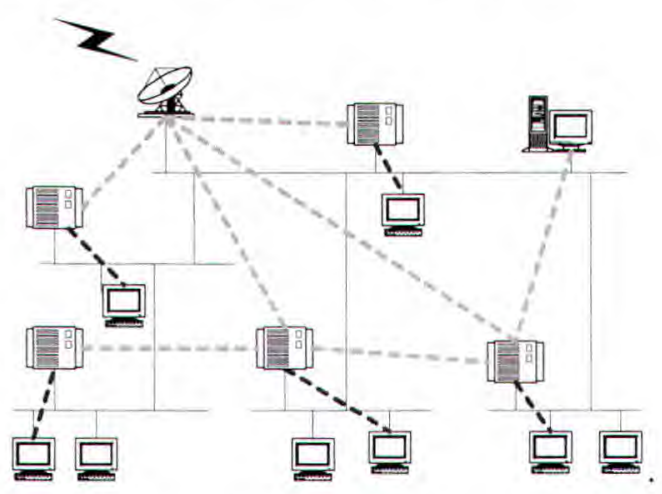

FIGURA 3.3: Caches Cooperativos.

Um cache cooperativo pode ser criado simplesmente para balanceamento de carga, pois um único cache pode não ter recursos para atender a uma comunidade de usuários maior. Uma instituição com vários departamentos pode desejar ter alguns caches em um mesmo nível (um por departamento, por exemplo), capazes de cooperar entre si para 
atender às requisições. Esta cooperação pode ser feita usando diversos protocolos para comunicação entre caches cooperativos.

Rodriguez, et al. (1999) concluíram que uma solução híbrida que combina as vantagens das duas abordagens discutidas pode reduzir os tempos de conexão e transmissão. O grau de cooperação entre os caches de um mesmo nível pode ser ajustado para minimizar o tempo de recuperação de objetos, assim como o uso de largura de banda dependendo do congestionamento na rede, da carga no cache em níveis superiores ou nos servidores de origem.

\subsection{Políticas de Substituição de Objetos em Caches na Web}

Em qualquer sistema de cache real, o espaço de armazenamento é finito. Quando o cache estiver cheio e, for solicitado um objeto que não esteja presente no cache, será necessário definir o(s) objeto(s) que será(ão) retirado(s) do cache para ceder lugar ao objeto que está sendo inserido. Essa tarefa é cumprida pelas políticas de substituição de objetos.

É importante ressaltar a importância das políticas de substituição em selecionar, de maneira conveniente, qual ou quais objetos serão removidos do cache, pois se a seleção não for adequada, irá comprometer diretamente a eficácia do uso de caches na Web. Para uma escolha mais consciente de quais objetos devem ser substituídos, são considerados diversos fatores, como: a recentidade, a freqüência de acesso, o tamanho dos objetos, o período de validade do objeto no cache e os tempos de transferência.

As políticas tradicionais de substituição, usadas em sistemas de arquivos, não apresentam bom desempenho quando usadas para objetos Web (Markatos, 1996), pelas seguintes razões:

- a granulosidade do cache tradicional é diferente;

- as políticas tradicionais colocam blocos de arquivos no cache, enquanto o cache Web deve guardar todo o objeto;

- os objetos Web são acessados em um modo somente-leitura, diferente dos sistemas de arquivos que tem que lidar com tráfego somente-leitura e de 
leitura-escrita, o que introduz uma complexidade adicional para esses sistemas.

Quando as políticas de substituição favorecem objetos menores, a Taxa de Acerto é maximizada, pois, nesse caso, mais objetos poderão ser armazenados. Por outro lado, se objetos maiores forem armazenados no cache, aumenta a probabilidade de se ter uma economia do tempo de transferência e uma maior Taxa de Acertos por Bytes.

A seguir, são descritas diversas políticas de substituição de objetos propostas na literatura. As políticas foram classificadas de acordo com a quantidade de parâmetros considerados para substituição.

\subsubsection{Políticas que Consideram Somente um Parâmetro na Substituição}

\section{Least Recently Used (LRU)}

É uma das políticas mais tradicionais e substitui os objetos que não foram requisitados há mais tempo. É uma das mais simples, pois não requer parametrização. Esta política trabalha bem quando há uma elevada localidade temporal de referência na carga, isto é, quando os objetos acessados recentemente são mais prováveis de serem referenciados novamente em um futuro próximo. Essa política é implementada usando uma lista ordenada pelo último tempo de acesso. Adicionar ou remover elementos nessa lista é feito em tempo constante $O(1)$, tempo necessário somente para acessar a cauda da lista (Dilley et al., 1999). Esta política possui a desvantagem de não considerar o tamanho do objeto e o tempo decorrido para recuperá-lo, mas garante, de uma maneira direta, que os objetos com acessos mais recentes sempre estejam no cache.

\section{Least Frequently Used (LFU)}

É outra política tradicional que mantém um contador de referências para cada objeto no cache. O objeto que possui o menor contador é selecionado para ser substituído, ou seja, o objeto que foi acessado menos vezes. Se mais de um objeto tem o mesmo valor do contador, uma segunda política pode ser usada (por exemplo, a LRU). Um inconveniente para a LFU é que alguns objetos podem acumular contadores com valores altos e nunca serem candidatos a ser substituídos do cache, isto é, objetos muito referenciados no passado e que não serão mais referenciados no futuro podem permanecer no cache por muito tempo. 
Ao contrário da política LRU, a política LFU não pode ser implementada como uma lista encadeada simples, cada remoção ou inserção pode levar um tempo de ordem linear $O(n)$. Pode-se usar uma estrutura de dados heap para implementar essa política, neste caso, as operações de inserção e remoção são de ordem logarítmica $O(\operatorname{logN})$ (Dilley et al., 1999).

\section{LFU-Aging}

Para amenizar o problema da política LFU, uma técnica de envelhecimento (aging) pode ser implementada. Requer dois parâmetros: um deles é $A_{\max }$, que coloca um limite superior para o valor médio do contador de referência para todos os objetos do cache; o outro parâmetro é $M_{\text {Refss }}$ que impõe um limite superior para o contador de referência que pode ser obtido para um único objeto. Sempre que a média do contador de referência para os óbjetos no cache ultrapassa $A_{\max }$, o contador de cada objeto é reduzido por um fator de dois (Arlitt et al., 2000).

\section{LFU*}

Esta política apresentada em (Arlitt \& Williamson, 1996b) tem o objetivo de minimizar o impacto dos objetos acessados somente uma vez. Assim como na política LFU, é mantido um contador de referências para cada objeto presente no cache. Os objetos candidatos à remoção são somente os que tiveram um único acesso. No caso de ocorrer uma falha (miss), o objeto só será inserido no cache, se o somatório do tamanho dos objetos que tiverem somente um acesso for maior ou igual ao objeto que se pretende inserir. Independente de o novo objeto ser inserido ou não no cache, serão descartados os objetos que estiverem registrados somente um acesso. Vale destacar que é mantida dinamicamente a quantidade de espaço dos objetos que tiveram somente um acesso. Não será adicionado mais nenhum objeto no cache caso todos os objetos presentes no cache tiverem dois ou mais acessos e não houver mais espaço disponível no cache. Isto pode não ser um problema, caso os objetos que estão presentes no cache continuarem populares, porém pode ser desastroso, se os objetos presentes no cache não forem mais acessados.

\section{LFU*-Aging}

Para amenizar o problema apresentado pela política LFU*, é utilizada uma técnica de envelhecimento que reduz objetos com poucos acessos a somente um, tornando-os novamente candidatos à remoção (Arlitt \& Williamson, 1996b). 


\section{Size Policy}

Foi proposta em (Williams et al., 1996), especificamente para caches na Web. Esta política remove os objetos maiores do cache quando for necessário espaço para armazenar novos objetos. Assim como a política LRU, esta política possui a vantagem de não necessitar de parametrização (Arlitt et al., 2000). Percebe-se que esta política tende a reter os objetos menores, responsáveis pelo maior número de acerto no cache. Porém, existe a possibilidade de reter objetos pequenos indefinidamente que podem não ser mais referenciados, se nenhum mecanismo de expiração for utilizado.

\section{Least Dynamic Frequency Rule ( $L D R F)$}

Aggarwal e Yu (1997) implementaram uma política que usa a freqüência de acesso de um objeto como parâmetro para remover um objeto do cache. Deste modo, sempre que um novo objeto for inserido no cache, o conjunto de objetos adjacentes com menor freqüência de acesso é escolhido para ser retirado. Este esquema é chamado de LDRF e é uma generalização direta da política LRU para o caso de objetos Web. Deve-se lembrar que este esquema pode criar fragmentos de espaços vazios, que são usados sempre que um novo objeto de tamanho inferior ao fragmento for adicionado no cache. A desvantagem apresentada por essa política é que exige muito tempo para verificação da freqüência de cada objeto no cache. Para minimizar este tempo é proposta uma implementação mais rápida, chamada de Localized Least Dynamic Frequency (LLDR). Esta política utiliza um cache auxiliar, onde são armazenados os objetos mais recentemente acessados (seguindo uma política LRU). O conteúdo do cache auxiliar é usado para reduzir a complexidade na escolha do grupo de objetos que devem ser excluídos do cache principal.

\subsubsection{Políticas que Consideram dois Parâmetros na Substituição}

\section{Segmented LRU (SLRU)}

Esta política foi originalmente projetada para ser usada em caches de disco. Ela considera tanto a freqüência quanto quão recentemente um objeto foi requisitado para realizar a substituição. Essa política divide o cache em dois segmentos: um protegido (para armazenar objetos que são acessados com mais freqüência) e outro não-protegido. Quando um objeto é requisitado pela primeira vez, o mesmo é adicionado no segmento nãoprotegido. Quando ocorre um acerto no cache, o mesmo é movido para o segmento 
protegido. Os dois segmentos são gerenciados pela política LRU. No entanto, somente os objetos que estão no segmento não-protegido podem ser eleitos para uma substituição. Quando for necessário espaço para adicionar novos objetos, aqueles que foram menos usados no segmento não-protegido são removidos. Objetos removidos do segmento protegido são adicionados no segmento não protegido como os que tiveram acesso mais recente. Essa política requer um parâmetro, que determina qual porcentagem do cache é alocada para o segmento protegido (Arlitt et al., 2000).

\section{LRU-K}

Esta política considera na escolha de um objeto para substituição, tanto a freqüência de atualização quanto quão recente ocorreu sua requisição. Na tentativa de melhorar o desempenho, essa política requer dois parâmetros (Arlitt et al., 2000):

- K: um contador que indica o número de vezes que um objeto foi requisitado. A política mantém as $\mathrm{K}$ referências mais novas para cada objeto, mesmo que ele tenha sido removido do cache. Objetos com poucas referências são os primeiros candidatos para substituição;

- RP: usado para limitar o tempo em que serão mantidas as informações dos objetos que não estão mais presentes no cache. É necessário para evitar o acúmulo de muitos dados históricos dos objetos que foram removidos e não serão mais referenciados ou referenciados em um futuro próximo.

\section{Frequency-Based Replacement (FBR)}

Esta política apresentada em Arlitt \& Williamson (1996b) usa uma combinação das políticas LRU e LFU na decisão de quais objetos serão removidos. O cache é dividido em três seções (Figura 3.4). O tamanho de cada seção é definido por dois parâmetros, $F_{(n e w)}$ e $F_{\text {old }}$ que especificam a quantidade de espaço dedicada a cada seção. $F_{(n e w)}$ especifica a quantidade de espaço disponível para a seção new; já o $\mathrm{F}_{(o l d)}$ delimita o espaço para a seção old. $\mathrm{O}$ espaço remanescente é dedicado à seção middle. 


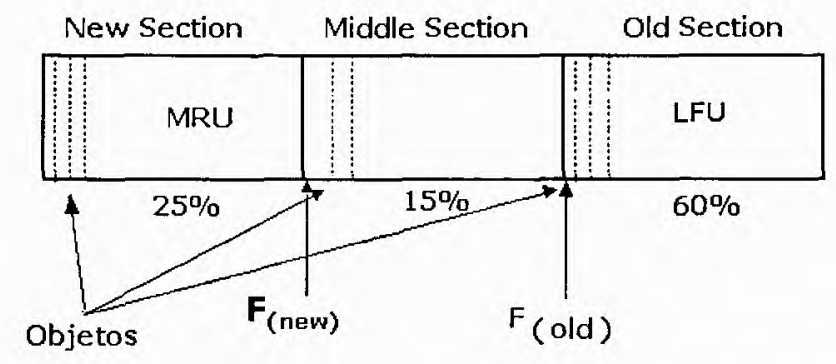

FIGURA 3.4: Organização das seções na política FBR.

Os objetos são inicialmente adicionados na seção new; conforme vão sendo inseridos novos objetos nesta seção, os objetos mais antigos, através da política LRU, são movidos para a seção middle; se o objeto continuar a "envelhecer" sem ser referenciado será transportada para a seção old. Somente os objetos na seção old podem ser removidos do cache, neste caso, o objeto será selecionado de acordo com a política LFU. Se o objeto referenciado encontra-se na seção middle ou old, o seu contador de referência é incrementado, enquanto que na seção new, se o objeto for referenciado o contador de referência não é incrementado.

\section{Greedy Dual-Size (GD-Size)}

Proposta por Cao e Irani (1997), essa política considera o tamanho dos objetos e quão recente cada um deles foi requisitado, para fazer a decisão de substituição. Os objetos são ordenados conforme um valor $H$ definido por $H=$ custo / tamanho. O objeto que tiver o menor valor de $\mathrm{H}\left(\min _{H}\right)$ é selecionado para substituição. Quando o objeto é acessado, o valor de $H$ é calculado e somado com o valor anterior, privilegiando os objetos acessados mais recentes. Esta política não considera o tempo decorrido para recuperar o objeto e a freqüência que o objeto foi referenciado. Cao e Irani propuseram algumas variações nessa política que favorecem a taxa de acerto ou a taxa de acerto por bytes. Com custo $1, \mathrm{Gd}$ Size(1), foi alcançado a melhor Taxa de Acerto, enquanto que GD-Size (pacotes), sendo pacote $=2+$ tamanho/536, obteve a melhor Taxa de Acerto por Bytes.

\section{Pyramidal Selection Scheme (PSS)}

Esta política, proposta por Aggarwal et al. (1997), trata de objetos com tamanhos diferentes e tem como idéia principal uma classificação piramidal dos objetos no cache, baseado nos seus tamanhos. Os objetos em cada grupo $i$ dessa classificação têm seus 
tamanhos limitados entre $2^{\mathrm{i}-1}$ e $2^{\mathrm{i}}-1$, e são ordenados pela política LRU. Sempre que um objeto tiver de ser excluído do cache, os objetos usados menos recentemente em cada grupo são comparados, considerando-se o seu tamanho e a sua freqüência de acesso. Os objetos com maior tamanho e menor freqüência de acesso são selecionados para serem removidos do cache. Os objetos são removidos até que haja espaço para o novo objeto que está sendo inserido no cache. Esta política também implementa um controle de admissão, onde o objeto acessado pela primeira vez é armazenado no cache somente se houver espaço suficiente. Caso não haja, é armazenado em um pequeno cache auxiliar a URL e o tempo do último acesso (timestamp). Quando o objeto for acessado pela segunda vez torna-se candidato a ser armazenado no cache.

\section{LRV (Lowest Relative Value)}

Esta política proposta por Rizzo e Vicisano (1998) inclui o custo e o tamanho de um objeto no cálculo de um valor que estima a utilidade de guardar um objeto no cache. $\mathrm{O}$ objeto com o menor valor é removido do cache. Este cálculo foi baseado em análise empírica de arquivos de $\log s$, onde encontraram funções matemáticas que são aproximações da distribuição dos tempos entre acessos ao mesmo objeto e da probabilidade de mais acessos dado que o objeto foi acessado previamente $i$ vezes. Para um dado valor $i$, $P_{i}$ denota a probabilidade de um objeto ser requisitado $i+1$ vezes, dado que o objeto foi requisitado i vezes. $P_{i}$ é calculado de uma maneira on-line, pegando a taxa $D_{i}+1 / D_{i}$, onde $D_{i}$ é o número tọtal de objetos atendidos até que tenha sido requisitado pelo menos $i$ vezes. $P_{i}(s)$ é o mesmo que $P_{i}$, exceto que o valor é determinado para somente um objeto de tamanho $s$. Sendo que $l-D(t)$ é a probabilidade de o objeto ser requisitado novamente com uma função do tempo em segundos. $D(t)$ é obtido através da seguinte fórmula:

$$
D(t)=0.035 \log (t+1)+0.45\left(1-e^{\frac{-t}{2 e 6}}\right)
$$

Esta política possui a desvantagem de possuir parametrização com funções logarítmicas e exponenciais que são computacionalmente "caras". 


\subsubsection{Políticas que Consideram Múltiplos Parâmetros na Substituição}

\section{Algoritmo baseado no tempo de recuperação dos objetos}

Bolot e Hoschka (1996) apresentaram um algoritmo de substituição em cache que objetiva minimizar o tempo de recuperação de objetos, considerando, explicitamente, o tamanho dos objetos e o tráfego da rede. Este algoritmo tenta minimizar a probabilidade de remoção de objetos com alto retardo de recuperação. Assim sendo, a política armazena, para cada objeto, os seguintes parâmetros: $t_{i}$, tempo em que o objeto foi referenciado pela última vez; $S_{i}$, tamanho do objeto; $R T T_{i}$, tempo levado para recuperar o objeto e $T T L_{i}$, tempo de validade do objeto. Com essas variáveis de estado, é possível modelar a maioria dos algoritmos existentes. Por exemplo, a função de peso $W\left(t_{i}, S_{i}, R T T_{i}, T T L_{i}\right)=1 / t_{i}$ modela a política LRU, pois os objetos têm o peso inversamente proporcional ao tempo de último acesso ao objeto.

O algoritmo proposto por Bolot e Hoschka (1996) usa a seguinte função para medir o valor de cada objeto:

$\mathrm{W}\left(\mathrm{t}_{\mathrm{i}}, \mathrm{S}_{\mathrm{i}}, \mathrm{RTT}_{\mathrm{i}}, \mathrm{TTL}_{\mathrm{i}}\right)=\left(\mathrm{W}_{1} \mathrm{RTT}_{\mathrm{i}}+\mathrm{W}_{2} \mathrm{~S}_{\mathrm{i}}\right) / \mathrm{TTL}_{\mathrm{i}}+\left(\mathrm{W}_{3}+\mathrm{W}_{4}\right) / \mathrm{t}_{\mathrm{i}}$

Os valores de $W_{1}, W_{2}, W_{3} e W_{4}$ são constantes, cujos valores devem ser determinados dependendo do objetivo.

Bolot e Hoschka chegaram à conclusão de que o algoritmo proposto obteve melhor desempenho que o algoritmo LRU, mostrando a vantagem de se usar um algoritmo de substituição baseado no tempo de recuperação dos objetos.

\section{Hybrid}

Esta política proposta por Wooster e Abrams (1997) associa para cada objeto $i$ um custo dado pela seguinte fórmula.

$$
\frac{\operatorname{Nref}_{i}^{C_{2} *}\left(R T T_{s}+\frac{C_{1}}{b w_{s}}\right)}{\text { size }_{i}}
$$

Onde $C_{1}$ e $C_{2}$ são constantes fornecidas (os valores padrão são 8196 e 0.9 , respectivamente), o índice $s$ representa o servidor em que o objeto $i$ foi recuperado; Nref $f_{i}$ corresponde ao número de referências feitas ao objeto $i, R T T_{\mathrm{s}}$ são baseadas no tempo gasto 
para trazer o objeto do servidor ao cache em um passado recente, e $b w_{i}$ corresponde à largura de banda disponível para recuperar o objeto.

Esta política tem a vantagem de manter informações sobre a latência e a largura de banda disponível para recuperar cada objeto. Porém esta abordagem requer muitas informações adicionais e torna o seu custo de implementação proibitivo.

\section{Dinâmica}

Essa política utiliza três filas (Brandão \& Anido, 2001). Essas filas contêm os mesmos objetos ordenados de maneira diferente (Figura 3.5). A primeira fila é ordenada utilizando a política LRU; a segunda, usando a LFU, e a última é ordenada pela política SIZE. Dessa maneira, é possível considerar tanto o tamanho dos objetos quanto a freqüência com que foram acessados e o tempo desde seu último acesso.

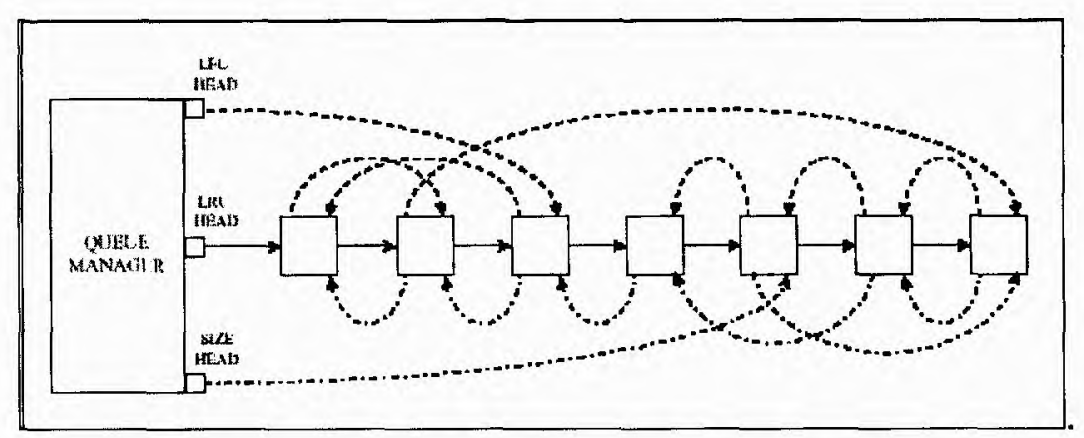

FIGURA 3.5: Modelo da política de substituição dinâmica (Brandão \& Anido, 2001).

\subsection{Considerações Finais}

O tráfego da Web tem crescido bastante nestes últimos anos e isto pode vir a gerar situações de congestionamento temporárias ou de longo prazo. O uso de caches para armazenar objetos Web pode aliviar não só a carga nos diversos links da rede, mas também diminuir o tempo de acesso aos objetos remotos.

O uso de caches na Web diminui a necessidade de ter que buscar objetos requisitados com maior freqüência nos servidores de origem. Isto possibilita a diminuição do tempo de espera por informações, proporciona melhor uso da largura de banda, assim como melhora o desempenho e a disponibilidade em ambientes Web. 
Vale destacar a importância das políticas de substituição de objetos que decide quais objetos serão retirados do cache. Os algoritmos que implementam as políticas de substituição procuram considerar os parâmetros de carga que afetam o desempenho. Os parâmetros mais comuns são: o tamanho dos objetos, a freqüência de acesso, o tempo do último acesso ao objeto e o tempo de busca para o caso de uma falha (miss) no cache.

No presente capítulo, foi apresentada uma visão geral dos caches na Web. Primeiramente, foram feitas algumas considerações iniciais, abordaram-se seus principais aspectos, assim como os caches tradicionais e caches na Web, frisando as suas principais diferenças. Comentou-se sobre o problema de consistência de caches e suas topologias (hierárquica e cooperativa). Um mapa das principais políticas, categorizando-as de acordo com a quantidade de parâmetros considerados nos algoritmos de substituição, foi apresentado. Para maiores detalhes sobre o assunto, consultar (Cao \& Irani, 1997) e (Arlitt et al., 2000). 
Capitulo 4

\section{Caracterização de Carga de Servidores Proxy com Aplicação em Caches na Web}

Este capítulo apresenta os resultados do estudo de caracterização de carga que foi realizado com quatro servidores proxy que implementam caches na Web. A finalidade deste estudo é identificar características comuns nas cargas de trabalho nos servidores atuais, provendo um embasamento ao entendimento da caracterização de carga da Web. Esta caracterização será utilizada neste trabalho para validar as cargas que são utilizadas para avaliação de desempenho de políticas de substituição de objetos em caches na Web. Alguns resultados encontrados são similares a caracterizações já publicadas na literatura, o que reforça os resultados obtidos, enquanto que outros resultados diferentes destacam a evolução nas características de carga da Web.

Na seção 4.1, são apresentados diversos estudos relacionados com a caracterização de carga na Web; na seção 4.2, é detalhada a coleção de dados que foi utilizada neste estudo; na seção 4.3, é analisada a taxa de utilização dos métodos e códigos de status retornados pelos protocolos HTTP/1.1 e ICP; na seção 4.4, são descritos os resultados do estudo de caracterização de carga de trabalho que influenciam diretamente no desempenho de caches na Web, destacando-se as classes de objetos definidas por tamanho e tipos de 
objetos; na seção 4.5, são apresentados diversos gráficos de freqüência acumulada; e na seção 4.6, são apresentadas as considerações finais.

\subsection{Trabalhos Relacionados}

$\mathrm{O}$ crescimento da Web tem motivado várias pesquisas que buscam caracterizar o tráfego na Web, com intuito de propor solução visando melhorar o seu desempenho e a sua escalabilidade. A análise cautelosa e a compreensão das características de carga na Web são fundamentais para um bom planejamento e implementação de caches na Web, à medida que são proporcionadas técnicas que melhorem o uso de largura de banda e reduzam a latência.

A caracterização da carga de trabalho é feita através da análise de dados obtidos de servidores Web configurados para armazenar informações sobre as solicitações dos usuários ou através de servidores proxy. Podem ser usados, também, browsers instrumentados para armazenar informações dos clientes. A escolha entre coletar dados nas máquinas clientes, servidores Web ou servidores proxy depende do tipo de estudo que se deseja realizar. As cargas obtidas nos servidores Web e proxy são mais apropriadas para avaliar medidas de desempenho no nível de sistema, como a demanda de largura de banda, enquanto as cargas obtidas nos clientes são mais apropriadas para caracterizar o comportamento dos usuários.

Arlitt e Williamson (1996a) realizaram estudos com o objetivo de identificar invariantes no tráfego de servidores Web. Nestes estudos foram utilizados seis diferentes logs de acesso: três de ambientes acadêmicos, dois de instituições de pesquisa e um de provedor de Internet. Os conjuntos de dados obtidos foram coletados em intervalos de tempo entre uma semana e um ano de atividade. Identificaram-se dez características no tráfego dos servidores Web, comportamentos que se aplicam a todos os conjuntos de dados utilizados. Estas características representam, potencialmente, constantes universais a todos os servidores Web. As constantes encontradas são resumidas na Tabela 4.1. 
TABELA 4.1: Invariantes sobre o tráfego nos servidores Web.

\begin{tabular}{|c|c|c|}
\hline Constante & Nome & Descrição \\
\hline 1 & Taxa de sucesso & $\begin{array}{l}\text { A taxa de sucesso para pesquisas nos servidores é } \\
\text { aproximadamente } 88 \%\end{array}$ \\
\hline 2 & Tipo de objetos & $\begin{array}{l}\text { Objetos HTML e de imagens compreendem cerca de } 90 \% \text { dos } \\
\text { pedidos }\end{array}$ \\
\hline 3 & $\begin{array}{l}\text { Tamanho médio de } \\
\text { transferência }\end{array}$ & $\begin{array}{l}\text { O tamanho médio de transferência é menor ou igual a } 21 \\
\text { Kbytes }\end{array}$ \\
\hline 4 & Pedidos distintos & $\begin{array}{l}\text { Entre todos os pedidos feitos ao servidor, menos de } 3 \% \text { são } \\
\text { para objetos distintos }\end{array}$ \\
\hline 5 & Referência única & $\begin{array}{l}\text { A proximadamente um terço dos objetos e dos bytes acessados } \\
\text { nos servidores são acessados uma única vez }\end{array}$ \\
\hline 6 & $\begin{array}{l}\text { Distribuição do } \\
\text { tamanho }\end{array}$ & $\begin{array}{l}\text { O tamanho dos objetos segue a distribuição de Pareto com } 0.40 \\
<\alpha<0.63\end{array}$ \\
\hline 7 & $\begin{array}{l}\text { Concentração de } \\
\text { referências }\end{array}$ & $\begin{array}{l}10 \% \text { dos objetos acessados correspondem a } 90 \% \text { dos pedidos } \\
\text { ao servidor e a } 90 \% \text { dos bytes transferidos }\end{array}$ \\
\hline 8 & $\begin{array}{l}\text { Tempos entre } \\
\text { referências }\end{array}$ & $\begin{array}{l}\text { O tempo entre referências de objetos é exponencialmente } \\
\text { distribuido e independente }\end{array}$ \\
\hline 9 & Pedidos remotos & $\begin{array}{l}\text { Sites remotos compreendem cerca de } 70 \% \text { dos acessos aos } \\
\text { servidores Web e } 60 \% \text { dos bytes transferidos }\end{array}$ \\
\hline 10 & Uso em áreas amplas & $\begin{array}{l}\text { Os servidores Web são acessados por milhares de domínios, } \\
\text { com } 10 \% \text { dos domínios correspondendo a cerca de } 75 \% \text { do } \\
\text { uso. }\end{array}$ \\
\hline
\end{tabular}

A constante 2 mostra uma grande concentração das referências para objetos HTML e de imagens. A constante 4 mostra a existência de um grande número de referências para um pequeno número de objetos. A constante 7 mostra a concentração de referências a estes objetos, e a constante 3 mostra que os tamanhos destes objetos são pequenos. A constante 5 indica que cerca de um terço dos objetos presentes no cache é preenchido com objetos que não serão mais acessados. Estes resultados mostram que o armazenamento de objetos Web pode melhorar o desempenho de servidores Web e diminuir o uso de largura de banda.

Crovella e Bestavros (1996) chegaram à conclusão de que o tráfego na Web exibe um comportamento que é consistente com modelos de tráfego auto-similar (self-similar), já que o tráfego na Web coletado apresentava rajadas observáveis em quatro escalas de tempo. Um tráfego com rajadas em várias ou em todas as escalas de tempo pode ser descrito estatisticamente usando a noção de auto-similaridade. 
Abdulla et al. (1997) identificaram dez características comuns para os servidores proxy, similares aos estudos de Arlitt e Williamson (1996a) sobre servidores Web. As constantes identificadas na Tabela 4.2 são úteis para a implementação de caches em servidores proxy.

TABELA 4.2: Constantes para servidores proxy.

\begin{tabular}{|c|c|c|}
\hline Constante & Nome & Descrição \\
\hline 1 & Mediana & Aproximadamente 2 Kbytes \\
\hline 2 & Média Aritmética & O tamanho médio dos objetos é menor que 27 Kbytes \\
\hline 3 & Tipo de objetos (acessado) & $\begin{array}{l}90 \% \text { a } 98 \% \text { dos objetos acessados são para documentos } \\
\text { HTML, arquivos de imagem e programas CGI }\end{array}$ \\
\hline 4 & Tipo de objetos (bytes) & A maioria dos bytes transferidos é de objetos de imagens \\
\hline 5 & Acesso a um único servidor & Menos de $11 \%$ do acesso é feito a um único servidor \\
\hline 6 & $\begin{array}{l}\text { Servidores referenciados uma } \\
\text { única vez }\end{array}$ & $\begin{array}{l}\text { Menos de } 5 \% \text { dos servidores são referenciados uma única } \\
\text { vez }\end{array}$ \\
\hline 7 & $\begin{array}{l}\text { Concentração de acesso } \\
\text { (servidores) }\end{array}$ & $\begin{array}{l}25 \% \text { dos servidores são responsáveis por } 80 \text { a } 95 \% \text { das } \\
\text { referências }\end{array}$ \\
\hline 8 & $\begin{array}{l}\text { Concentração de bytes } \\
\text { (servidores) }\end{array}$ & $\begin{array}{l}25 \% \text { dos servidores são responsáveis por } 90 \% \text { dos bytes } \\
\text { acessados }\end{array}$ \\
\hline 9 & Taxa de sucesso & $\begin{array}{l}88 \text { a } 99 \% \text { das referências feitas ao proxy resultam em } \\
\text { sucesso de transferência para os clientes }\end{array}$ \\
\hline 10 & Auto-similaridade & $0,59 \leq \mathrm{H} \leq 0,94$ \\
\hline
\end{tabular}

Mahanti e Williamson (1999) desenvolveram estudos para caracterizar a carga de servidores proxy. As principais observações foram:

- objetos HTML e Imagens correspondem a 95\% das requisições;

- o tamanho dos objetos segue uma distribuição de cauda pesada (Pareto, com $\alpha \cong$ $1,3)$;

- entre todos os objetos acessados, 70 \% são acessados somente uma vez;

- aproximadamente $30 \%$ dos objetos correspondem a $80 \%$ das referências;

- o tamanho médio dos objetos transferidos variou entre 7 e 15 Kbytes, enquanto que a mediana, entre 2 e 3 Kbytes.

Murta (1999) desenvolveu um estudo de caracterização de carga com objetivo de identificar propriedades nas cargas que afetam as Taxa de Acerto e a Taxa de Acerto por 
Bytes em caches na Web. Este mesmo estudo também apresentou uma solução para o problema gerado pela grande variabilidade, o modelo de organização do espaço de caches denominado PART.

Os resultados dos trabalhos de Arlitt e Williamson (1996a), Abdulla et al. (1997), Mahanti e Williamson (1999) e Murta (1999) são comparados com os resultados apresentados neste trabalho no decorrer deste capítulo.

\subsection{Coleta de Dados}

Esta seção descreve o formato das cargas de trabalho utilizadas neste estudo de caracterização de carga e, também, são detalhados os locais em que estas cargas de trabalho foram obtidas.

As cargas de trabalho foram obtidas a partir do registro em ordem cronológica de logs de acesso do Squid ${ }^{4}$ que armazenam as solicitações dos usuários, sendo que cada linha do log corresponde a uma URL solicitada pelo usuário e contém as informações apresentadas na Tabela 4.3 .

TABELA 4.3: Formato do $\log$ de acesso do Squid.

\begin{tabular}{|c|c|}
\hline CAMPO & DESCRIÇÃO \\
\hline Timestamp & $\begin{array}{l}\text { Tempo em que o pedido foi completado, especificado em segundos desde } 1 \text { de janeiro de } \\
1970\end{array}$ \\
\hline Elapsed & $\begin{array}{l}\text { Tempo gasto em milissegundos para completar a requisição. Corresponde ao tempo entre } \\
\text { os métodos accept(t) e close } 0 \text { do socket } T C P\end{array}$ \\
\hline Client & Endereço IP da máquina cliente \\
\hline Action & Descreve como a requisição foi tratada localmente (hit, miss, etc) \\
\hline Code & $\begin{array}{l}\text { Código de resposta HTTP retornado pelo servidor Web. Para requisições ICP é sempre } \\
\text { " } 000 \text { ". Caso o código de retorno não seja fornecido, será atribuído o valor } 555\end{array}$ \\
\hline Size & $\begin{array}{l}\text { Número de bytes transferidos do servidor proxy para o cliente. Para requisições TCP, } \\
\text { corresponde ao total de bytes transferidos. Para requisições UDP, corresponde ao } \\
\text { tamanho da requisição }\end{array}$ \\
\hline
\end{tabular}

\footnotetext{
${ }^{4} \mathrm{O}$ Squid (http://www.squid-cache.org/) é um servidor proxy que implementa caches na Web e utiliza o protocolo ICP para comunicação com outros caches. Este servidor é derivado do projeto Harvest desenvolvido na Universidade do Colorado em Boulder.

${ }^{5} \mathrm{O}$ método accept ( ) indica o início de uma conexão.

${ }^{6} \mathrm{O}$ método close ( ) indica o término de uma conexão.
} 


\begin{tabular}{|l|l|}
\hline \multicolumn{1}{|c|}{ CAMPO } & \multicolumn{1}{c|}{ DESCRIÇÃO } \\
\hline Metbod & Método HTTP (GET, POST, etc.), ou ICP_QUERY para requisições ICP. \\
\hline URJ & Localização do objeto solicitado \\
\hline Hierarcby & Descrição de como e onde o objeto requisitado foi obtido \\
\hline From & Nome da máquina em que o objeto foi obtido \\
\hline Content & Tipo de objeto. Especificado no formato MIME (Multipurpose Internet Mail Extensions) \\
\hline
\end{tabular}

No presente trabalho, identificaram-se algumas limitações nas cargas de trabalho. Por exemplo: o timestamp registra quando um pedido foi processado, e não quando chegou a solicitação; também não é armazenada nenhuma informação das condições de tráfego do momento em que o objeto foi recuperado; além disso, não há nenhuma distinção entre transferências de objetos causadas por solicitações explícitas dos usuários e transferências de objetos causadas por software (por exemplo, ferramentas de buscas). Os logs de acesso também não armazenam informações sobre o tempo em que o objeto permanecerá válido no cache (TTL), tornando difícil a observação do impacto da manutenção de consistência em caches na Web. Essas quatro questões estão fora da extensão deste trabalho. As cargas de trabalho disponíveis são suficientes para fornecer estatísticas úteis para: tipos, tamanho e popularidade de objetos, popularidade de servidores, tempo médio para recuperar objetos, avaliação de desempenho, limitações de cache na Web, dentre outras estatísticas.

As cargas de trabalho utilizadas neste estudo foram obtidas de quatro servidores proxy. Segue um resumo com a descrição dos locais onde foram obtidas as cargas de trabalho:

- CISC: Cache institucional para clientes internos da Universidade de São Paulo São Carlos. Este cache atende a centenas de usuários e está implantado no CISC; as requisições são feitas a servidores dentro e fora do domínio "sc.usp.br". Este cache é formado por um computador Pentium III $500 \mathrm{MHz}, 64$ Mbytes de memória principal e 10,8 Gbytes de memória secundária rodando o sistema operacional Conectiva Linux 6.0 e Linux Virtual Server que recebe as solicitações dos usuários através de uma interface ATM (Asynchronous Transfer Mode) de 155Mbps e distribui as solicitações entre o agrupamento (cluster) de três computadores (Pentium II $300 \mathrm{MHz}, 96 \mathrm{Mbytes}$ de memória principal e 4,5 Gbytes de memória secundária), executando o sistema operacional Conectiva Linux 6.0 e o Squid 
versão 2.2.4. Os computadores estão interligados por uma rede padrão Ethernet 100 Mbps, conforme apresentado na Figura 4.1.

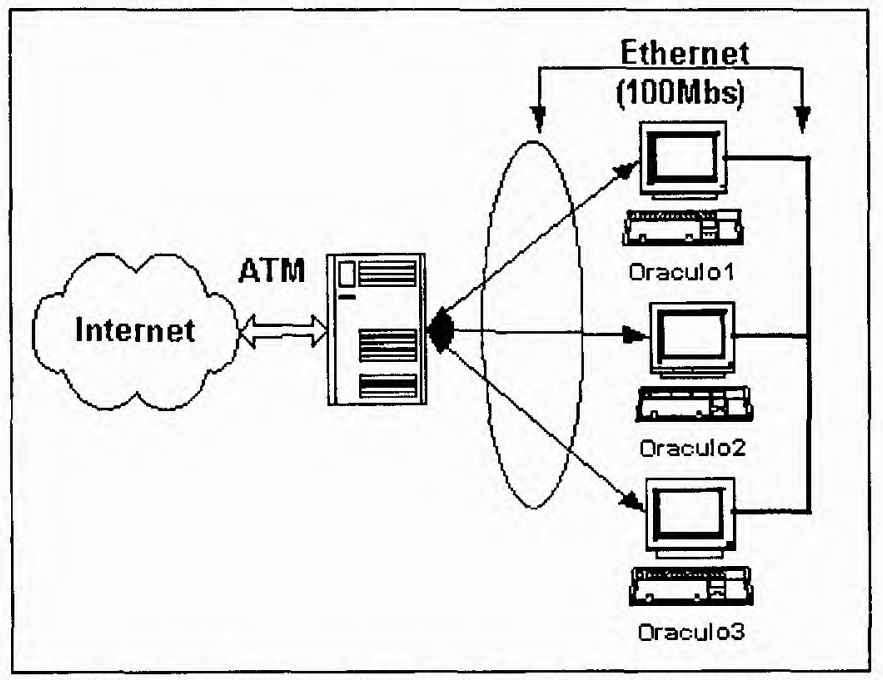

FIGURA 4.1: Organização de caches Web no CISC.

- NLANR (NLANR, 2001): Estes arquivos de log fazem parte do projeto de caches distribuídos dos Estados Unidos (IRCache), atualmente administrado pelo Computer and Information Sciences and Engineering. As cargas de trabalho escolhidas são:
- (1) Universidade do Colorado, Boulder (BO2) (bo2.us.ircache.net);
- (2) Palo Alto, Califórnia (PA) (pa.us.ircache.net);
- (3) Vale do Silício, Califórnia (SV) (sv.us.ircache.net).

Esses logs de acesso podem ser obtidos em: ftp://ircache.nlanr.net/Traces/.

A Tabela 4.4 apresenta algumas características gerais das cargas de trabalho, como: suas respectivas datas, o total e médias diárias de requisições e bytes transferidos. Foram analisadas 3.949.318 requisições que correspondem a 27,55 Gbytes transferidos.

TABELA 4.4: Resumo das cargas de trabalho.

\begin{tabular}{|c|c|c|c|c|}
\hline ITENS & CISC & NLANR - BO2 & NLANR - SV & NLANR - PA \\
\hline Duração do $\log$ & 10 dias & 4 dias & $1 \mathrm{dia}$ & 3 dias \\
\hline Data de início & $22 / 05 / 2001$ & $11 / 06 / 2001$ & $11 / 06 / 2001$ & $13 / 06 / 2001$ \\
\hline Data de término & $01 / 06 / 2001$ & $14 / 06 / 2001$ & $11 / 06 / 2001$ & $15 / 06 / 2001$ \\
\hline Total de requisições & 838.532 & 808.748 & 1.239 .504 & 1.062 .534 \\
\hline Média diária das requisições & 83.853 & 202.187 & 1.239 .504 & 354.178 \\
\hline Tot. de Bytes transferidos (Gbytes) & 2,73 & 7,88 & 7,72 & 9,22 \\
\hline Bytes Transferidos por dia (Mbytes) & 273,1 & 1.972 & 7.726 & 3.074 \\
\hline
\end{tabular}




\subsection{Análise dos Códigos de Status Retornados pelos Protocolos HTTP e ICP}

Nesta seção são analisadas as classes de resposta dos protocolos HTTP e ICP ${ }^{7}$, a utilização dos seus principais métodos e os principais códigos de status que influenciam diretamente na utilização de caches na Web.

A Tabela 4.5 apresenta a utilização das classes de respostas retornadas pelos protocolos HTTP $^{8}$ (apresentados na Tabela 2.2) e ICP. Cinco classes de respostas podem ser obtidas na carga de trabalho do CISC e quatro na carga de trabalho do NLANR.

É importante ressaltar que as cargas de trabalho que pertencem ao sistema de caches NLANR foram configuradas para registrar somente os códigos de respostas do protocolo HTTP, enquanto que o cache do CISC registra, além dos códigos de status HTTP, as requisições para os caches compartilhados usando o protocolo ICP (o que não resulta na cópia do objeto para o cache que o solicitou).

TABELA 4.5: Classes de respostas do protocolo HTTP e ICP.

\begin{tabular}{|c|c|c|c|c|}
\hline CLASSES & CISC $(\%)$ & NLANR-BO2 (\%) & NLANR-SV (\%) & NLANR-PA (\%) \\
\hline 2 XX & 34,13 & 62,89 & 52,62 & 59,83 \\
\hline $3 X X$ & 21,53 & 28,30 & 29,59 & 30,96 \\
\hline $4 X X$ & 04,28 & 02,22 & 01,08 & 01,31 \\
\hline $5 X X$ & 01,11 & 05,96 & 16,07 & 07,65 \\
\hline ICP & 38,88 & - & - & - \\
\hline Outros & 0,65 & 2,88 & 0,46 & 0,61 \\
\hline
\end{tabular}

Verificou-se que o $\log$ de acesso do CISC registrou 38,88\% das requisições para o ICP e $34,13 \%$ foram para classes $2 \mathrm{XX}$, totalizando $73 \%$ das requisições. Os proxies que fazem parte do NLANR tiveram entre 52,62\% (SV) e 62,89\% (BO2) dos códigos de status referentes à classe $2 \mathrm{xx}, \mathrm{o}$ que denota que a solicitação foi recebida, compreendida e aceita.

A classe de resposta $3 \mathrm{XX}$ variou de 21 a $30 \%$ das respostas em todas as quatro cargas analisadas, o que significa que outras ações precisam ser tomadas para completar a solicitação (por exemplo, requisitar uma outra URL).

\footnotetext{
${ }^{7} \mathrm{O}$ ICP é implementado usando primitivas UDP e seu objetivo é prover um método rápido e eficiente de comunicação entre servidores cache, oferecendo mecanismos para o estabelecimento de hierarquias de servidores cache.

${ }^{8}$ Todos os quatros servidores proxy analisados utilizam o protocolo HTTP versão 1.1
} 
As classes $4 \mathrm{XX}$ e $5 \mathrm{XX}$ correspondem a erros no cliente e no servidor respectivamente. O servidor proxy do CISC apresentou a maior taxa de erros no cliente, sendo que $4,28 \%$ das solicitações possuíam sintaxe inválida ou não podiam ser atendidas, enquanto que NLANR-SV registrou $16 \%$, a maior taxa de erros para a classe $5 \times x$, o que significa que o servidor não conseguiu atender a uma solicitação aparentemente válida; isto ocorreu devido ao grande volume de requisições diárias, em torno de 1,2 milhão de requisições.

A Tabela 4.6 fornece uma visão geral de utilização dos métodos HTTP versão 1.1 (apresentados na Tabela 2.1) para todas as cargas de trabalho e do ICP (ICP_QUERY) para a carga do CISC.

TABELA 4.6: Utilização dos métodos HTTP/1.1 e ICP.

\begin{tabular}{|c|c|c|c|c|}
\hline MÉTODOS & CISC (\%) & NLANR-BO2 (\%) & NLANR - SV (\%) & NLANR- PA (\%) \\
\hline GET & 60,45 & 97,11 & 99,54 & 99,39 \\
\hline POST & 01,32 & 02,56 & 00,24 & 0,38 \\
\hline HEAD & 00,03 & 0,0006 & 0,005 & 0,012 \\
\hline PUT & - & - & - & - \\
\hline CONNECT & 00,33 & - & 0,0029 & 0,014 \\
\hline ICP_QUERY & 37,79 & - & - & - \\
\hline Outros & 00,07 & 00,32 & 00,21 & 00,20 \\
\hline
\end{tabular}

O $\log$ de acesso do CISC registrou que aproximadamente $37,79 \%$ das requisições usaram o método ICP_QUERY ${ }^{9}$ e $60,45 \%$ usaram o método GET, totalizando $98,24 \%$ das requisições; já os logs de acesso que pertencem ao sistema de cache do NLANR registraram entre 97,11 e $99,54 \%$ das solicitações para o método GET. O método POST (envia dados para o servidor) teve apenas, em média, 1,1\% das requisições $(0,24-2,56 \%)$. Já a utilização dos métodos HEAD, PUT e CONNECT teve uso inexpressivo. Estes resultados evidenciam que os usuários na maioria das vezes fazem o download de informação e não enviam qualquer informação ao servidor, o que comprova que a Web ainda é utilizada maciçamente para leitura. Cabe ressaltar que nenhuma das cargas estudadas é de comércio eletrônico, nesse caso o comportamento deveria ser bastante diferente.

\footnotetext{
${ }^{9}$ Procura por um objeto em caches vizinhas.de modo a determinar se algum deles possui o objeto solicitado. Se o objeto for encontrado, ele será retornado ao cliente que o solicitou.
} 
A Tabela 4.7 fornece uma visão geral dos códigos de resposta mais observados nas cargas de trabalho. O código de status 200 indica que foi encontrado um objeto válido no servidor e retornado ao cliente; o código 302 indica que o recurso solicitado utiliza temporariamente uma URL diferente; já o código de status 304 significa que o cliente executou uma solicitação condicional com GET e o acesso foi permitido, mas o objeto não foi modificado desde a data e hora especificados no campo If-Modified-Since (utilizado pelos caches para verificar se o objeto foi atualizado no servidor de origem). $\mathrm{O}$ servidor responderá com esse código de status e não enviará um cabeçalho Entity-Body ao cliente. $O$ código de status 000 é destinado às solicitações ICP.

TABELA 4.7: Análise das dos códigos de status mais observados nas cargas de trabalho.

\begin{tabular}{|c|c|c|c|c|}
\hline Código de resposta & CISC (\%) & BO2 $(\%)$ & SV (\%) & PA (\%) \\
\hline $200(\mathrm{OK})$ & 34,13 & 62,81 & 52,58 & 59,80 \\
\hline $000(\mathrm{ICP})$ & 38,88 & - & - & - \\
\hline 302 (Found) & 02,06 & 12,53 & 04,75 & 07,10 \\
\hline 304 (Not Modified) & 19,12 & 15,52 & 24,62 & 23,63 \\
\hline Total de Erros & 05,74 & 08,59 & 17,79 & 09,17 \\
\hline
\end{tabular}

Uma primeira ressalva importante é a fração do código de resposta 200 que ficou entre $52,58 \%$ (SV) e $62,81 \%$ (BO2) (com exceção para o CISC que obteve $34,13 \%$; isto ocorreu devido ao ICP que registrou $38,88 \%$ das requisições). Outra observação importante é o uso do GET Condicional (304) que ficou entre 15,5\% e 24,6\%. Os códigos de resposta 200, 304 e 000, que resultam no sucesso para obtenção do objeto solicitado pelo cliente, obteve em média $83 \%$ (72,2\%-SV a $92,1 \%$-CISC) nas quatro cargas analisadas.

\subsection{Caracterização de Carga}

Esta seção apresenta uma análise das referencias e dos bytes transferidos sob diversos enfoques. Na seção 4.4.1, são apresentadas, de maneira mais detalhada, as cargas de trabalho com algumas estatísticas básicas e uma avaliação do impacto dos acessos únicos na Taxa de Acerto e na Taxa de Acerto por Bytes. Na seção 4.4.2, será mostrado o padrão de acesso para classes de objetos classificadas pela extensão dos arquivos. Na seção 4.4.3, será exibido o padrão de acesso dos objetos delimitados pelo tamanho; e na seção 4.4.4, é realizada uma comparação entre estes dois padrões de acesso. 
No decorrer desta análise serão considerados somente os acessos feitos aos servidores originais e que resultaram na transferência do objeto ao cliente, ou seja, todas as requisições com código de resposta $200(\mathrm{OK})$ do protocolo HTTP.

\subsubsection{Análise das Cargas de Trabalho}

$\mathrm{Na}$ Tabela 4.8, são apresentados: o total de requisições e bytes transferidos, o total de objetos distintos, de clientes e de servidores, também, são mostradas algumas estatísticas básicas em relação ao tamanho dos objetos, como: o tamanho médio, o desvio padrão que mostra a dispersão ou variabilidade dos dados, o coeficiente de variação para comparar a variabilidade das quatro cargas analisadas e a mediana. Observou-se que cada servidor proxy manipula centenas de milhares de objetos distintos, localizados em milhares de servidores acessados por dezenas ou centenas de clientes.

TABELA 4.8: Características das quatro cargas de trabalhos analisadas.

\begin{tabular}{|l|cccc|}
\hline \multicolumn{1}{|c|}{ ITENS } & CISC & NLANR-BO2 & NLANR-SV & NLANR-PA \\
\hline Total de requisições (200 - OK) & 272.881 & 489.251 & 647.191 & 630.364 \\
Tot. De bytes transferidos (Gbytes) & 2,40 & 6,43 & 6,39 & 6,86 \\
\hline Total de objetos & 116.426 & 316.310 & 379.666 & 313.869 \\
Total de clientes & 113 & 136 & 78 & 220 \\
Total de servidores acessados & 5.242 & 28.015 & 25.268 & 21.875 \\
\hline Tam. médio dos objetos (bytes) & $8.916,77$ & $13.156,39$ & $10.966,08$ & $13.415,41$ \\
Desvio padrão (bytes) & 289.753 & 281.866 & 235.282 & 170.438 \\
Coeficiente de variação & 32,49 & 21,42 & 21,45 & 12,70 \\
Mediana (Kbytes) & 2,28 & 2,57 & 2,68 & 3,0 \\
\hline
\end{tabular}

Os resultados da Tabela 4.8 revelam algumas características, como: a mediana variou de 2,28 a 3 Kbytes, ficando bem abaixo da média que variou de 8,9 a 13,4 Kbytes, resultados semelhantes ao estudo de Mahanti e Williamson (1999); e o coeficiente de variação que variou de 12,7 a 32,49 , denotando a grande variabilidade do conjunto de objetos analisados. Com estas observações, pode-se evidenciar que em virtude da mediana ser sempre menor que a média e a grande variabilidade observada no coeficiente de variação, caracteriza uma distribuição de cauda pesada. Estas conclusões foram igualmente observadas em (Abdulla et al., 1997) e (Murta, 1999). Notou-se, também, que a mediana apresentou valores próximos em todas as cargas analisadas, o que pode caracterizar bem a maioria dos objetos. 
A Tabela 4.9 mostra um resumo do conjunto de objetos e dos bytes distintos (não considera o total de acessos), a razão dos objetos e bytes distintos pelo total de objetos e bytes referenciados, respectivamente, a fração dos objetos e bytes acessados somente uma vez e mais que dez vezes, respectivamente, e algumas estatísticas em relação ao tamanho dos objetos distintos: a média, a mediana e o coeficiente de variação.

Vale destacar que objetos referenciados uma única vez "polui" os caches com objetos que não serão mais referenciados.

TABELA 4.9: Características dos objetos distintos.

\begin{tabular}{|l|cccc|cc|}
\hline ITENS & CISC & BO2 & SV & PA & Média & Desv. Padrão \\
\hline Objetos distintos & 116.426 & 316.310 & 379.666 & 313.869 & 281.568 & 114229,97 \\
Total de bytes dos objetos distintos (Gbytes) & 1,46 & 5,15 & 3,97 & 4,11 & 3,67 & 1,57 \\
\hline $\begin{array}{l}\text { Razão do total de objetos distintos pelo total } \\
\text { de requisições }\end{array}$ & $42,66 \%$ & $64,65 \%$ & $58,66 \%$ & $49,79 \%$ & $53,94 \%$ & $10 \%$ \\
$\begin{array}{l}\text { Razão do total de bytes dos objetos distintos } \\
\text { pelo total de bytes transferidos }\end{array}$ & $60,94 \%$ & $80,11 \%$ & $62,19 \%$ & $60,11 \%$ & $65,83 \%$ & $10 \%$ \\
\hline $\begin{array}{l}\text { Porcentagem dos objetos acessados somente } \\
\text { uma vez }\end{array}$ & $76,92 \%$ & $91,93 \%$ & $71,19 \%$ & $67,99 \%$ & $77,01 \%$ & $11 \%$ \\
Porcentagem de bytes dos objetos acessados & $79,52 \%$ & $89,96 \%$ & $73,67 \%$ & $73,13 \%$ & $79,07 \%$ & $8 \%$ \\
somente uma vez & & & & & & \\
\hline $\begin{array}{l}\text { Porcentagem dos objetos acessados menos que } \\
\text { dez vezes }\end{array}$ & $97,48 \%$ & $99,26 \%$ & $99,43 \%$ & $99,23 \%$ & $98,85 \%$ & $1 \%$ \\
$\begin{array}{l}\text { Porcentagem dos bytes dos objetos acessados } \\
\text { menos que dez vezes }\end{array}$ & $98,79 \%$ & $99,57 \%$ & $98,95 \%$ & $98,19 \%$ & $98,88 \%$ & $1 \%$ \\
\hline $\begin{array}{l}\text { Média (Kbytes) } \\
\text { Coeficiente de Variação }\end{array}$ & 13 & 15,09 & 10,82 & 14,13 & 13,26 \\
Mediana (Kbytes) & 2,40 & 2,68 & 2,76 & 3,01 & 2,71 \\
\hline
\end{tabular}

A primeira observação importante é que, em média, 53,94\% $(42,66 \%-64,5 \%)$ e $65,83 \%(60,11 \%-80,11 \%)$ das requisições e dos bytes transferidos foram para objetos distintos, respectivamente.

Observou-se que $77 \%(67,99 \%$ - 91,93\%) do total de objetos foram referenciados uma única vez. Estes resultados revelam que, em média, apenas $23 \%$ do total de objetos foram referenciados mais de uma vez, ou seja, existe uma concentração das referências para um pequeno número de objetos. Servidores Web (Arlitt \& Williamson,1996a) apresentaram uma fração muito menor dos bytes e objetos distintos. Essa observação faz sentido, pois o 
cliente de um proxy pode acessar qualquer objeto disponível na Web, enquanto que em servidores Web, os objetos estão restritos a um único conjunto de cardinalidade conhecida.

A razão entre os bytes transferidos de objetos acessados somente uma vez e o total de bytes dos objetos distintos apresentou valores bastante elevados, variando de $73,13 \%$ (PA) a $89,96 \%(\mathrm{BO} 2)$.

Verificou-se, também, que os tamanhos médios para os conjuntos de objetos únicos apresentaram pequena diferença em relação ao total de objetos referenciados. A única exceção foi o CISC, que teve um aumento bem mais significativo (de 9 para 13 Kbytes), a mediana também teve um aumento moderado em todas as quatro cargas analisadas.

A Tabela 4.10 apresenta os valores máximos para a Taxa de Acerto (HR) e para a Taxa de Acerto por Bytes (BHR) para todas as cargas analisadas, considerando-se duas situações: a primeira presume que os objetos com mais de um acesso ainda não estão presentes no cache, sendo contabilizada uma falha (miss) no primeiro acesso; a segunda situação considera que todos os objetos com mais de um acesso já estejam presentes no cache, sendo contabilizado um acerto (hit) no primeiro acesso.

Estes resultados mostram o impacto da quantidade de objetos acessados somente uma vez. Considerando-se a primeira situação, os valores máximos encontrados para a $H R$ variaram de $35,35 \%(\mathrm{BO} 2)$ a $57,33 \%$ (CISC), e a $\mathrm{BHR}$ obteve entre $19,88 \%(\mathrm{BO} 2)$ e $39,88 \%$ (PA). Na segunda situação, os valores máximos encontrados para a $\mathrm{HR}$ variaram de $40,57 \%$ (BO2) a $67,11 \%$ (CISC), e a BHR, de 27,92\% (BO2) a 56,03\% (PA). Estas medidas podem ser igualmente obtidas quando o cache tiver espaço suficiente para armazenar todos os objetos. No capítulo 5, serão considerados caches com tamanho suficiente para armazenar todos os objetos.

Se a $H R_{M A X}$ e a $B H R_{M A X}$ de todos os caches forem atingidas, os respectivos caches teriam atendido a 293.879 requisições com economia de 2,48 Gbytes de tráfego na Internet.

TABELA 4.10: Valores máximos para HR e BHR.

\begin{tabular}{|l|llll|l|}
\hline ITENS & CISC & BO2 & SV & PA & Média \\
\hline HR $_{\text {MAX }}$ & $57,33 \%$ & $35,35 \%$ & $41,33 \%$ & $50,21 \%$ & $46,05 \%$ \\
BHR $_{M A X}$ & $39,05 \%$ & $19,88 \%$ & $37,81 \%$ & $39,88 \%$ & $34,15 \%$ \\
\hline HR $_{M A X}$ (Objeto já está no cache) & $67,17 \%$ & $40,57 \%$ & $58,23 \%$ & $66,14 \%$ & $58,03 \%$ \\
BHR $_{\text {MAX }}$ (Objeto já está no cache) & $51,53 \%$ & $27,92 \%$ & $54,18 \%$ & $56,03 \%$ & $47,42 \%$ \\
\hline
\end{tabular}




\subsubsection{Caracterização de Requisições por Classe de Objetos}

Esta análise classifica os objetos requisitados pelos usuários baseados segundo suas extensões. Foram definidas 8 classes apresentadas na Tabela 4.11.

TABELA 4.11: Classes de Objetos.

\begin{tabular}{|l|l|}
\hline \multicolumn{1}{|c|}{ Classes de Objetos } & \multicolumn{1}{|c|}{ Extensões } \\
\hline HTML/XML/TEXTO & $\begin{array}{l}\text { html, shtml, htm, htx, htw, map, xml, xsl, dtd, smi, css, txt, dat, bib, } \\
\text { readme, desc, faq }\end{array}$ \\
\hline Imagens & $\begin{array}{l}\text { xbm, ipg, ipeg, gif, gif89, tif, tiff, bmp, ief, ipe, ras, pnm, pgm, ppm, rgb, } \\
\text { xpm, xwd, pbm, pic, xwd, pcx, png, crd }\end{array}$ \\
\hline Áudios & $\begin{array}{l}\text { au, wav, snd, lha, mid, aif, aiff, aifc, mp3, ram, asf, ra rmi, wma, vqf, asx, } \\
\text { rip, dsf }\end{array}$ \\
\hline Vídeos & mov, qt, avi, mpe, movie, mpeg, mpg, mp2, viv, wmv \\
\hline Documentos & ps, pdf, dvi, ppt, tex, rtf, src wsrc, xls, ppz \\
\hline Dinâmicos & cgi, pl, perl, php, php3, php4, phps, asp, jsp, cfm, (?, cgi-bin, HTTPs) \\
\hline Binários/Compactados & exe, bin, hqx, class, dll, ocx, rpm, cab, lib, Z, gz, zip zoo, tgz, taz, tar, jar \\
\hline Script cliente/Animação & js, vs, vbs, swf, dcr, class \\
\hline
\end{tabular}

Qualquer objeto que não esteja incluído em nenhuma das classes descritas na Tabela 4.11 foi inserido em uma classe chamada Outros.

A Tabela 4.12 apresenta um resumo dos resultados obtidos da análise dos quatro servidores proxy caracterizando por classes de objetos, conforme definidas na Tabela 4.11. As duas primeiras colunas são referentes à porcentagem das requisições e dos objetos pertencentes a cada classe, enquanto que as colunas 3 e 4 mostram a porcentagem dos bytes transferidos e dos bytes únicos, sem considerar o total de acessos (a porcentagem dos bytes únicos é utilizada no capítulo 5 para definir a quantidade de espaço destinada para cada partição no cache); já as três últimas colunas mostram algumas estatísticas em relação ao tamanho dos objetos, como: a média, a mediana e o coeficiente de variação. 
Caracterização de Carga de Servidores Proxy com Aplicação em Caches na Web

TABELA 4.12: Caracterização das requisições por classe de objetos.

\begin{tabular}{|c|c|c|c|c|c|c|c|c|}
\hline Cargas & Classes & $\begin{array}{c}\% \text { das } \\
\text { Referências }\end{array}$ & $\begin{array}{c}\% \text { dos } \\
\text { objetos }\end{array}$ & $\begin{array}{c}\% \\
\text { dos } \\
\text { bytes }\end{array}$ & $\begin{array}{l}\% \text { dos } \\
\text { bytes } \\
\text { únicos }\end{array}$ & $\begin{array}{l}\text { Média } \\
\text { (bytes) }\end{array}$ & $\begin{array}{c}\text { Mediana } \\
\text { (bytes) }\end{array}$ & $\begin{array}{l}\text { Coef. de } \\
\text { Variação }\end{array}$ \\
\hline \multirow{9}{*}{ CISC } & HTML/ XML/Texto & 11,22 & 11,09 & 14,56 & 09,02 & 11569,38 & 3788 & 1,86 \\
\hline & Imagens & 65,89 & 72,45 & 32,57 & 35,47 & 4408,13 & 1510 & 2,61 \\
\hline & Áudio & 00,16 & 00,23 & 00,73 & 00,65 & 41465,10 & 8628 & 5,68 \\
\hline & Vídeo & 00,03 & 00,05 & 03,70 & 03,84 & 978260,73 & 52273 & 3,91 \\
\hline & Documentos & 00,12 & 00,17 & 06,09 & 06,68 & 433132,94 & 66939 & 2,67 \\
\hline & Dinâmicos & 15,78 & 08,85 & 16,39 & 09,39 & 9259,73 & 1574 & 9,08 \\
\hline & Binários/Compactados & 00,31 & 00,25 & 20,81 & 30,10 & 585948,83 & 7348,5 & 8,02 \\
\hline & $\begin{array}{l}\text { Scripts Cliente/ } \\
\text { Animação } \\
\end{array}$ & 01,62 & 01,85 & 02,92 & 03,00 & 16034,61 & 7617 & 2,53 \\
\hline & Outros & 04,83 & 05,06 & 02,21 & 01,89 & 4072,63 & 805 & 6,86 \\
\hline \multirow{9}{*}{$\begin{array}{c}\text { NLANR } \\
\text { BO2 }\end{array}$} & HTML/ XML/Texto & 11,68 & 12,94 & 13,85 & 12,26 & 15599,22 & 8802 & 1,88 \\
\hline & Imagens & 52,23 & 68,38 & 22,78 & 28,87 & 5738,70 & 2049 & 2,50 \\
\hline & Áudio & 0,18 & 00,25 & 07,07 & 07,77 & 501164,24 & 11576 & 5,12 \\
\hline & Vídeo & 0,14 & 00,18 & 08,51 & 10,21 & 796815,43 & 184694 & 3,82 \\
\hline & Documentos & 0,09 & 00,11 & 02,92 & 02,61 & 408409,95 & 37608 & 5,11 \\
\hline & Dinâmicos & 25,98 & 10,43 & 14,97 & 07,13 & 7583.31 & 1502 & 4,20 \\
\hline & Binários/Compactados & 0,25 & 00,21 & 12,03 & 09,18 & 628773,39 & 19368 & 5,73 \\
\hline & $\begin{array}{l}\text { Scripts Cliente/ } \\
\text { Animação }\end{array}$ & 01,32 & 01,72 & 02,76 & 03,37 & 27578,35 & 5085 & 4,22 \\
\hline & Outros & 08,10 & 05,78 & 15,08 & 18,59 & 24486.76 & 817 & 17,13 \\
\hline \multirow{9}{*}{$\begin{array}{c}\text { NLANR } \\
\text { SV }\end{array}$} & HTML/ XML/Texto & 09,27 & 09,79 & 11,56 & 12,40 & 13677,87 & 7006 & 1,70 \\
\hline & Imagens & 74,37 & 80,24 & 37,29 & 46,02 & 5498,58 & 2378 & 2,24 \\
\hline & Áudio & 00,34 & 00,32 & 03,44 & 02,92 & 112201,83 & 17219 & 4,56 \\
\hline & Video & 00,11 & 00,06 & 13,22 & 03,59 & 1342962,54 & 199023 & 2,03 \\
\hline & Documentos & 00,06 & 00,07 & 01,30 & 00,88 & 222270,36 & 49818 & 6,84 \\
\hline & Dinâmicos & 08,10 & 03,27 & 05,82 & 03,57 & 7877,84 & 1484 & 9,19 \\
\hline & Binários/Compactados & 00,69 & 00,23 & 14,92 & 14,05 & 234843,53 & 8588 & 9,70 \\
\hline & $\begin{array}{l}\text { Scripts Cliente/ } \\
\text { Animação }\end{array}$ & 01,68 & 01,74 & 04,21 & 04,61 & 27436,59 & 5157 & 3,49 \\
\hline & Outros & 05,36 & 04,27 & 08,22 & 11,94 & 16810,86 & 1380 & 19,32 \\
\hline \multirow{9}{*}{$\begin{array}{c}\text { NLANR } \\
\text { PA }\end{array}$} & HTML/ XML/Texto & 10,12 & 11,36 & 13,31 & 11,19 & 14369,85 & 7262 & 1,48 \\
\hline & Imagens & 64,38 & 74,28 & 36,91 & 39,47 & 6264,13 & 2748 & 2,31 \\
\hline & Áudio & 00,20 & 00,22 & 01,47 & 01,52 & 78212,75 & 20084 & 3,79 \\
\hline & Vídeo & 00,23 & 00,20 & 17,68 & 21,86 & 835394,25 & 139215 & 3,24 \\
\hline & Documentos & 00,09 & 00,12 & 01,28 & 01,94 & 156026,27 & 41052 & 3,02 \\
\hline & Dinâmicos & 15,07 & 05,32 & 10,21 & 05,25 & 7405,33 & 1380 & 5,85 \\
\hline & Binários/Compactados & 00,60 & 00,31 & 09,73 & 10,73 & 176085,39 & 13318 & 5,76 \\
\hline & \begin{tabular}{|l|} 
Scripts Cliente/ \\
Animação \\
\end{tabular} & 01,26 & 01,35 & 02,90 & 02,76 & 25045,68 & 4505 & 3,35 \\
\hline & Outros & 08,02 & 06,83 & 06,48 & 05,27 & 8835,91 & 6213 & 8,01 \\
\hline
\end{tabular}

Verificou-se um aumento significativo para as requisições dinâmicas (requisições que não podem ser armazenadas em um cache), em relação a estudos anteriores. $O$ atual estudo obteve uma média de 16,2\% (8\%- 25,8\%). Mahanti e Williamson (1999) registraram valores bem inferiores (menos de $1 \%$ das requisições). Este aumento significativo nas requisições dinâmicas ocorreu, principalmente, em razão da popularização de scripts que executam no lado servidor, tais como PHP (Hypertext Preprocessor), JSP (JavaServer 
Pages) e ASP (Active Server Pages). O total de objetos únicos nas requisições dinâmicas é sempre menor que o total de referências em todas as cargas analisadas, sendo que em média $6,97 \%(3,27 \%-10,43 \%)$ dos objetos correspondem a $16,2 \%$ das referências.

Objetos HTML/XML/TEXTO correspondem a 10,5\% $(9,27 \%-11,68 \%)$ das referências. É importante frisar que estudos anteriores, Mahanti e Williamson (1999) e Abdulla et al. (1997) apresentaram valores bem mais elevados, entre $18 \%$ e $28 \%$ para requisições HTML. Esta diminuição ocorreu, principalmente, em virtude da popularização de scripts que executam no lado servidor. Para armazenar os objetos dessa classe seria necessário um espaço entre $9,02 \%$ (CISC) e $12,40 \%$ (SV) do espaço disponível em um cache.

Outra observação importante é que a classe Imagens corresponde à maioria das requisições, $64,2 \%(52,23 \%$ - 74,37\%), resultados semelhantes aos estudos de Mahanti e Williamson (1999) e Abdulla et al. (1997). Porém observou-se que os bytes transferidos variaram de $22,72 \%$ (BO2) a 37,29\% (SV), resultados que ficaram bem abaixo, entre $40 \%$ e $52 \%$ menores que os resultados de Mahanti e Williamson (1999). Esta redução nos bytes transferidos pode ser justificada pela diminuição tanto no tamanho médio quanto na mediana, ficando em média $32 \%$ e $21 \%$ menores, respectivamente. Notou-se, também, uma quantidade elevada de objetos únicos variando de $72,45 \%$ (CISC) a $80,24 \%$ (SV), enquanto que a quantidade de espaço necessária para armazená-los seria de $28,87 \%$ (BO2) a 46,02\% (SV).

Objetos das classes Binários/Compactados e Vídeos tiveram apenas entre $0,34 \%$ (CISC) e $0,83 \%$ (PA) das referências, o suficiente para gerar de $20,54 \%$ (BO2) a $28,14 \%$ (SV) dos bytes transferidos. Essa observação é confirmada pelos elevados valores apresentados nas suas médias e medianas.

A classe Scripts Cliente/Animação (scripts e animações que executam no lado clientes) manteve um comportamento bem parecido em todas as cargas analisadas, variando de $1,32 \%$ (BO2) a $1,68 \%$ (SV) das requisições e contribuíram com aproximadamente $3,2 \%$ dos bytes transferidos.

A Tabela 4.13 apresenta uma análise dos objetos referenciados somente uma vez baseada em classes de objetos definidas na Tabela 4.11. São apresentados dois resultados 
para cada carga analisada: (1) a razão entre os objetos acessados somente uma vez pelo total de objetos; (2) a razão entre os objetos acessados somente uma vez por todos os objetos da mesma classe.

TABELA 4.13: Fração dos acessos únicos por classe de objetos.

\begin{tabular}{|c|c|c|c|c|c|c|c|c|c|c|c|}
\hline \multirow[t]{2}{*}{ CLASSES } & $\operatorname{CISC}(\%)$ & \multicolumn{2}{|c|}{$\mathrm{BO2}(\%)$} & \multicolumn{2}{|c|}{ SV (\%) } & \multicolumn{2}{|c|}{ PA (\%) } & \multicolumn{2}{|c|}{ Média } & \multicolumn{2}{|c|}{ Desv. Padrão } \\
\hline & (1) & (1) & (2) & (1) & (2) & (1) & (2) & (1) & (2) & (1) & (2) \\
\hline HTV & $11,3 \quad 78,51$ & 12,6 & 88,89 & 10,9 & 77,35 & 11,3 & 78,51 & 11,53 & 80,82 & 0,74 & 5,41 \\
\hline IMAGENS & $71,8 \quad 76,30$ & 70,8 & 94,56 & 78,5 & 67,89 & 71,8 & 76,30 & 73,23 & 78,76 & 3,55 & 11,25 \\
\hline DINÂI & $8,8 \quad 76,12$ & 8,5 & 74,87 & 3,1 & 65,92 & 8,8 & 76,12 & 7,30 & 73,26 & 2,80 & 4,93 \\
\hline OUTROS & $8,1 \quad 81,47$ & 8,1 & 88,05 & 7,5 & 77,59 & 8,1 & 81,47 & 7,95 & 82,15 & 0,30 & 4,34 \\
\hline
\end{tabular}

Verificou-se que para todas as cargas que há uma quantidade significativa de objetos acessados somente uma vez em cada classe de objetos. Os resultados mostram que Imagens correspondem, em média, a $73 \%(71 \%$ - 78,5\%) de todos os objetos acessados uma única vez e $78,76 \%(67,89 \%-94,56 \%)$ de acessos únicos a esta classe. Objetos das classes HTML/XML/TEXTO, Imagens e Dinâmicos tiveram, em média, 91,3\% de todos os objetos referenciados uma única vez.

\subsubsection{Caracterização das Requisições por Classes de Tamanho}

Este estudo tem por objetivo definir os tamanhos de cada partição que serão utilizados na avaliação de desempenho de políticas de substituição de objetos no capítulo 5 .

A escolha destas classes foi baseada no modelo de particionamento de cache (PART) desenvolvido para organizar o espaço de tamanho dos caches, proposto em (Murta, 1999). A proposta é dividir o espaço do cache em partições, sendo que cada partição é dedicada ao armazenamento de objetos cujos tamanhos pertencem a um intervalo.

As classes foram definidas com os intervalos apresentados na Tabela 4.14:

TABELA 4.14: Classes de tamanho.

\begin{tabular}{|c|l|}
\hline Classe & \multicolumn{1}{|c|}{ Tamanho } \\
\hline Classe 1 & 0 a 1 Kbyte \\
\hline Classe 2 & 1 a 10 Kbytes \\
\hline Classe 3 & 10 a 100 Kbytes \\
\hline Classe 4 & 100 a 1000 Kbytes \\
\hline Classe 5 & Maiores que 1 Mbyte \\
\hline
\end{tabular}


A Tabela 4.15 sintetiza o padrão de acesso das requisições definidas por classes de tamanho (Tabela 4.14). A primeira coluna apresenta a porcentagem das requisições; a coluna 2 mostra a fração dos objetos distintos para cada classe; a coluna 3 apresenta a porcentagem dos bytes transferidos e a coluna 4 mostra a fração dos bytes únicos (estes resultados serão utilizados no capítulo 5 para definir a quantidade de espaço destinada para cada partição no cache). As três últimas colunas mostram algumas estatísticas em relação ao tamanho médio dos objetos (a média, a mediana e o coeficiente de variação).

TABELA 4.15: Caracterização das requisições por classe de tamanho.

\begin{tabular}{|c|c|c|c|c|c|c|c|c|}
\hline CARGAS & Classes & $\begin{array}{c}\% \text { das } \\
\text { referências }\end{array}$ & $\begin{array}{c}\% \text { dos } \\
\text { objetos }\end{array}$ & $\begin{array}{l}\% \text { dos } \\
\text { bytes }\end{array}$ & $\begin{array}{l}\% \text { dos } \\
\text { bytes } \\
\text { únicos }\end{array}$ & Média & Mediana & $\begin{array}{c}\text { Coef. } \\
\text { Variação }\end{array}$ \\
\hline \multirow{5}{*}{ CISC } & CLASSE 1 & 36,45 & 28,27 & 02,46 & 01,46 & 598,88 & 559 & 0,31 \\
\hline & CLASSE 2 & 49,68 & 54,47 & 18,71 & 15,01 & 3335,16 & 2531 & 0,68 \\
\hline & CLASSE 3 & 13,37 & 16,55 & 36,59 & 32,94 & 24217,92 & 18568,5 & 0,68 \\
\hline & CLASSE 4 & 00,43 & 00,62 & 11,86 & 12,25 & 243335,9 & 158064 & 0,75 \\
\hline & CLASSE 5 & 00,05 & 00,08 & 30,36 & 38,33 & 4979985,3 & 1974060 & 2,43 \\
\hline \multirow{5}{*}{$\begin{array}{c}\text { NLANR } \\
\text { B02 }\end{array}$} & CLASSE 1 & 32,15 & 28,15 & 01,22 & 01,12 & 574,32 & 544 & 0,33 \\
\hline & CLASSE 2 & 48,41 & 51,00 & 12,24 & 12,49 & 3820,81 & 3087 & 0,62 \\
\hline & CLASSE 3 & 18,65 & 19,93 & 30,89 & 32,40 & 25038,86 & 18568,5 & 0,67 \\
\hline & CLASSE 4 & 0,67 & 00,79 & 10,43 & 12,10 & 235339,15 & 171936 & 0,73 \\
\hline & CLASSE 5 & 0,11 & 00,12 & 45,20 & 41,88 & 5826547,6 & 3823740 & 1,29 \\
\hline \multirow{5}{*}{$\begin{array}{c}\text { NLANR } \\
\text { SV }\end{array}$} & CLASSE 1 & 26,85 & 23,79 & 01,48 & 01,46 & 626,68 & 605 & 0,30 \\
\hline & CLASSE 2 & 56,24 & 58,37 & 18,66 & 20,64 & 3729,36 & 3052 & 0,62 \\
\hline & CLASSE 3 & 16,19 & 17,21 & 34,20 & 39,84 & 23743,84 & 171199 & 0,69 \\
\hline & CLASSE 4 & 00,63 & 00,58 & 14,05 & 12,50 & 248938,02 & 189322 & 0,72 \\
\hline & CLASSE 5 & 00,08 & 00,05 & 31,59 & 25,55 & 4484916,9 & 3002470 & 1,65 \\
\hline \multirow{5}{*}{$\begin{array}{c}\text { NLANR } \\
\text { PA }\end{array}$} & CLASSE 1 & 21,46 & 21,30 & 01,18 & 01,04 & 634,52 & 617 & 0,30 \\
\hline & CLASSE 2 & 60,18 & 58,94 & 20,92 & 16,83 & 4015,83 & 3249 & 0,61 \\
\hline & CLASSE 3 & 17,58 & 18,85 & 37,95 & 35,86 & 24939,49 & 18332 & 0,68 \\
\hline & CLASSE 4 & 00,71 & 00,82 & 13,93 & 14,55 & 225755,30 & 169099 & 0,72 \\
\hline & CLASSE 5 & 00,06 & 00,08 & 26,01 & 31,70 & 4599541,5 & 2438460 & 1,08 \\
\hline
\end{tabular}

Os resultados mostram que $53,6 \%(48,4 \%$ - 60\%) das requisições são para classe 2 , que compreende objetos entre 1 e 10 Kbytes e, em média, $82,8 \%$ das requisições são para objetos das classes 1 e 2 . As classes 1, 2 e 3 compreendem $99,3 \%$ das requisições.

As classes 3 e 5 têm, em média, $68 \%$ dos bytes transferidos; já as classes 3,4 e 5 correspondem a $80,7 \%$ dos bytes transferidos. Outra observação relevante é que a classe 5 , 
apesar de ter apenas, em média, 0,07\% das requisições, alcançou entre $26,01 \%$ (PA) e $45,2 \%$ (BO2) dos bytes transferidos.

Murta (1999) apresentou resultados semelhantes, sendo que $80 \%$ das requisições são para objetos de até $10^{4}$ bytes, e $98 \%$ das requisições compreendem objetos com até $10^{5}$ bytes; entre $75 \%$ e $85 \%$ dos bytes requisitados são de objetos maiores que $10^{4}$ bytes.

Dessa forma, tem-se que apesar de $99,3 \%$ dos objetos serem das classes 1,2 e 3 e $80,7 \%$ dos bytes transferidos serem das classes 3,4 e 5 , esses resultados evidenciam que as métricas HR e BHR são grandezas inversamente proporcionais.

A Tabela 4.16 apresenta uma análise dos objetos referenciados somente uma vez baseada em classes de tamanho definidas na Tabela 4.14. São apresentados dois resultados para cada carga analisada: (1) a razão entre os objetos acessados somente uma vez pelo total de objetos; (2) a razão entre os objetos acessados somente uma vez pelo total de objetos da mesma classe.

TABELA 4.16: Fração dos acessos únicos por classes de tamanho.

\begin{tabular}{|c|c|c|c|c|c|c|c|c|c|c|c|c|}
\hline \multirow[t]{2}{*}{ CLASSES } & \multicolumn{2}{|c|}{ CISC (\%) } & \multicolumn{2}{|c|}{$\mathrm{BO2}(\%)$} & \multicolumn{2}{|c|}{ SV (\%) } & \multicolumn{2}{|c|}{$\mathrm{PA}(\%)$} & \multicolumn{2}{|c|}{ Média } & \multicolumn{2}{|c|}{ Desv. Padrão } \\
\hline & (1) & (2) & (1) & (2) & (1) & (2) & (1) & (2) & (1) & (2) & (1) & (2) \\
\hline CLASSE 1 & 26,71 & 72,50 & 27,99 & 90,70 & 22,73 & 66,23 & 20,98 & 66,70 & 24,60 & 74,03 & 3,29 & 11,47 \\
\hline CLASSE 2 & 55,42 & 78,25 & 51,79 & 92,65 & 58,95 & 70,10 & 58,30 & 67,25 & 56,12 & 77,06 & 3,27 & 11,39 \\
\hline CLASSE 3 & 17,13 & 79,64 & 19,33 & 88,47 & 17,67 & 71,28 & 19,74 & 71,17 & 18,47 & 77,64 & 1,26 & 8,24 \\
\hline CLASSE 4 & 0,63 & 78,91 & 0,78 & 89,49 & 0,60 & 71,46 & 0,88 & 73,08 & 0,72 & 78,24 & 0,13 & 8,16 \\
\hline CLASSE 5 & 0,09 & 83,00 & 0,11 & 85,29 & 0,04 & 64,70 & 0,08 & 68,07 & 0,08 & 75,27 & 0,03 & 10,39 \\
\hline
\end{tabular}

Verificou-se que para todas as cargas, em cada classe (situação 2), existe uma quantidade significativa de objetos acessados somente uma vez. Os resultados mostram, também, que a classe 2 contribuiu, em média, com 56,12\% (51,79\% - 58,30\%) dos objetos acessados somente uma vez, considerando-se todos os objetos e, $77,6 \%(67,25 \%-92,65 \%)$ de acessos únicos para esta classe. Os objetos das classes 1, 2 e 3 obtiveram, em média, $99,17 \%$ de todos os objetos referenciados uma única vez.

\subsubsection{Comparação entre Classes de Objetos e Tamanho}

Nas classes de objetos (Tabela 4.11) observou-se que o coeficiente de variação apresentou valores bem maiores que nas classes de tamanho (Tabela 4.14), enquanto que as 
classes de tamanho apresentaram coeficientes de variação menores e aproximados para todas as cargas analisadas, ou seja, conseguiu controlar melhor a variabilidade.

Conclui-se que as classes de tamanho podem lidar melhor com a variabilidade dos objetos e eliminar o problema de trocas entre centenas ou milhares de objetos menores pela chegada de um objeto "grande"; também, evita-se a possibilidade de liberação excessiva de espaço no cache quando um objeto grande é substituído por um menor. Este fenômeno é chamado na literatura de cache disruption.

Para exemplificar esta situação, observou-se que o CISC registrou $0,05 \%$ das requisições para objetos acima de 1 Mbyte, ou seja, a cada 2.000 requisições será solicitado um objeto de tamanho acima de 1 Mbyte. Considerando-se que aproximadamente existem 80.000 requisições por dia, o cache terá 40 requisições para objetos extremamente grandes em um único dia, podendo gerar a retirada de centenas ou milhares de objetos do cache e mudar completamente o seu estado, além de comprometer a eficácia de políticas de substituição de objetos.

\subsection{Caracterização de Carga (Freqüência Acumulada)}

Esta seção apresenta uma análise de caracterização da carga de servidores proxy, onde são apresentados diversos gráficos de freqüência acumulada. Na seção 4.5.1, é apresentada a distribuição das referências; na seção 4.5.2, a distribuição dos bytes transferidos, e na seção 4.5.3, mostra três funções de distribuição acumulada, ordenadas pelo tamanho dos objetos transferidos.

\subsubsection{Distribuição das Referências}

Esta análise foca a freqüência acumulada das referências. É importante destacar que alguns objetos são muito acessados enquanto que outros não. Na Figura 4.2, é apresentado um gráfico com a freqüência acumulada de todas as requisições (iniciado com os objetos mais populares) versus a fração do total de objetos referenciados para as cargas de trabalhos (CISC, BO2, PA e SV). 


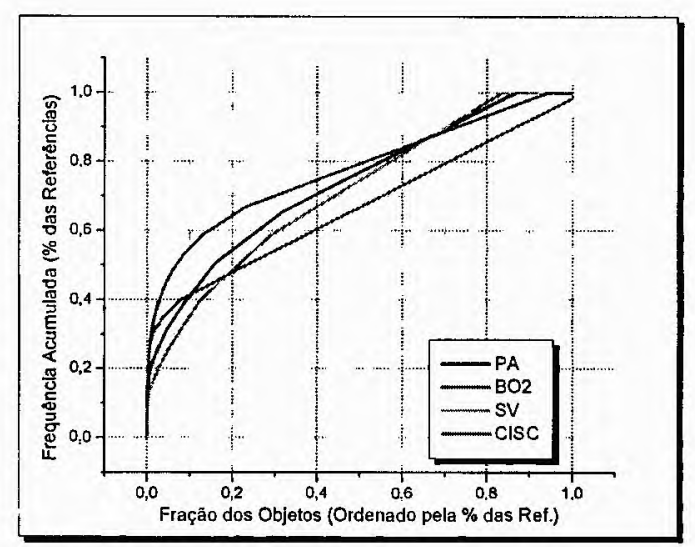

FIGURA 4.2: Concentração das referencias.

Os resultados mostram que $20 \%$ dos objetos foram responsáveis por $50 \%$ (BO2) a $65 \%$ (CISC) das requisições. Estes resultados ilustram um padrão não uniforme no comportamento das referências. Vale destacar que Arlitt e Williamson (1996a) em seu estudo de caracterização de carga em servidores Web apresentou uma concentração bem maior das referências para um conjunto pequeno de objetos (10\% dos objetos correspondem de 80 a $95 \%$ de todas as requisições recebidas). Isto ocorreu em razão de servidores Web trabalharem com um conjunto mais estável e limitado de objetos.

Para as quatro cargas analisadas observou-se que o CISC obteve a maior concentração das referências, sendo que $30 \%$ dos objetos acessados alcançaram $80 \%$ das referências, e os $70 \%$ dos objetos remanescentes corresponderam a $20 \%$ das requisições, sendo em sua maioria acessados somente uma vez, enquanto que os outros proxies apresentaram uma concentração menor. No caso, a carga $\mathrm{BO} 2$ apresentou a menor concentração das referências, sendo que $30 \%$ dos objetos alcançaram $54 \%$ das referências. Esse resultado já era esperado, pois conforme apresentado na Tabela 4.9, a carga BO2 teve $91,93 \%$ dos objetos acessados somente uma vez.

Notou-se, também, que depois de $30 \%$ dos objetos acessados os gráficos apresentaram um comportamento praticamente linear, mostrando que $70 \%$ dos objetos tiveram poucos acessos, sendo em sua maioria somente uma vez.

\subsubsection{Distribuição dos Bytes Transferidos}

Na Figura 4.3, são apresentados dois gráficos com a freqüência acumulada dos bytes transferidos, sendo que, no gráfico 4.3 (a) os objetos estão organizados de acordo 
com os bytes transferidos, enquanto que no gráfico 4.3 (b) os objetos estão ordenados pelo total de referências.

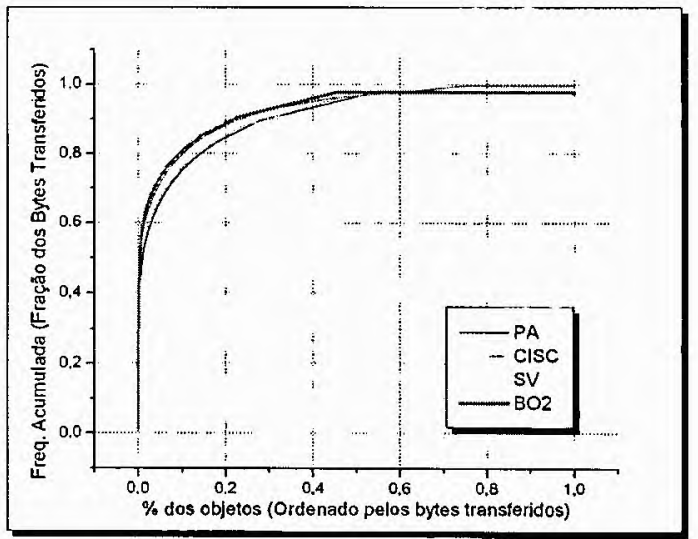

(a) ordenados pelos bytes transferidos.

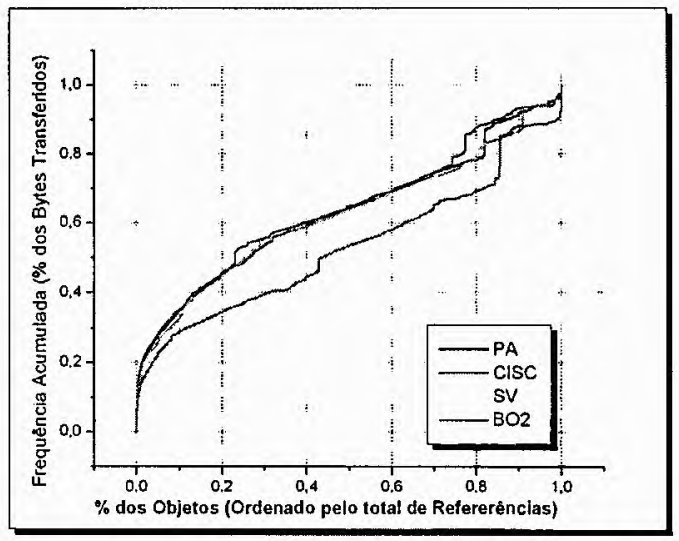

(b) ordenados pelo total das referências.

FIGURA 4.3: Concentração dos bytes transferidos

O gráfico 4.3 (a) mostra que $10 \%$ do conjunto de objetos correspondem a $80 \%$ dos bytes transferidos. Este resultado mostra uma concentração bem acentuada para uma pequena quantidade de objetos, enquanto que no gráfico 4.3 (b), que ordena os objetos pelo total de referências, mostrou que $10 \%$ dos objetos foram responsáveis por apenas $30 \%$ dos bytes transferidos, concentração bem abaixo dos resultados apresentados no gráfico 4.3 (a) que ordena a função de freqüência acumulada de acordo com os bytes transferidos.

Estes resultados evidenciam que a maioria dos acessos é para objetos pequenos, o que reflete os gráficos apresentados na Figura 4.3 (b) que apresentou uma concentração bem menor para os bytes transferidos.

\subsubsection{Distribuição das Referências Considerando o Tamanho dos Objetos}

A Figura 4.4 mostra três funções de distribuição acumulada, ordenadas pelo tamanho dos objetos transferidos para os quatro proxies analisados, usando uma escala logarítmica no eixo x. As funções estão acumuladas pelos bytes transferidos, pelo total de referências e pelo tamanho dos objetos.

Observou-se para todas as cargas analisadas, que a maioria das transferências é para

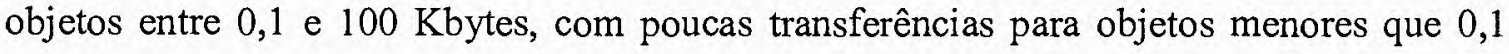


Kbytes e, também, poucas transferências para objetos maiores que 100 Kbytes (resultados análogos foram relatados na Tabela 4.15). Estas observações são semelhantes aos resultados obtidos em (Mahanti \& Williamson, 1999) e (Murta, 1999).

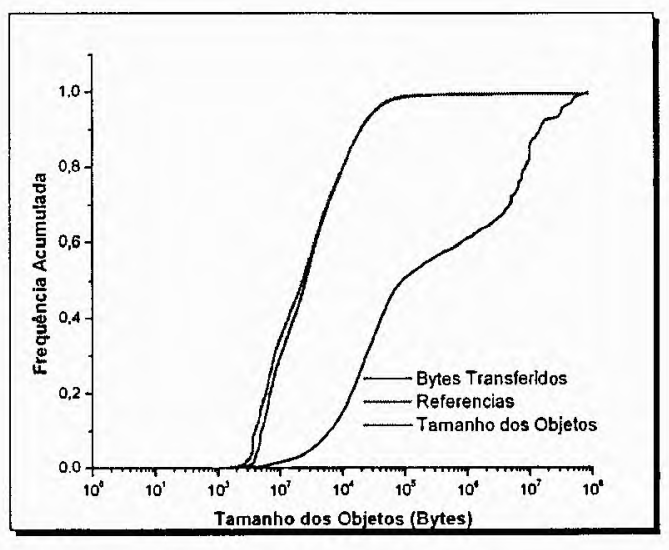

(a) - NLANR - $\mathrm{BO} 2$

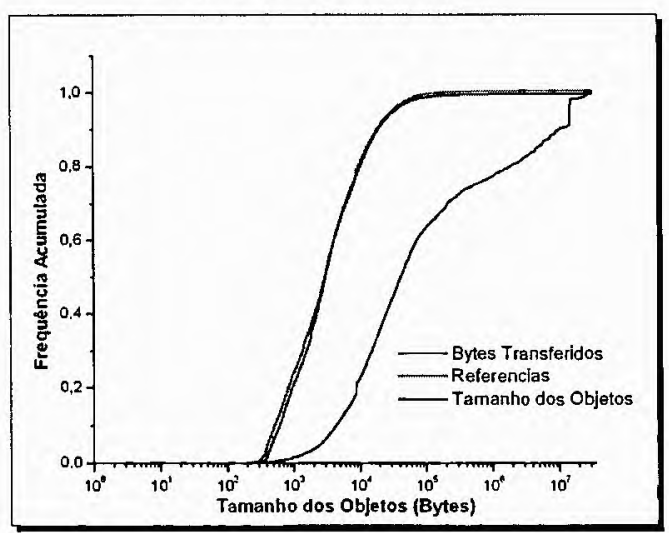

(c) - NLANR - PA

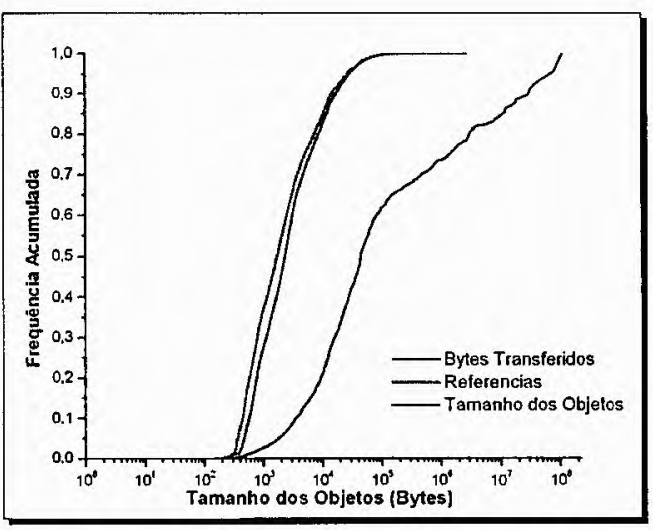

(b) - CISC

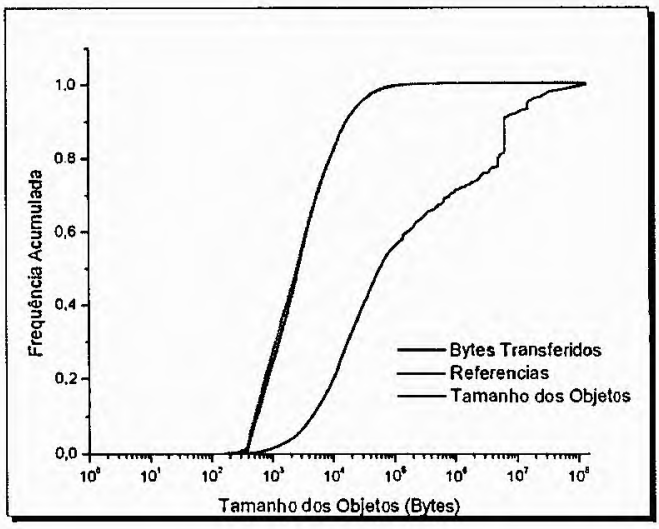

(d) - NLANR -c SV

FIGURA 4.4: Frequência acumulada ordenada pelo tamanho dos objetos.

Para exemplificar melhor estes resultados, observou-se nos gráficos apresentados na Figura 4.4 (a) que objetos com até 10 Kbytes alcançaram $86 \%$ das referências, $83 \%$ dos objetos e $21 \%$ dos bytes transferidos,

Os gráficos de freqüência acumulada pelo tamanho dos objetos e das referências tiveram um comportamento bastante semelhante, revelando a correlação entre as referências e o tamanho dos objetos e comprovando que a maioria dos acessos é feita para objetos pequenos. Já a curva dos bytes transferidos ratifica que objetos menores têm uma contribuição pequena na fração dos bytes transferidos. 


\subsection{Considerações Finais}

$\mathrm{O}$ crescimento contínuo da Web tem motivado pesquisas que explorem técnicas para fornecer desempenho na Web. Na primeira parte deste capítulo foram apresentados alguns trabalhos relacionados com a caracterização de carga da Web.

Em seguida foi desenvolvido um estudo de caracterização de carga para servidores proxy. Foram estudadas as cargas de quatro servidores proxy que implementam caches na Web: (i) CISC (Centro de Informática de São Carlos); (ii) Universidade do Colorado, Boulder (BO2); (iii) Palo Alto, Califórnia (PA) e (iv) Vale do Silício, Califórnia (SV), sendo observadas algumas características para este conjunto de cargas, como:

- a metade dos objetos acessados é menor que 3 Kbytes, ficando bem abaixo da média que variou de 8,9 a 13,4 Kbytes, sendo que a média é influenciada por poucos objetos de tamanho muito elevado;

- entre $97,11 \%$ e $99,54 \%$ das solicitações foram para o método GET, o que comprova que a Web ainda é utilizada maciçamente para leitura;

- os códigos de status 200, 304 e 000, que resultam no sucesso para obtenção do objeto solicitado pelo cliente, ficaram em torno de $83 \%$;

- o valor máximo encontrado para a $H R$ variou de 40,56\% (BO2) a $67,11 \%$ (CISC) enquanto que a BHR variou de $27,92 \%$ (BO2) a $56,03 \%$ (PA);

- a fração dos objetos acessados somente uma vez corresponde a uma fração considerável da cardinalidade do conjunto de objetos, ficando acima de $70 \%$, estes resultados são semelhantes aos apresentados em Mahanti e Williamson (1999);

- observou-se um aumento significativo para as requisições dinâmicas, entre $8 \%$ (SV) e 25,8\% (BO2) em relação aos resultados de Mahanti e Williamson (1999) que registraram valores bem inferiores (menos de $1 \%$ das requisições);

- imagens correspondem à maioria das requisições entre $52,23 \%$ (BO2) e $74,37 \%$ (SV), resultados semelhantes aos estudos de Mahanti e Williamson (1999) e Abdulla et al. (1997), porém observou-se uma diminuição nos bytes transferidos; 
- $99,3 \%$ das requisições compreendem objetos menores que 100 Kbytes, evidenciando que objetos maiores que 100 Kbytes correspondem a uma fração muito pequena do total de acessos;

- objetos acima de $1 \mathrm{Mbyte}$, apesar de ter, em média, somente $0,07 \%$ das referências, são responsáveis por $33,22 \%$ dos bytes transferidos;

- $20 \%$ dos objetos correspondem de $50 \%$ a $65 \%$ das requisições;

- $10 \%$ dos objetos correspondem a $80 \%$ dos bytes transferidos.

O próximo capítulo desta dissertação se concentra na avaliação de desempenho de políticas de substituição de objetos em caches na Web. 


\section{Capitulo}

\section{Avaliação de Desempenho de Caches na Web}

Este capítulo mostra a análise dos resultados da avaliação de desempenho de caches através de simulações trace-driven, focando as questões discutidas no capítulo 4. Este estudo tem o objetivo de avaliar o desempenho de diversas políticas de substituição de objetos, considerando caches não particionados e particionados por classes de objetos e tamanho.

A seção 5.1 descreve as cargas de trabalho utilizadas neste estudo; na seção 5.2, são mostradas a estrutura e funcionalidades do simulador; na seção 5.3, são discutidas algumas medidas de desempenho; na seção 5.4 , são apresentados diversos parâmetros considerados na avaliação de desempenho e algumas considerações preliminares sobre o estudo de avaliação de desempenho; na seção 5.5, comenta-se a validação do simulador e; na seção 5.6 , apresentam-se análises dos resultados obtidos.

\subsection{Cargas de Trabalho}

As cargas de trabalho utilizadas na avaliação de desempenho dos caches foram discutidas no estudo de caracterização de carga apresentado no capítulo 4 (CISC, Boulder- 
BO2, Palo Alto - PA, Vale do Silício - SV). Um sumário destas cargas de trabalho é apresentado na Tabela 4.4 .

É importante ressaltar que somente uma pequena quantidade de informações presente em cada linha das cargas de trabalho é suficiente para a avaliação de desempenho dos caches. Em virtude deste fato, foi realizado o pré-processamento das cargas de trabalho, reduzindo drasticamente seus tamanhos. Esta etapa é muito importante para um desempenho satisfatório na simulação, permitindo um ganho sobremaneira em seu desempenho, já que é gerado um arquivo mais compacto composto por apenas quatro atributos, sendo: 1) um identificador único para cada objeto, 2) o tamanho do objeto em bytes, 3) a classe à qual o objeto pertence, e 4) o tempo decorrido para recuperar o objeto no servidor de origem.

\subsection{Estrutura e Funcionalidades do Simulador}

O simulador utilizado neste estudo foi projetado Arlitt e Williamson, 1996b, inicialmente, para avaliar o desempenho de caches em servidores Web. Como o enfoque deste trabalho envolve caches de proxy, foram realizadas diversas modificações para trabalhar com cargas de trabalho de servidores proxy.

As diversas funcionalidades implementadas em relação ao simulador original para este estudo de avaliação de desempenho são:

- a atualização das classes de objetos (HTML, Imagens, Vídeos, etc.) para novos objetos, como: xml, php, asp, etc;

- a implementação de particionamento do cache por classes de tamanho;

- o tratamento para cada partição como um cache individual;

- a implementação da política SIZE; e

o desenvolvimento de uma nova política de substituição, denominada PESO, apresentada na seção 5.7.3. 
A estrutura básica do simulador é apresentada na Figura 5.1. Este simulador determina a efetividade de políticas de substituição de objetos na redução de largura de banda e na porcentagem de objetos atendidos pelo cache.

Os parâmetros de entrada são a carga de trabalho, o período de warm-up (seção 5.5), o nome dos arquivos de saída para armazenar as medidas de desempenho HR e BHR e um arquivo que armazena diversas estatísticas gerais da simulação, como: total de requisições, total de bytes, tamanho do cache e o total de objetos no cache após o término da simulação.

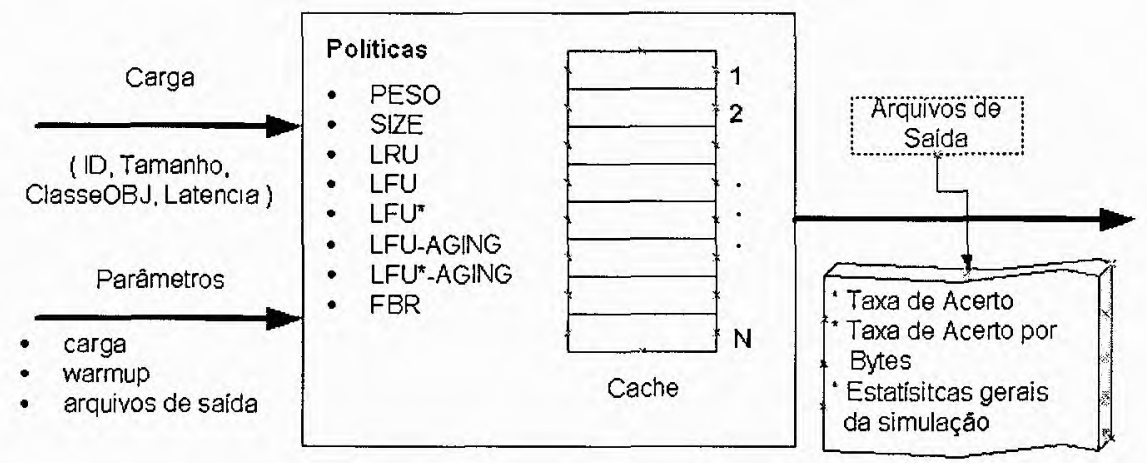

FIGURA 5.1: Estrutura básica do simulador.

Este simulador é capaz de determinar partições para classes de objetos e tamanhos em tempo de compilação. Para cada uma das partições é atribuída uma porcentagem de espaço, sendo que o somatório das partições tem de ser igual a 100\% do tamanho do cache. Cada partição pode ser vista como um cache individual por ter sua própria lista de objetos e medidas de desempenho. As substituições só podem ocorrer entre objetos pertencentes à mesma classe.

A simulação é baseada em registros de cargas reais (trace-driven simulation), ordenados cronologicamente de acordo com as solicitações dos usuários. O funcionamento básico deste simulador ocorre da seguinte maneira: quando chega uma nova requisição, é verificado o conteúdo do cache para verificar se o objeto referenciado se encontra no cache (de acordo com sua URL). Caso verdadeiro, o conteúdo do cache fica inalterado e são atualizadas a HR e a BHR. Caso contrário, ocorreu uma falha (miss), e o objeto solicitado será armazenado no cache. Se o cache estiver cheio, será removido um ou mais objetos de acordo com a política de substituição adotada. 
A Figura 5.2 mostra as duas principais estruturas de dados utilizados no simulador. A estrutura lnode é composta por uma lista duplamente encadeada com $\mathrm{N}$ posições, onde $\mathrm{N}$ corresponde ao total de objetos. A informação armazenada para cada objeto constitui-se do tamanho do objeto, do tempo para recuperá-lo no servidor de origem, do tempo do último acesso, do número de referências, status (indica se o objeto está ou não no cache) e ponteiros para os objetos seguintes e anteriores. A estrutura de dados Caches é composta por um vetor, sendo cada posição referente a um cache, cada cache possui uma lista duplamente encadeada para todos os objeto, um ponteiro para o primeiro e último objeto, o tamanho em bytes do cache, o total de bytes utilizados atualmente pelo cache, o número de objetos, o total de acertos, o total de falhas, o total de bytes atendidos pelo cache e o total de bytes não atendidos.

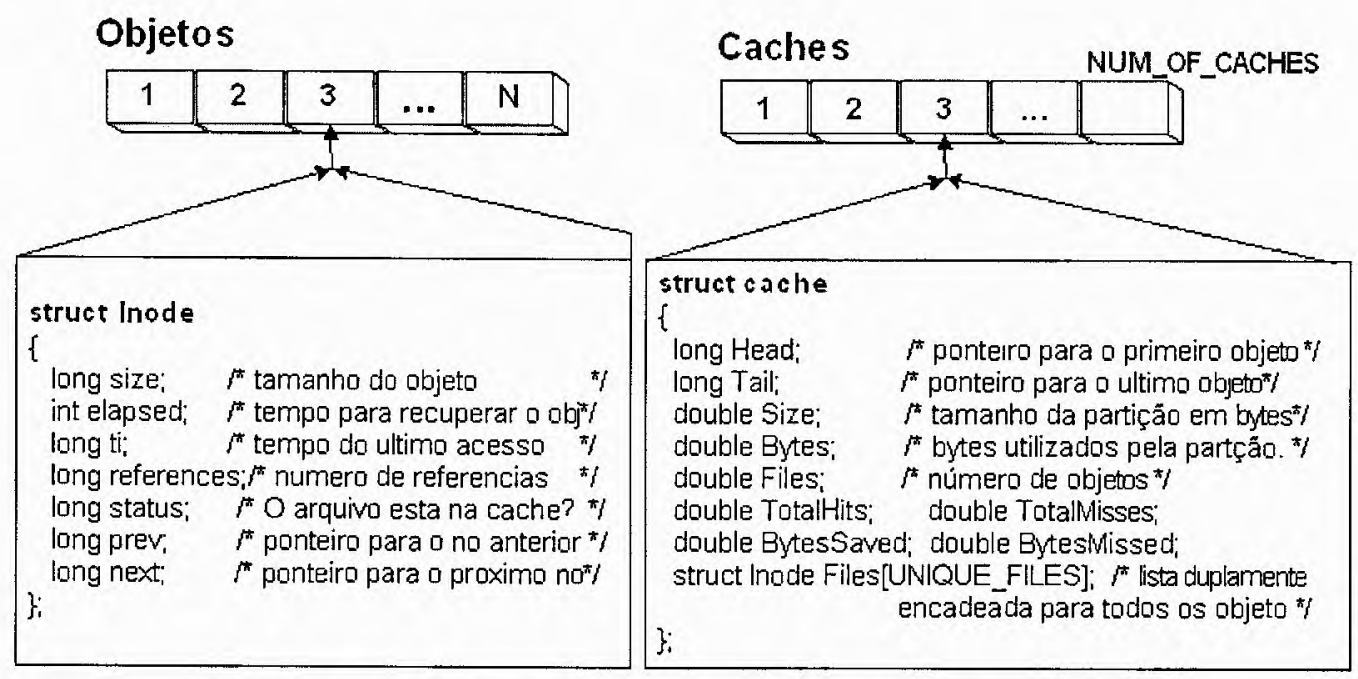

FIGURA 5.2: Principais estruturas de dados do simulador.

\subsection{Medidas de Desempenho}

Avaliar o desempenho de um sistema é avaliar a capacidade deste sistema no atendimento de sua demanda de serviço. Para essa avaliação definem-se métricas de desempenho de interesse e observa-se o comportamento dessas métricas diante de diferentes situações para o sistema em estudo. Algumas métricas são utilizadas para medir a eficiência de cache na Web: a HR, a BHR e a Latência.

A HR é a proporção de acertos para todas as requisições. Já a BHR é mensurada a partir do tamanho dos objetos, ou seja, é a razão entre os bytes atendidos pelo cache e o 
somatório dos bytes de todas as requisições. $\mathrm{O}$ aumento da HR pode levar à diminuição da latência na recuperação de objetos a partir de uma rede local, enquanto que a BHR melhora o uso de largura de banda, evitando requisições redundantes ao mesmo objeto.

A latência é uma métrica importante para avaliação de desempenho, porque esta representa o tempo esperado por requisições Web. Mas não é tarefa fácil medí-la. O cache armazena o tempo gasto para recuperar uma requisição num determinado momento, mas não há como saber exatamente quando o primeiro pacote requisitado foi transmitido e quando o último pacote de resposta foi recebido. Além disso, os valores dependem de muitos fatores, tais como a velocidade da conexão Internet, hora do dia, dia da semana, localização geográfica, velocidade entre os caches e seus usuários e a sobrecarga experimentada pelo servidor no momento da requisição. Cao e Irani (1997) constataram que, maximizando a HR, obtém-se uma redução na latência bem mais significativa do que com a utilização de políticas projetadas especificamente para reduzir a latência.

Neste estudo foram adotadas as métricas HR e BHR na avaliação de desempenho. A latência não foi incluída devido à falta de informações necessárias para uma avaliação mais precisa.

\subsection{Validação do Simulador}

Um programa para simulação pode ser desenvolvido de duas formas: (a) usando ferramentas gerais e poderosas, como linguagens de simulação ou pacotes baseados em sub-rotinas escritas em linguagem de programação de propósito geral; (b) usando uma linguagem de programação de propósito geral - no caso deste simulador foi utilizada a linguagem C padrão ANSI (American National Standards Institute).

Com a preocupação de garantir o funcionamento correto deste simulador, foram realizados diversos testes para assegurar a validade do simulador. Estes testes foram conduzidos com cargas de trabalho de 100 e 200 requisições e foram comparados os resultados analíticos com os resultados da simulação, assim como a realização de alguns testes utilizando ferramentas de depuração de código. Verificou-se, também que a HR e a BHR foram iguais em caches de tamanho muito elevado (infinito) para diferentes políticas 
de substituição. Em alguns casos em que se repetiram as avaliações efetuadas por Arlitt $e t$ al., (2000) e Rizzo e Vicisano, 1998 os resultados foram similares.

\subsection{Parâmetros de Simulação}

- Tamanho do Cache. Indica a quantidade de espaço definido para armazenar os objetos no cache. Neste estudo foram considerados 14 tamanhos de cache, sendo: 1 , 2, 4, 8, 16, 32, 64, 128, 256, 512 Mbytes, 1, 2, 4 e 16Gbytes. Como 16Gbytes pode armazenar todos os objetos solicitados em um intervalo de tempo, será referenciado como um cache de tamanho infinito, ou seja, nunca são realizadas substituições de objetos. Com caches de tamanho elevado pode-se chegar a valores máximos de HR e BHR, assim como observar até que ponto é vantajoso aumentar o tamanho do cache.

- Objetos dinâmicos. São objetos gerados no momento da requisição e que podem variar a cada requisição, pois dependem de parâmetros próprios. Como conseqüência eles não são armazenados no cache. Como exemplo de objetos dinâmicos, pode-se citar objetos gerados a partir de um mecanismo de busca, de uma consulta a um banco de dados ou um aplicativo baseado na Web.

- Atualização de objetos. Um dos aspectos mais importantes no funcionamento de caches na Web é garantir que os objetos que estão no cache permanecerão válidos; tipicamente é associado um tempo de vida TTL (seção 3.3). No escopo desta dissertação não é tratada a questão da atualização de objetos em virtude das cargas de trabalho não fornecerem nenhuma informação de tempo em que os objetos permanecerão válidos no cache. Uma alternativa, que foi pensada inicialmente, seria verificar se o tamanho do objeto foi alterado, porém não é possível garantir sempre se o objeto que foi atualizado modificou o seu tamanho.

- Políticas de substituição de objetos. Foram apresentadas diversas políticas de substituição de objetos propostas na literatura (seção 3.5). Para este estudo foram selecionadas as políticas: LRU, LFU, LFU-Aging, LFU*, LFU*-Aging, FBR, SIZE e PESO. As políticas LRU e LFU foram escolhidas por serem largamente utilizadas em sistemas de caches tradicionais, além de serem bastante utilizada em 
implementações de caches na Web. Foram escolhidas mais três variações da política LFU (LFU-Aging, LFU* e LFU*-Aging), sendo que LFU* e LFU*-Aging atacam de maneira direta os objetos com um único acesso, selecionando-os para substituição. Já a política SIZE seleciona os objetos maiores para substituição. A política FBR que tem como objetivo isolar os objetos com poucos acessos e que não foram referenciados em um certo intervalo de tempo.

- Período de aquecimento do cache (warm-up). Determina a quantidade de requisições em que o cache não coletará nenhuma estatística de HR e BHR. Devido ao cache inicialmente estar vazio, haverá uma quantidade significativa de falhas (miss), não retratando a situação de um cache real em produção. $\mathrm{O}$ objetivo do período de warm-up é fazer com que o cache passe de um estado transiente a um estado estável de operação. É importante frisar que, determinar onde termina o estado transiente e começa o estado estável é um problema difícil (Jain, 1991). Arlitt et al. (2000) constataram que o cache estabiliza com aproximadamente $8 \%$ do total de requisições. Em função disso, considerou-se nesta avaliação o período de warm-up para todas as cargas de trabalho com $10 \%$ do total de requisições.

\subsection{Análise dos Resultados Obtidos}

Esta seção descreve as avaliações de desempenho de políticas de substituição de objetos, considerando-se diversas configurações, como: um limite inferior e superior ao tamanho dos objetos que serão aceitos no cache, particionamento do cache por tamanho e por classes de objetos.

Primeiramente, na seção 5.6.1 é determinada a melhor parametrização das políticas LFU-Aging e LFU*-Aging com objetivo de na seção 5.6 .2 apresentar uma avaliação destas políticas com as políticas LFU e LFU*; nesta avaliação é selecionada a política com melhor desempenho para utilização no decorrer deste capítulo. Na seção 5.6.3, é apresentada a proposta de uma nova política de substituição; na seção 5.6 .4 , é desenvolvida a avaliação de desempenho de políticas de substituição de objetos, considerando os caches como uma partição única e que não impõem limite de tamanho aos objetos aceitos no cache; na seção 5.6.5, é analisado o efeito de atribuir um limiar inferior e superior aos objetos aceitos no 
cache; na seção 5.6.6, será realizada a avaliação de desempenho, considerando o particionamento por classes de objetos e; na seção 5.6.7, é apresentada a avaliação de desempenho considerando o particionamento do cache de acordo com o tamanho dos objetos.

\subsubsection{Determinação do Parâmetro $A_{\max }$ às Políticas LFU-Aging e LFU*- Aging}

Entre todas as políticas analisadas as políticas LFU-Aging e LFU*-Aging requerem uma parametrização adequada para funcionarem de maneira apropriada. Conforme apresentado na seção 3.5.1, estas políticas implementam uma técnica de envelhecimento para garantir que objetos muito referenciados e que não serão mais acessados permaneçam por muito tempo no cache. Estas políticas mantêm um contador de referências para cada objeto presente no cache. $\mathrm{O}$ parâmetro $A_{\max }$ representa o envelhecimento dos objetos no cache, isto é, sempre que a média do contador de referência para os objetos no cache ultrapassa $A_{\max }$, o contador de cada objeto é reduzido por um fator de dois. Quando maior o valor de $A_{\max }$ mais tempo os objetos muito utilizados no passado demorarão a ser retirados do cache.

Foram testados diferentes valores de $A_{\max }$ com objetivo de encontrar o valor que proporciona o melhor desempenho nas métricas HR e BHR. Na Tabela 5.1, são apresentados os resultados da política LFU-Aging para as cargas CISC BO2, PA e SV, sendo considerado $A_{\max }$ igual a 3,5 e 10 .

Os resultados da Tabela 5.1 revelam que o valor ideal de $A_{\max }$ depende tanto do tamanho do cache quanto da carga de trabalho. Para as cargas consideradas tem-se que os caches entre 32 Mbytes e 1 Gbytes para o CISC e de 128 Mbytes a 2 Gbytes para SV apresentaram uma melhor HR quando $A_{\max }=3$, enquanto que os outros resultados foram melhores para $A_{\max }=5$ ou 10 . Estes resultados mostram que não existe uma relação diretamente proporcional ou monolítica entre as métricas analisadas e o parâmetro $A_{\max }$. Verificou-se também que os parâmetros de "envelhecimento" têm pouco ou nenhum impacto em caches de tamanhos elevados. Observou-se, também que a BHR é consideravelmente pior em todas as cargas analisadas quando $A_{\max }$ é igual a 3 . 
Para $\mathrm{A}_{\max }$ igual a 5 e 10 a $\mathrm{HR}$ e a $\mathrm{BHR}$ foram iguais. Isto ocorreu, principalmente, devido à grande quantidade de objetos que tiveram somente um acesso, conforme os resultados apresentados no capítulo 4 . No decorrer desta análise o valor de $A_{\max }$ será igual a 5 para a política LFU-Aging.

TABELA 5.1: Efeito do parâmetro $A_{\text {max }}$ na política LFU-Aging.

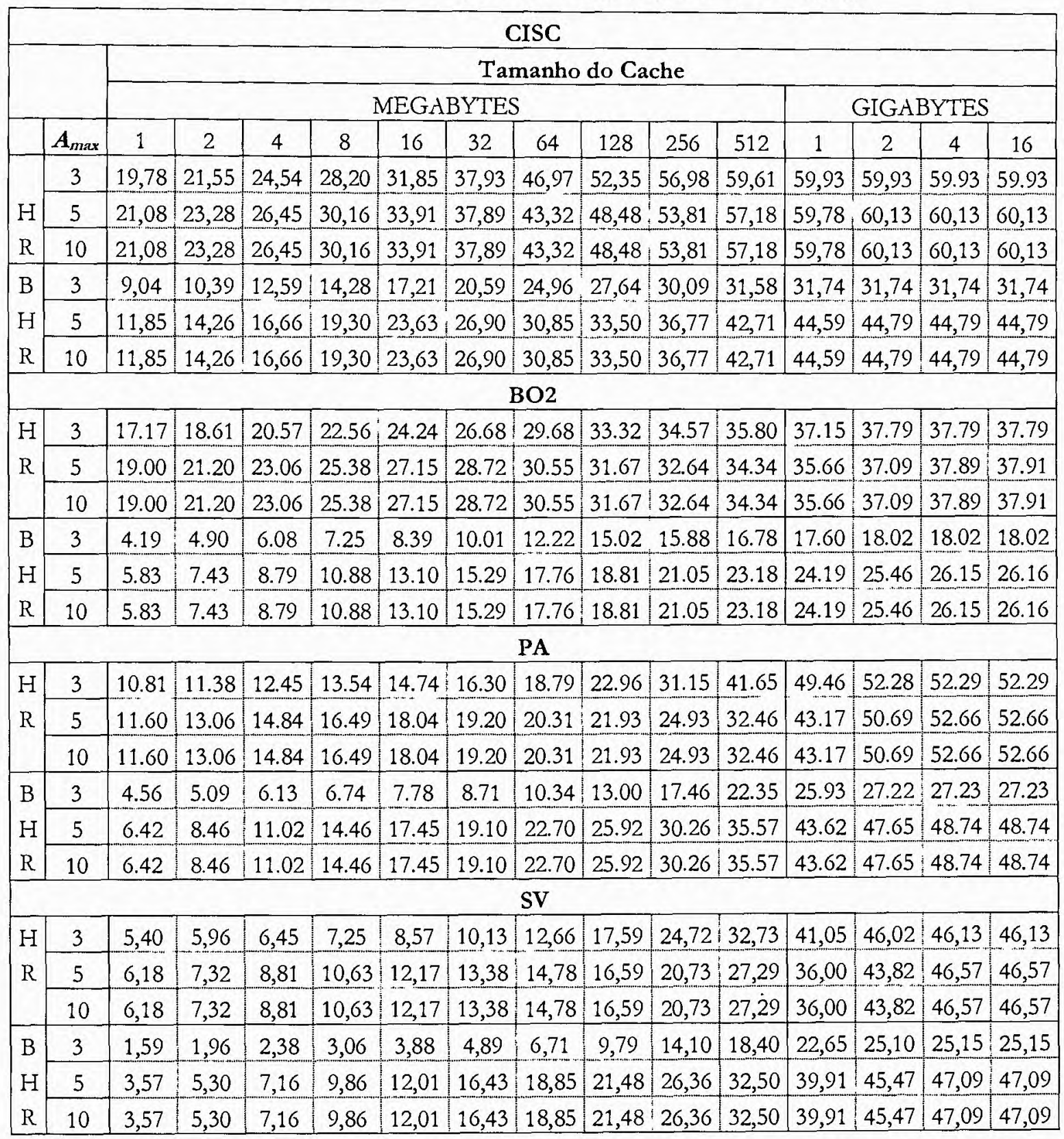

Na Tabela 5.2 são apresentadas as HR e BHR para a política $L_{F U}^{*}$-Aging com as cargas CISC, BO2 PA e SV, sendo considerado $A_{\max }$ igual a 3, 4, 5 e 10 . 
Os parâmetros de $A_{\max }$ têm pouca influência nas métricas $\mathrm{HR}$ e BHR, sendo que foram apresentadas HR e BHR próximos com $A_{\max }$ igual a 3, 4 e 5, já quando $A_{m a x}=10$ os resultados foram piores. Isto ocorreu por dois fatores, o primeiro é o número elevado de acessos únicos, o segundo é que este valor assumido por $A_{m a x}$ é relativamente elevado, permitindo a "poluição" do cache, pois uma quantidade mínima de objetos tem o total de acesso superior a 10, conforme apresentado na Tabela 4.9.

No decorrer desta análise a política LFU*-Aging terá o valor de $A_{\max }$ igual a 5 para as cargas $\mathrm{CISC}$ e $\mathrm{BO} 2,4$ para $\mathrm{SV}$ e 3 para $\mathrm{PA}$, em virtude de apresentarem desempenhos satisfatórios e sensivelmente melhores para a maioria dos caches, conforme mostrado na Tabela 5.2. 
TABELA 5.2: Efeito do parâmetro $A_{\max }$ na política LFU*-Aging.

\begin{tabular}{|c|c|c|c|c|c|c|c|c|c|c|c|c|c|c|c|}
\hline \multicolumn{16}{|c|}{ CISC } \\
\hline & \multirow[b]{3}{*}{$A_{\max }$} & \multicolumn{14}{|c|}{ Tamanho do Cache } \\
\hline & & \multicolumn{10}{|c|}{ MEGABYTES } & \multicolumn{4}{|c|}{ GIGABYTES } \\
\hline & & 1 & 2 & 4 & 8 & 16 & 32 & 64 & 128 & 256 & 512 & 1 & 2 & 4 & 16 \\
\hline \multirow{4}{*}{$\begin{array}{l}\mathrm{H} \\
\mathrm{R}\end{array}$} & 3 & 21,73 & 24,09 & 26,63 & 29,86 & 33,49 & 37,87 & 42,74 & 48,06 & 53,04 & 57,02 & 59,78 & 60,13 & 60,13 & 60,13 \\
\hline & 4 & 21,48 & 24,20 & 26,92 & 30,39 & 34,30 & 38,33 & 43,28 & 48,55 & 53,19 & 57,19 & 59,78 & 60,13 & 60,13 & 60,13 \\
\hline & 5 & 20,79 & 23,89 & 27,29 & 30,80 & 34,96 & 38,78 & 43,77 & 48,78 & 53,62 & 57,18 & 59,78 & 60,13 & 60,13 & 60,13 \\
\hline & 10 & 15,82 & 19,01 & 24,24 & 28,99 & 30,23 & 35,99 & 41,95 & 49,32 & 53,81 & 57,18 & 59,78 & 60,13 & 60,13 & 60,13 \\
\hline \multirow{4}{*}{$\mid \begin{array}{l}\mathrm{B} \\
\mathrm{H} \\
\mathrm{R}\end{array}$} & 3 & 12,26 & 14,77 & 17,34 & 20,40 & 23,57 & 26,54 & 29,57 & 33,02 & 36,30 & 42,61 & 44,59 & 44,79 & 44,79 & 44,79 \\
\hline & 4 & 11,73 & 14,55 & 17,10 & 20,46 & 24,38 & 26,98 & 30,23 & 33,36 & 36,31 & 42,70 & 44,59 & 44,79 & 44,79 & 44,79 \\
\hline & 5 & 11,05 & 13,66 & 16,27 & 19,80 & 23,66 & 27,35 & 30,58 & 33,63 & 36,62 & 42,71 & 44,59 & 44,79 & 44,79 & 44,79 \\
\hline & 10 & 7,47 & 10,08 & 13,34 & 16,12 & 19,36 & 24,21 & 28,48 & 33,80 & 36,77 & 42,70 & 44,59 & 44,78 & 44,78 & 44,78 \\
\hline \multicolumn{16}{|c|}{ BO2 } \\
\hline \multirow{4}{*}{$\begin{array}{l}\mathrm{H} \\
\mathrm{R}\end{array}$} & 3 & 18.68 & 21.05 & 23.27 & 25.29 & 26.62 & 28.19 & 29.50 & 30.95 & 32.67 & 34.11 & 35.63 & 37.09 & 37.89 & 37.91 \\
\hline & 4 & 18.98 & 21.35 & 23.63 & 25.61 & 27.06 & 28.41 & 29.71 & 31.29 & 32.91 & 34.27 & 35.66 & 37.09 & 37.89 & 37.91 \\
\hline & 5 & 19.08 & 21.49 & 23.73 & 25.67 & 27.17 & 28.61 & 29.91 & 31.41 & 33.00 & 34.31 & 35.66 & 37.09 & 37.89 & 37.91 \\
\hline & 10 & 17.78 & 20.41 & 22.69 & 24.71 & 27.15 & 29.18 & 30.68 & 31.87 & 33.22 & 34.34 & 35.66 & 37.09 & 37.89 & 37.91 \\
\hline \multirow{4}{*}{$\begin{array}{l}\text { B } \\
\mathrm{H} \\
\mathrm{R}\end{array}$} & 3 & 6.18 & 7.89 & 9.65 & 11.45 & 14.59 & 16.19 & 18.21 & 19.97 & 21.31 & 22.96 & 24.17 & 25.46 & 26.15 & 26.16 \\
\hline & 4 & 6.25 & 8.00 & 9.77 & 11.35 & 13.81 & 16.87 & 18.32 & 20.21 & 21.51 & 23.08 & 24.19 & 25.46 & 26.15 & 26.16 \\
\hline & 5 & 6.18 & 7.90 & 9.76 & 11.39 & 14.33 & 15.73 & 18.13 & 20.31 & 21.74 & 23.14 & 24.19 & 25.46 & 26.15 & 26.16 \\
\hline & 10 & 4.94 & 6.31 & 7.75 & 9.87 & 11.88 & 14.34 & 16.67 & 19.79 & 22.28 & 23.18 & 24.19 & 25.46 & 26.15 & 26.16 \\
\hline \multicolumn{16}{|c|}{ PA } \\
\hline \multirow{4}{*}{$\begin{array}{l}\mathrm{H} \\
\mathrm{R}\end{array}$} & 3 & 11,57 & 13,40 & 15,10 & 16,60 & 18,15 & 19,82 & 21,86 & 24,77 & 29,14 & 35,59 & 43,47 & 50,69 & 52,66 & 52,66 \\
\hline & 4 & 11,73 & 13,55 & 15,25 & 16,68 & 18,36 & 19,78 & 21,74 & 24,44 & 28,62 & 35,16 & 43,27 & 50,69 & 52,66 & 52,66 \\
\hline & 5 & 11,75 & 13,51 & 15,23 & 16,73 & 18,16 & 19,65 & 21,56 & 24,14 & 27,84 & 34,47 & 43,17 & 50,69 & 52,66 & 52,66 \\
\hline & 10 & 10,86 & 12,56 & 13,69 & 15,30 & 16,35 & 17,63 & 18,64 & 19,36 & 22,99 & 31,31 & 43,17 & 50,69 & 52,66 & 52,66 \\
\hline \multirow{4}{*}{$\begin{array}{l}\text { B } \\
\mathrm{H} \\
\mathrm{R}\end{array}$} & 3 & 6,99 & 9,06 & 11,46 & 14,79 & 19,10 & 22,47 & 27,03 & 31,21 & 35,10 & 39,31 & 43,79 & 47,65 & 48,74 & 48,74 \\
\hline & 4 & 6,95 & 9,05 & 11,16 & 14,25 & 17,89 & 22,62 & 27,06 & 31,17 & 35,04 & 38,90 & 43,67 & 47,65 & 48,74 & 48,74 \\
\hline & 5 & 6,73 & 8,82 & 10,99 & 14,02 & 17,78 & 22,74 & 26,92 & 31,20 & 34,49 & 38,52 & 43,62 & 47,65 & 48,74 & 48,74 \\
\hline & 10 & 5,41 & 6,85 & 8,35 & 9,85 & 12,12 & 14,83 & 19,81 & 23,94 & 22,12 & 31,93 & 43,62 & 47,65 & 48,74 & 48,74 \\
\hline \multicolumn{16}{|c|}{ SV } \\
\hline \multirow{4}{*}{$\begin{array}{l}\mathrm{H} \\
\mathrm{R}\end{array}$} & 3 & 5.82 & 7.30 & 9.13 & 10.85 & 12.65 & 14.44 & 16.48 & 18.99 & 22.30 & 27.69 & 35.63 & 43.82 & 46.57 & 46.57 \\
\hline & 4 & 6.12 & 7.50 & 9.18 & 10.89 & 12.74 & 14.49 & 16.39 & 18.79 & 22.07 & 27.65 & 36.00 & 43.82 & 46.57 & 46.57 \\
\hline & 5 & 6.18 & 7.32 & 8.81 & 10.63 & 12.17 & 13.38 & 14.78 & 16.59 & 20.73 & 27.29 & 36.00 & 43.82 & 46.57 & 46.57 \\
\hline & 10 & 5.83 & 7.25 & 8.40 & 9.26 & 10.36 & 11.49 & 12.29 & 12.48 & 17.96 & 26.70 & 36.00 & 43.82 & 46.57 & 46.57 \\
\hline \multirow{4}{*}{$\begin{array}{l}\mathrm{B} \\
\mathrm{H} \\
\mathrm{R}\end{array}$} & 3 & 3.79 & 5.70 & 7.73 & 10.41 & 13.82 & 18.49 & 21.85 & 24.55 & 28.66 & 33.12 & 39.55 & 45.47 & 47.09 & 47.09 \\
\hline & 4 & 3.82 & 5.59 & 7.66 & 10.25 & 13.70 & 17.76 & 21.31 & 24.70 & 28.50 & 32.86 & 39.91 & 45.47 & 47.09 & 47.09 \\
\hline & 5 & 3.57 & 5.30 & 7.16 & 9.86 & 12.01 & 16.43 & 18.85 & 21.48 & 26.36 & 32.50 & 39.91 & 45.47 & 47.09 & 47.09 \\
\hline & 10 & 3.16 & 4.42 & 5.63 & 7.37 & 8.61 & 9.69 & 11.75 & 15.67 & 22.58 & 32.04 & 39.91 & 45.47 & 47.09 & 47.09 \\
\hline
\end{tabular}


Em todos os valores de $A_{m a x}$ tanto na política LFU-Aging quanto LFU*-Aging, temse que as métricas $\mathrm{HR}$ e $\mathrm{BHR}$ crescem na medida em que o cache aumenta. Esse comportamento acontece até o momento em que se observa uma saturação e o aumento do tamanho do cache passa a influenciar cada vez menos. Esse resultado é esperado, uma vez que caches maiores levam a um maior armazenamento de objetos, reduzindo o número de substituições e tornando os resultados até independentes de $A_{\max }$.

\subsubsection{Comparação das Políticas LFU, LFU*, LFU-Aging e LFU*-Aging}

Nesta seção são comparadas as políticas LFU, LFU*, LFU-Aging e LFU*-Aging, que foram descritas na seção 3.5.1. O objetivo desta análise é selecionar a política com melhor desempenho para as avaliações posteriores. Uma análise semelhante foi desenvolvida em Arlitt e Williamson (1996b) para avaliar o desempenho dessas políticas de substituição em caches de servidores Web.

Na Figura 5.3, é apresentada uma comparação das HRs para as cargas de trabalho CISC, BO2, PA e SV com as politicas LFU, LFU*, LFU-Aging e LFU*-Aging. Em todas as cargas de trabalho observou-se que a política $\mathrm{LFU}^{*}$ apresentou os piores resultados para os caches de pequeno tamanho. Este observação é plausível, em virtude desta política não remover objetos com mais de um acesso e, no caso de caches pequenos, em que existe um número elevado de substituições, os resultados foram piores, pois o seu desempenho degrada com o tempo e os objetos que tiveram mais de um acesso e que não forem mais referenciados permanecerão indefinidamente no cache provocando a sua "poluição". Esta política só teria um bom desempenho se os objetos com mais de um acesso continuassem sempre populares, o que não acontece na prática. 


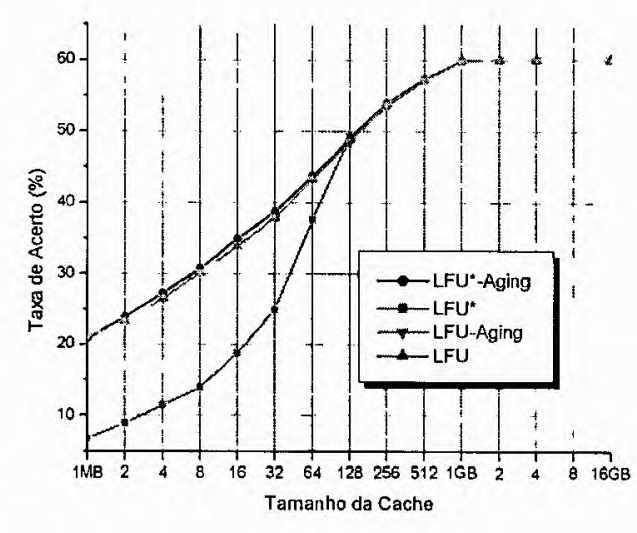

CISC - HR

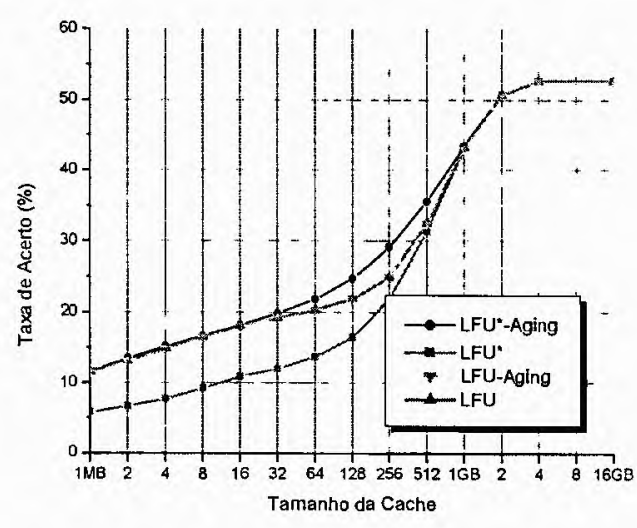

PA - HR

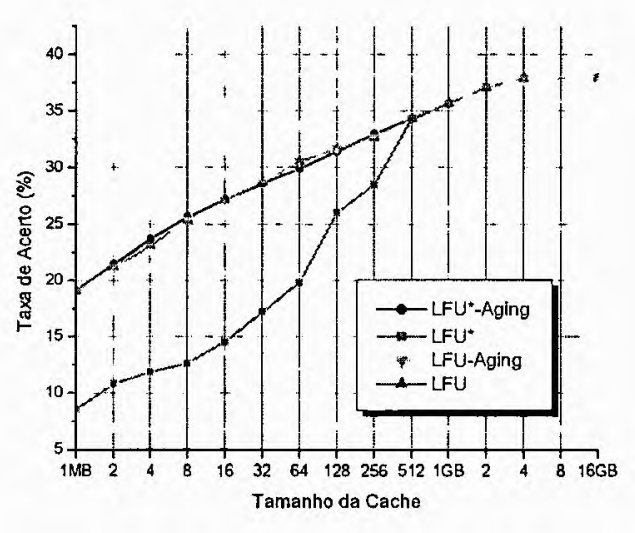

$\mathrm{BO} 2-\mathrm{HR}$

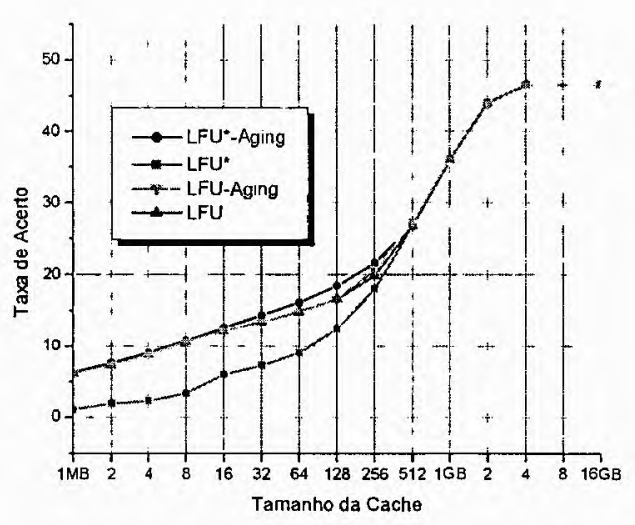

SV - HR

FIGURA 5.3: Comparação da HR para as políticas LFU, LFU*, LFU-Aging e LFU*-Aging.

As políticas LFU, LFU-Aging e LFU*-Aging apresentaram resultados semelhantes, sendo que nas cargas PA e SV a política LFU*-Aging apresentou resultados ligeiramente melhores para os caches entre 32 e 512 Mbytes. Estes resultados evidenciam que a técnica de "envelhecimento" previne a "poluição" do cache, assim como remove os objetos que tiveram somente um acesso.

Resultados semelhantes aos da Figura 5.3 são apresentados na Figura 5.4 para a BHR. Observou-se, também, que a política LFU* apresentou resultados bastante inferiores para os caches entre 1 e 512 Mbytes. 


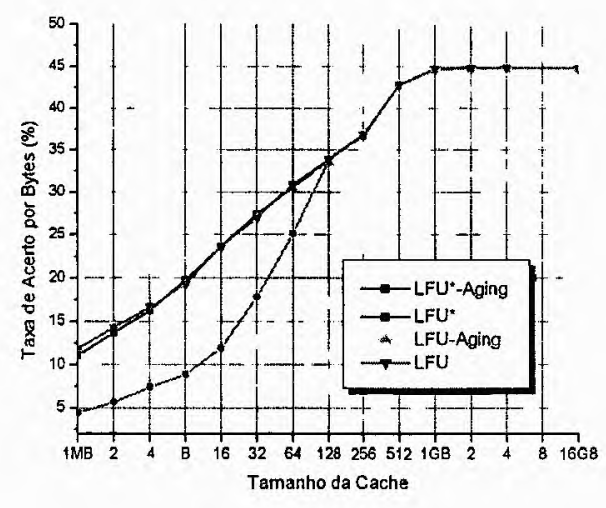

CISC- BHR

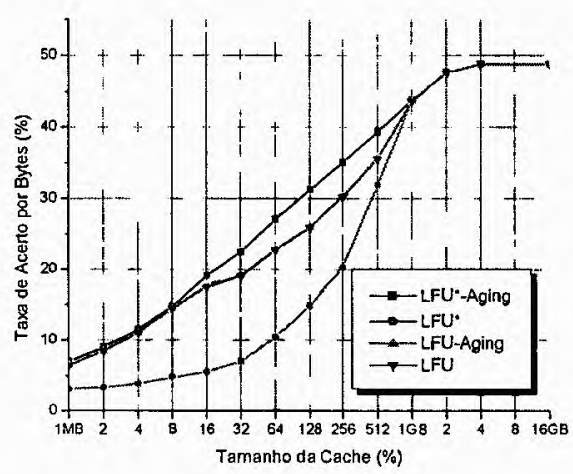

PA-BHR

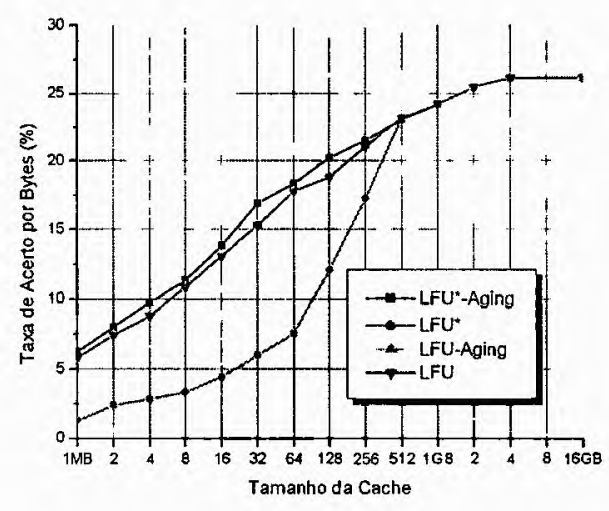

BO2- BHR

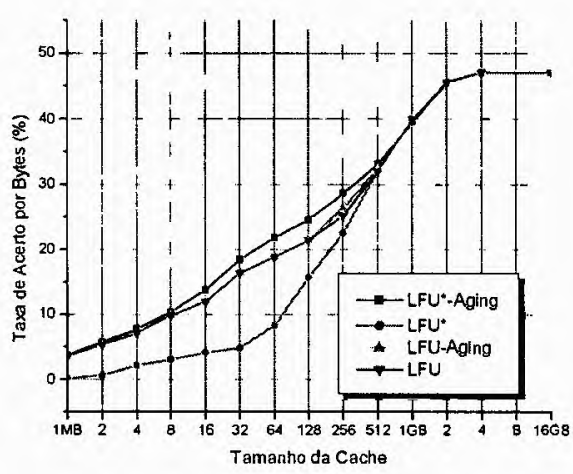

SV-BHR

FIGURA 5.4: Comparação da BHR para as políticas LFU, LFU*, LFU-Aging e LFU*-Aging.

A política $\mathrm{LFU}^{*}$-Aging apresentou as melhores $\mathrm{BHR}$ para as cargas $\mathrm{BO} 2, \mathrm{PA}$ e SV com caches de tamanho entre 32 e $512 \mathrm{MB}$ e na carga do CISC as políticas LFU, LFU-Aging e LFU*-Aging tiveram desempenhos semelhantes.

Os resultados das políticas LFU e LFU-Aging estão sobrepostos em todos os gráficos das Figuras 5.3 e 5.4, revelando que o parâmetro $A_{\max }$ para as cargas analisadas tem pouca influência nesta política. No decorrer desta análise serão consideradas as políticas LFU*-Aging, que apresentou resultados ligeiramente melhores, e a política tradicional LFU que também apresentou resultados satisfatórios.

\subsubsection{Uma Nova Política de Substituição: PESO}

Esta seção apresenta uma nova política de substituição denominada PESO. Para cada objeto, consideram-se cinco parâmetros que são utilizados na função PESO na escolha dos objetos que serão substituídos: 
- $\quad T_{i}$, tempo em que o objeto foi referenciado pela última vez;

- $S_{i}$, tamanho do objeto;

- $\quad N r e f_{i}$, o total de referências;

- $L A T_{i}$, tempo decorrido para recuperar o objeto;

- Class, a classe a que o objeto pertence, sendo que, para este estudo foram utilizadas três classes ("HTML/XML/TEXTO", "IMAGENS" e "OUTROS").

Esta política utiliza a seguinte função para atribuir um peso para cada objeto presente no cache.

$$
\text { Peso }_{i}=\frac{\operatorname{Nref}_{i} *\left(L A T_{i} / S_{i}\right)}{T_{i}} * \text { Class }_{i}
$$

São selecionados para substituição os objetos que tiverem o menor peso. Caso mais de um objeto tenha o mesmo peso, é aplicada uma segunda política: a LRU. Também, pode ser determinado um limite ao total de referências $\left(M A X_{N r e f}\right)$, para evitar o problema apresentado pela política LFU. O tempo gasto para recuperar um objeto foi normalizado apenas pelo seu tamanho $\left(L A T_{i} / S_{i}\right)$, pois o tempo decorrido para recuperar um objeto apesar de está diretamente relacionado com o tamanho do objeto, também é influenciado por outros fatores, como o congestionamento experimentado pela rede e pelo servidor no momento da requisição, a largura de banda disponível, a localização do servidor, dentre outros, que não são considerados neste estudo devido a falta de informações nas cargas de trabalho analisadas.

Outro parâmetro importante é o tempo em que o objeto foi referenciado desde a última vez $\left(T_{i}\right)$, sendo que quando maior for $T_{i}$, menor será o peso $\left(P_{i}\right)$ do objeto.

A utilização do parâmetro Class apresentarem taxas de atualização diferentes; por exemplo, documentos hipertextos são atualizados com mais freqüência que arquivos de áudio ou arquivos binários. O objetivo deste parâmetro é fazer com que objetos populares e com uma baixa taxa de atualização permaneçam no cache. No decorrer de estudo os valores assumidos por Class $i$ são: 0,10 para objetos da classe "HTML/XML/TEXTO"; 0,15 aos objetos da classe "IMAGENS"; e 0,20 aos objetos remanescentes. 


\subsubsection{Avaliação de Políticas de Substituição}

Esta seção apresenta os resultados da avaliação de desempenho de diferentes políticas de substituição de objetos em um cache não particionado e que não impõe limites de tamanho aos objetos aceitos no cache. Nesta seção, também é avaliado o desempenho da política proposta neste trabalho (PESO), descrita na seção anterior. As cinco políticas avaliadas são: PESO, SIZE, LRU, LFU*-Aging e FBR. As políticas consideradas com melhor desempenho são aquelas que apresentarem melhores HR e BHR.

As Figuras 5.5 a 5.8 apresentam os valores de HR e BHR para as cargas CISC, BO2, PA e SV. Conforme esperado, a HR e a BHR foram crescendo conforme o tamanho do cache é incrementado. Os caches de tamanho infinito tiveram um desempenho semelhante para todas as políticas analisadas. Isto ocorreu em virtude de não haver substituição de objetos. Os valores de HR e BHR para caches infinitos representam o desempenho máximo alcançado em cada carga de trabalho. As $\mathrm{HR}_{\max }$ foram $60,13 \%$, $37,91 \%, 52,66 \%$, 46,51\% para CISC, BO2, PA e SV. As BHR $\max$ foram 44,78\%, 26,15\%, $48,74 \%, 47,05 \%$ para CISC, BO2, PA e SV, respectivamente, considerando-se o período de warm-up de $10 \%$ do total de requisições. Esses valores representam a quantidade máxima de reutilização dos objetos no cache.

Os caches pequenos apresentaram resultados com diferenças mais evidentes, pois nestes caches ocorre um grande número de substituições que coloca em evidência a eficácia das políticas de substituição.

A política SIZE apresentou a melhor HR para todas as cargas, com exceção na carga BO2, cujo melhor resultado foi obtido com a política LFU*-Aging, que seleciona para substituição os objetos com somente um acesso. Esta mesma carga apresentou uma grande porcentagem de objetos com somente um acesso, conforme mostrado na seção 3.5.1. Esta observação ratifica que a política SIZE, devido ao fato de considerar somente o tamanho dos objetos na substituição, pode "poluir" o cache com muitos objetos pequenos e que não serão mais acessados.

As políticas PESO, LRU e FBR (que combina a política LRU na seção New Section e LFU na seção Old Section) apresentaram resultados intermediários, tanto na HR quanto na BHR, sendo que a política PESO obteve valores piores que estas políticas nas HR e 
BHR para a carga PA (Figura 5.7), enquanto que a política LRU mostrou um desempenho inferior na HR para o CISC e a política SIZE apresentou a pior BHR para todas as cargas analisadas, pois os objetos de tamanho elevado são selecionados para a substituição.

Verificou que os caches com $2 \mathrm{~GB}$ de tamanho apresentaram HR e BHR semelhantes. Esta observação evidencia que caches de tamanhos muito elevados não significa em ganhos substancias de desempenho.
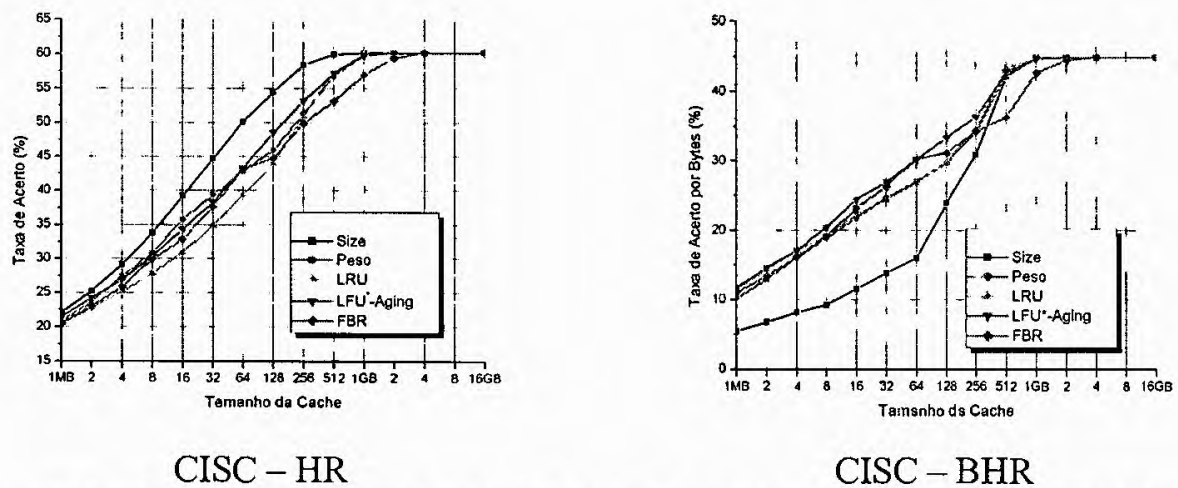

$\mathrm{CISC}-\mathrm{BHR}$

FIGURA 5.5: Comparação de políticas de substituição de objetos (CISC).

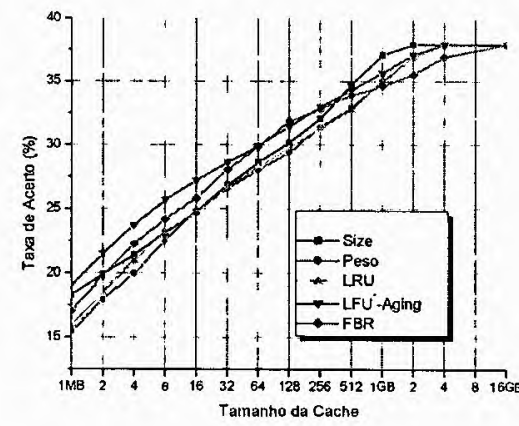

$\mathrm{BO} 2-\mathrm{HR}$

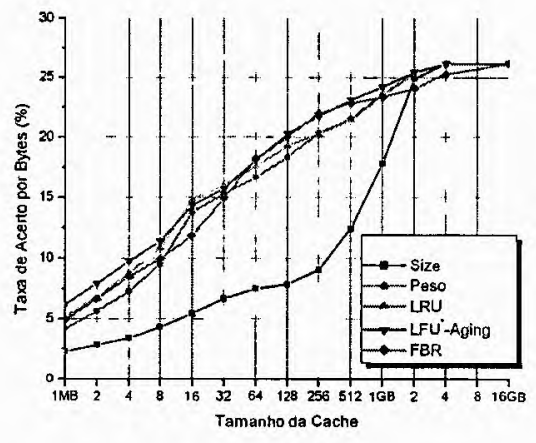

$\mathrm{BO} 2-\mathrm{BHR}$

FIGURA 5.6: Comparação de políticas de substituição de objetos. (BO2)

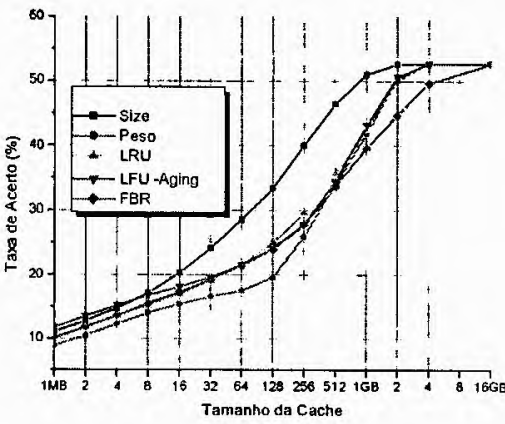

$\mathrm{PA}-\mathrm{HR}$

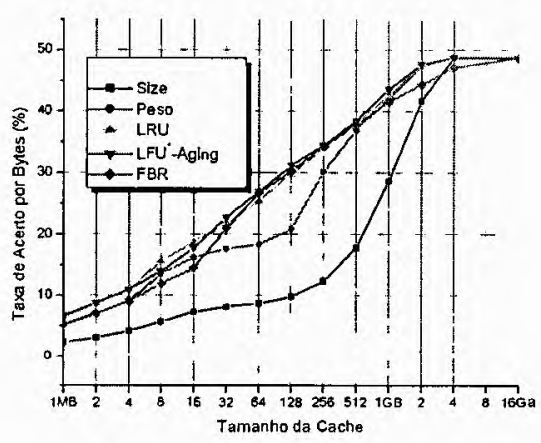

PA - BHR 
FIGURA 5.7: Comparação de politicas de substituição de objetos (PA).

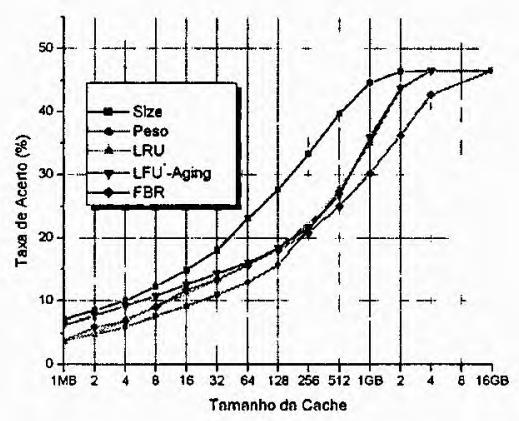

$\mathrm{SV}-\mathrm{HR}$

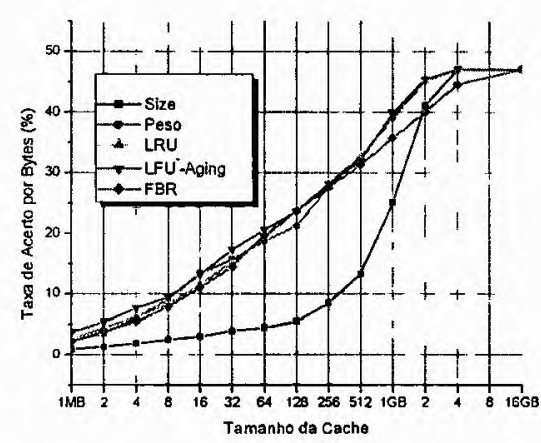

SV - BHR

FIGURA 5.8: Comparação de políticas de substituição de objetos (SV).

\subsubsection{Limites Inferior e Superior aos Objetos Aceitos no Cache}

Esta análise restringe os objetos aceitos pelo cache de acordo com um limite inferior e superior. $\mathrm{O}$ desenvolvimento desta análise foi motivado pelo estudo de caracterização de carga desenvolvido no capítulo 4 , no qual observou-se que $82,8 \%$ das requisições compreendem objetos menores que 10 Kbytes e $99,3 \%$ das requisições abrangem objetos com até 100 Kbytes, enquanto que uma quantidade significativa dos bytes transferidos é causada por poucos objetos de tamanhos elevados. O objetivo deste estudo é analisar o efeito de atribuir um limiar inferior e superior aos objetos aceitos no cache.

Pode-se privilegiar a HR ou a BHR de acordo com a faixa de valores escolhidos para aceitação. Foram analisados 4 intervalos: 0 a 10 Kbytes, 0 a 100 Kbytes, objetos maiores que 100 Kbytes e todos os objetos sem nenhuma restrição, sendo que estes intervalos foram baseados nos resultados apresentados na Tabela 4.15. É importante frisar que, quando for solicitado um objeto que está fora dos limites, será contabilizado um miss.

Os resultados desta análise são mostrados nas Figuras 5.9 a 5.12. Em cada uma destas Figuras os gráficos (a) e (b) apresentam os resultados da política PESO para as HR e BHR, respectivamente; os gráficos (c) e (d) apresentam os resultados da política LRU; os gráficos (e) e (f) apresentam os resultados da política FBR; os gráficos (g) e (h) apresentam os resultados da política LFU, e os gráficos (i) e (j) apresentam os resultados da política 
SIZE. A seguir são apresentadas algumas conclusões baseadas na análise dos gráficos apresentados na Figura 5.9 a 5.12.

- Em todas as cargas analisadas os caches que aceitam somente objetos com tamanho acima de 100 Kbytes tiveram uma HR inferior a $1 \%$, enquanto que a BHR chegou a $20 \%$ de acerto. Em todos os casos, a BHR se estabilizou apresentando um desempenho melhor apenas do que os caches que armazenam objetos menores que 10 Kbytes. Antes do ponto de estabilização o desempenho deste cache chega, por diversas vezes, a ser o pior entre todos os gráficos analisados. Em poucos casos, fica melhor que o cache armazenando objetos com até 100 Kbytes.

- Em todos os caches com até 512 Mbytes e que aceitam somente objetos com até 10 Kbytes, obtiveram HRs semelhantes ou melhores de que os caches que aceitam todos os objetos, com exceção da política SIZE, que em todas as cargas analisadas tiveram desempenho inferior; enquanto que a BHR não passou de $10 \%$ em todas as cargas analisadas. Estes resultados confirmam a influência de objetos com tamanhos de até 10 Kbytes na HR.

- Verificou-se, também, que as HR e BHR estabilizam a partir de um determinado tamanho de cache que varia de 512 Mbytes (CISC) a 4 Gbytes (SV), dependendo, principalmente, da carga considerada. A política utilizada apresenta pouca influência no ponto de estabilização. A partir do ponto de estabilização, o comportamento de caches que aceitam todos os objetos e objetos de até 100 Kbytes são praticamente idênticos.

- Observou-se que caches que aceitam objetos com até 100 Kbytes obtiveram desempenho igual ou superior aos caches que aceitam todos objetos. Já os caches de tamanhos elevados (infinitos) apresentaram HR semelhantes. Esses resultados evidenciam que objetos acima de 100 Kbytes praticamente não influenciam na HR.

- Para todos os casos analisados, a BHR apresentou melhores resultados quando objetos de todos os tamanhos são colocados no cache. 


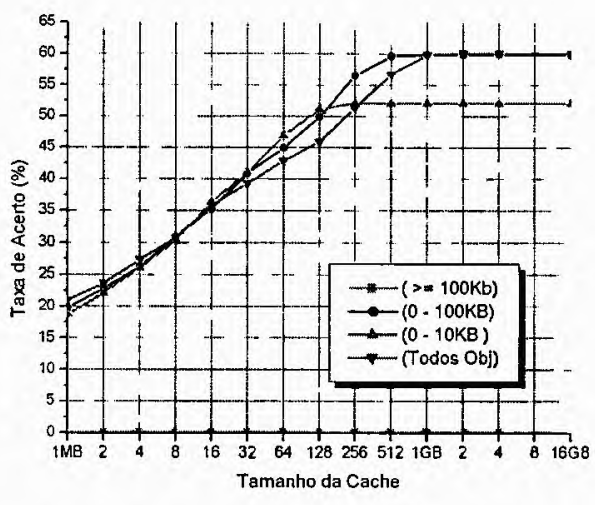

(a) Taxa de Acerto (CISC) - PESO

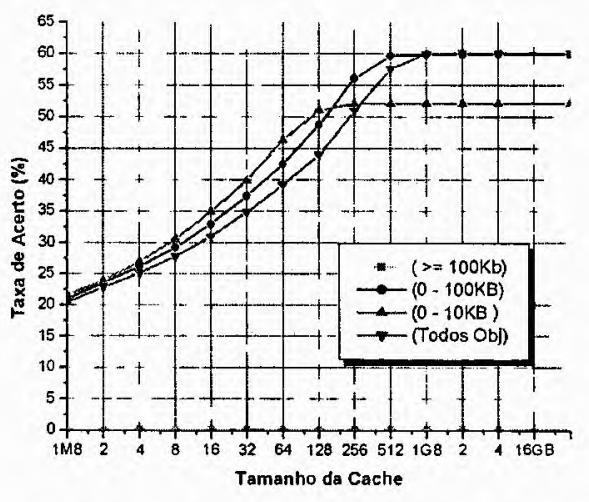

(c) Taxa de Acerto (CISC) - LRU

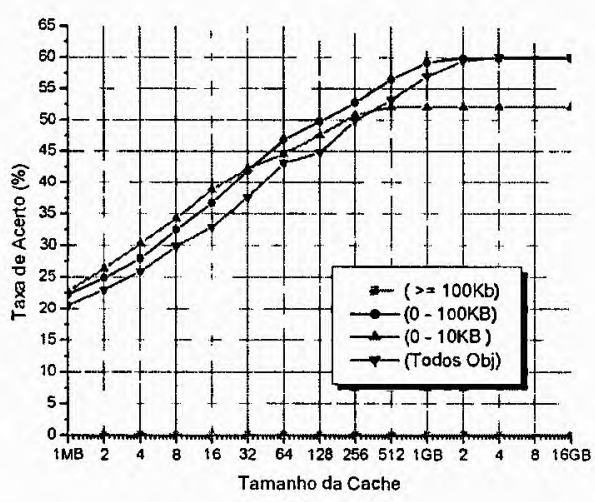

(e) Taxa de Acerto (CISC) - FBR

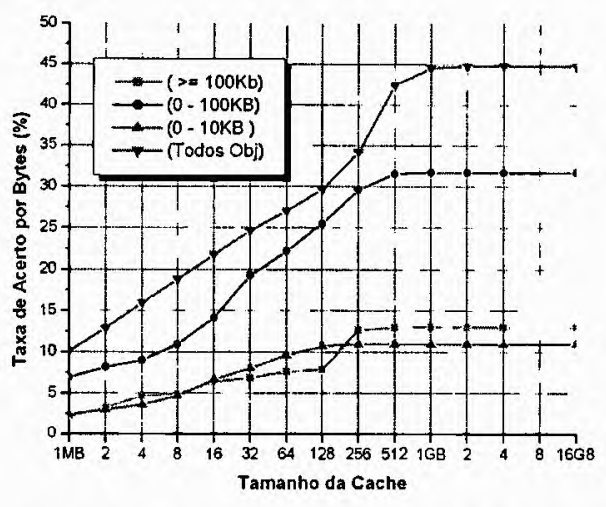

(b) Taxa de Acerto por Bytes (CISC) - PESO

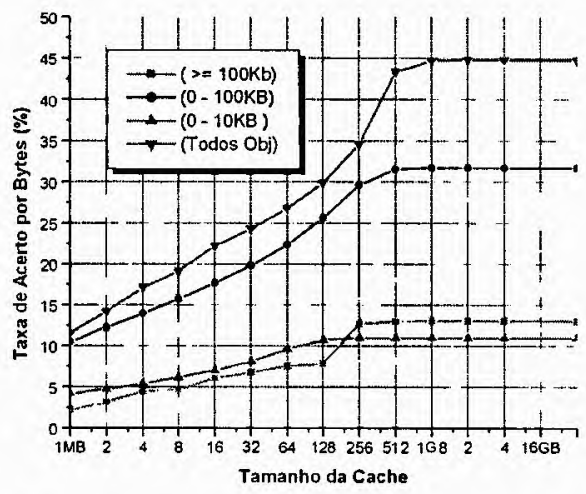

(d) Taxa de Acerto por Bytes (CISC) - LRU

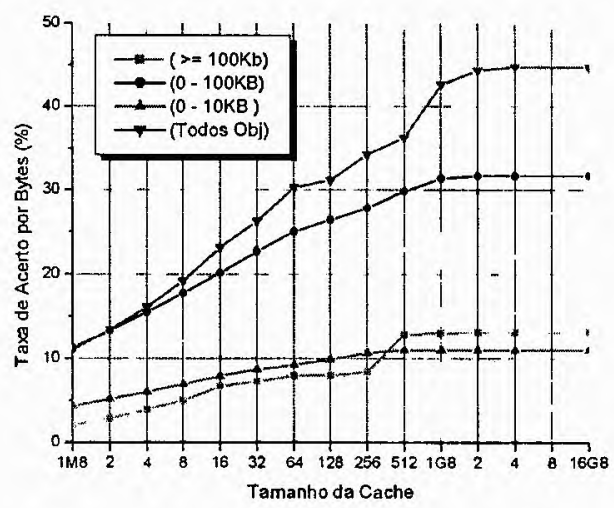

(f) Taxa de Acerto por Bytes (CISC) - FBR 


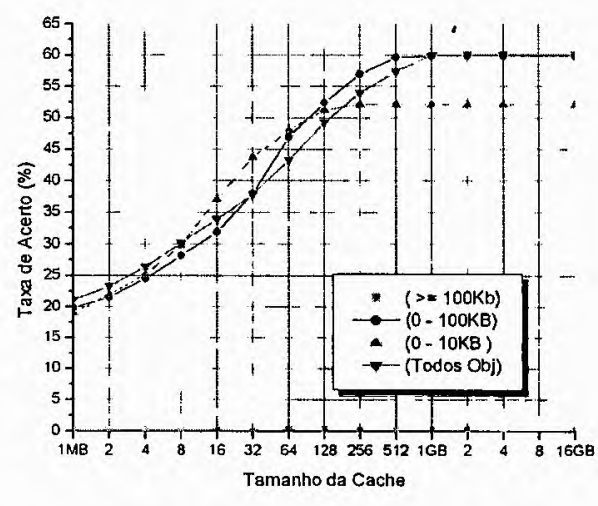

(g) Taxa de Acerto (CISC) - LFU

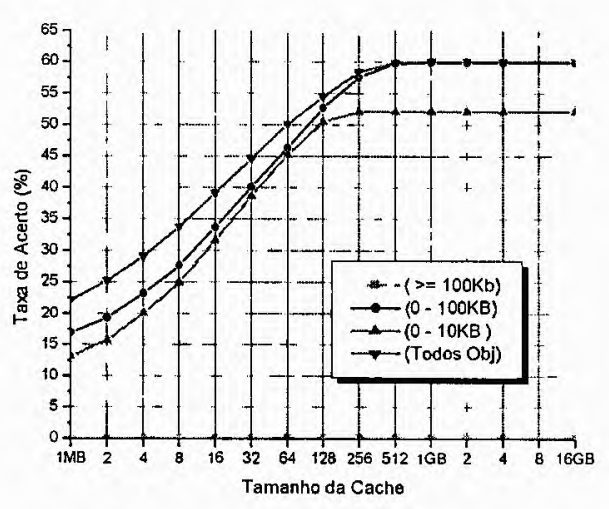

(i) Taxa de Acerto (CISC) - SIZE

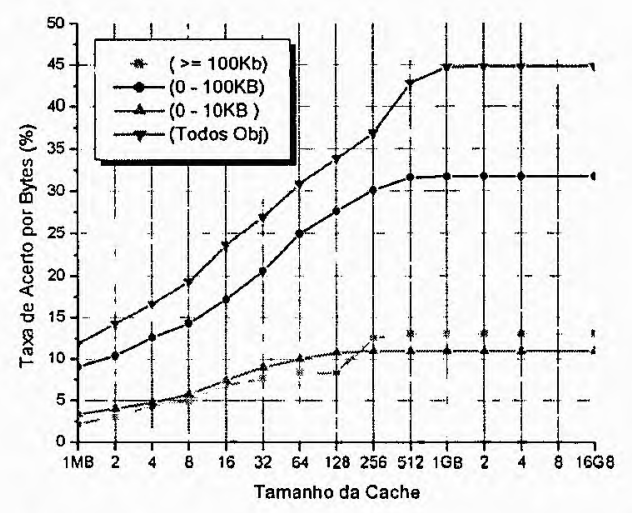

(h) Taxa de Acerto por Bytes (CISC) - LFU

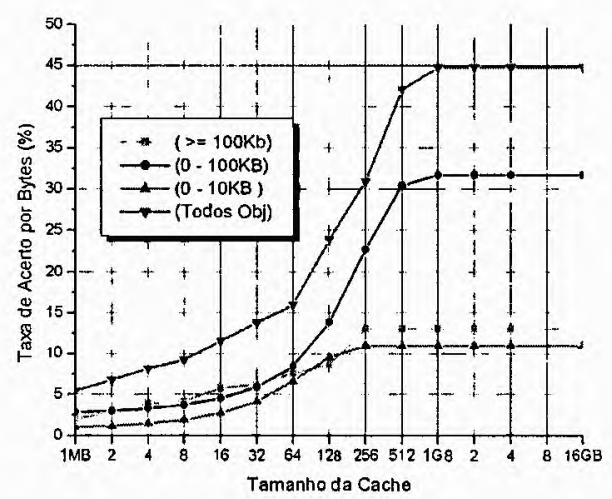

(j) Taxa de Acerto por Bytes (CISC) - SIZE

FIGURA 5.9: Comparação de políticas de substituição, considerando um limiar inferior e um superior (CISC).

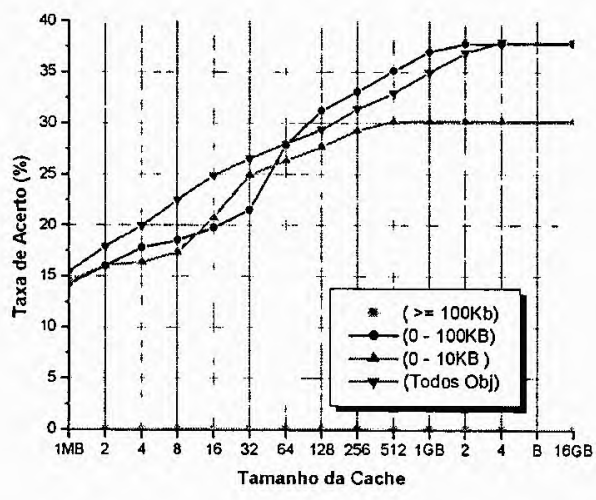

(a) Taxa de Acerto (BO2) - PESO

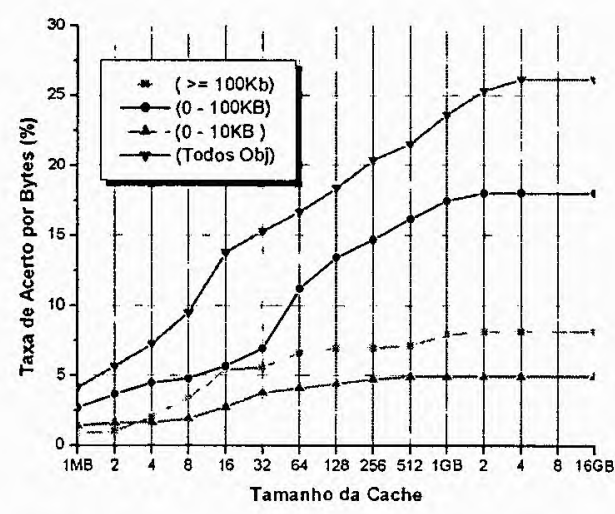

(b) Taxa de Acerto por Bytes(BO2) - PESO 


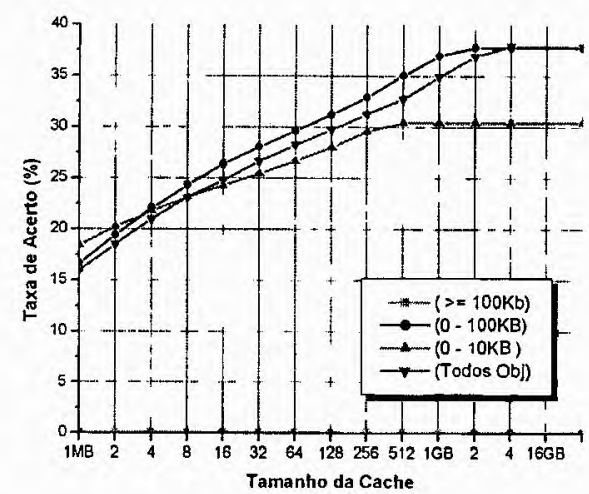

(c) Taxa de Acerto (BO2) - LRU

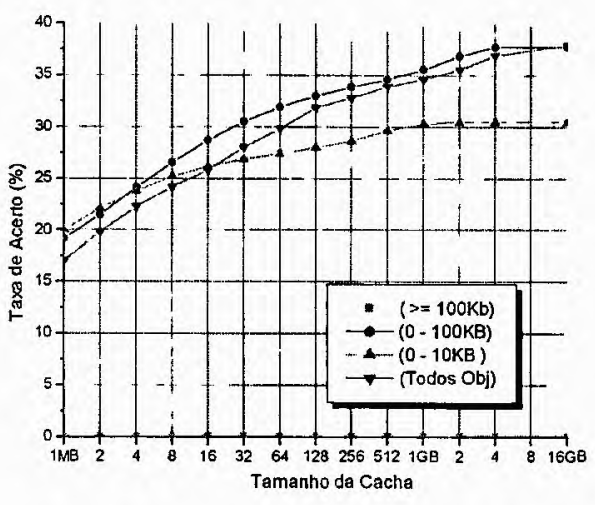

(e) Taxa de Acerto (BO2) - FBR

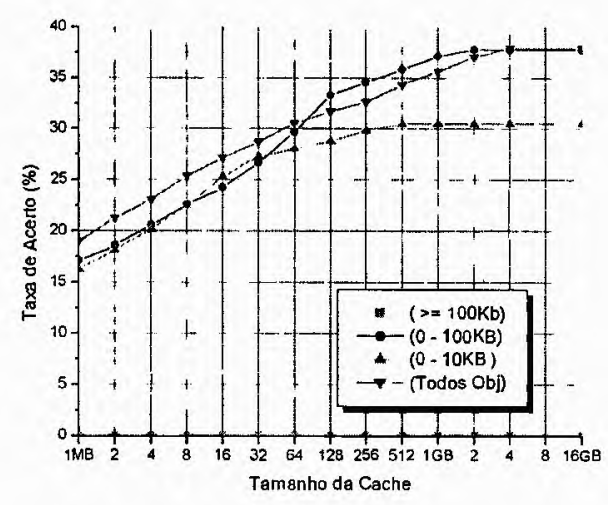

(g) Taxa de Acerto (BO2) - LFU

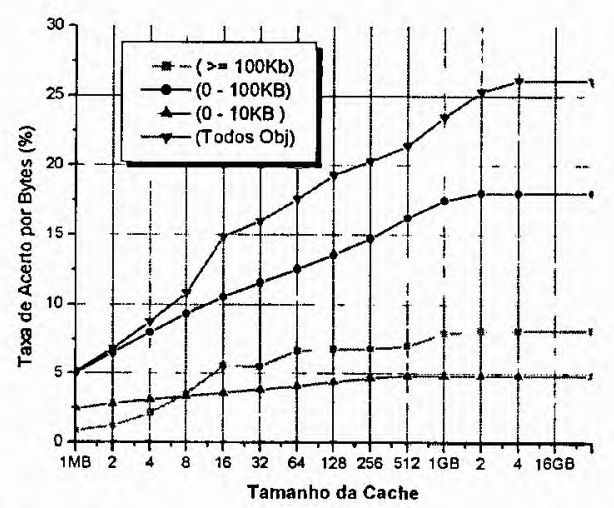

(d) Taxa de Acerto por Bytes (BO2) - LRU

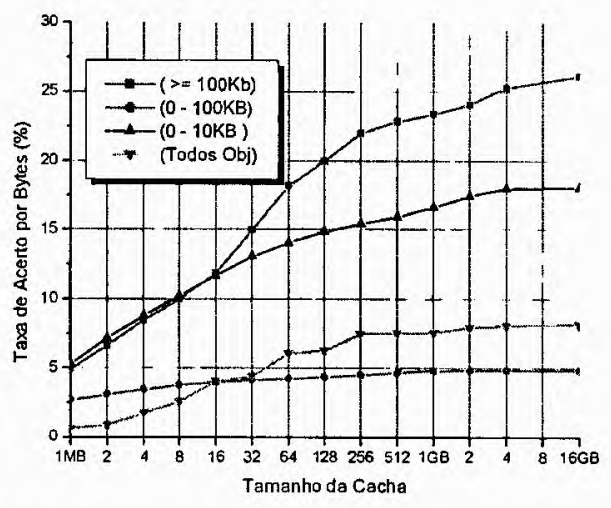

(f) Taxa de Acerto por Bytes(BO2) - FBR

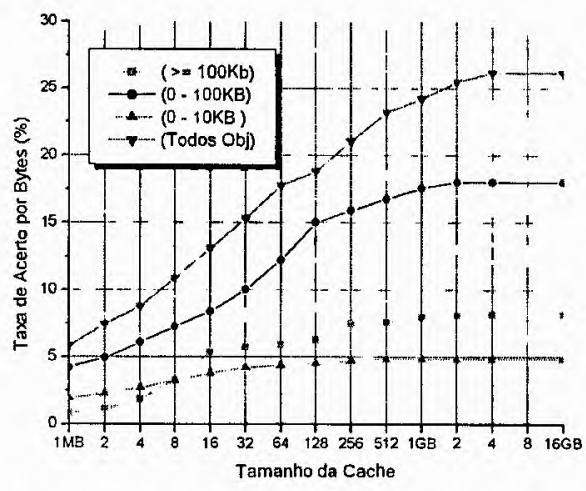

(h) Taxa de Acerto por Bytes(BO2) - LFU 


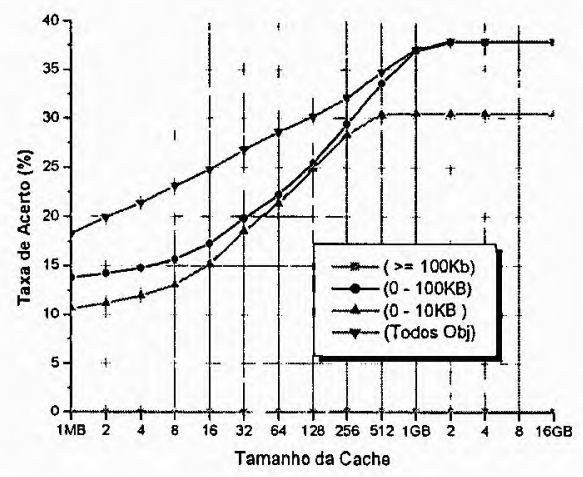

(i) Taxa de Acerto (BO2) - SIZE

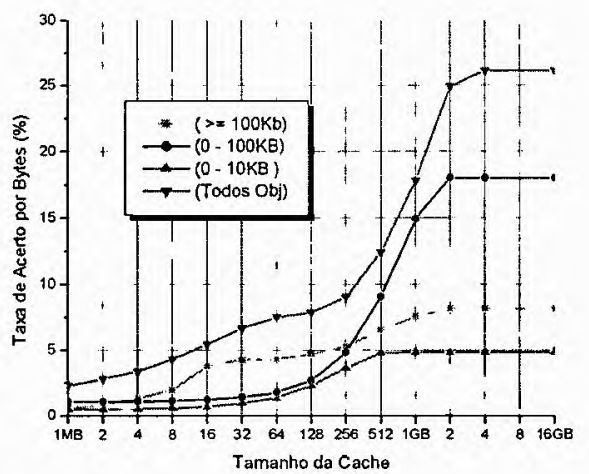

(j) Taxa de Acerto por Bytes (BO2) - SIZE

FIGURA 5.10: Comparação de políticas de substituição, considerando um limiar inferior e um superior (BO2).

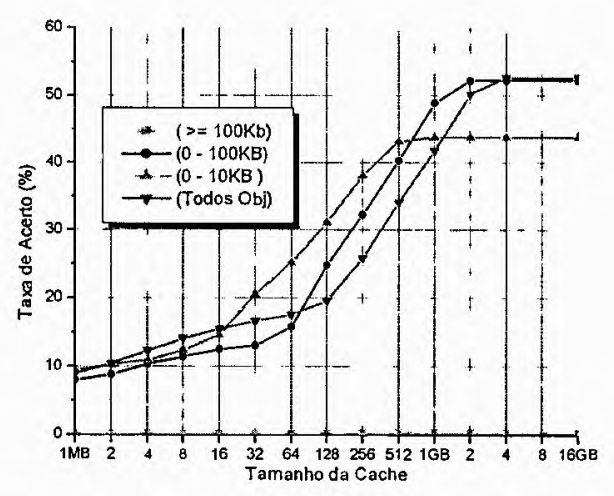

(a) Taxa de Acerto (PA) - PESO

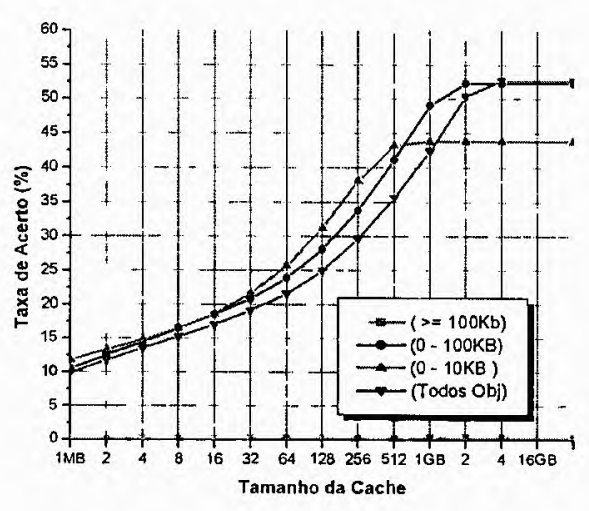

(c) Taxa de Acerto (PA) - LRU

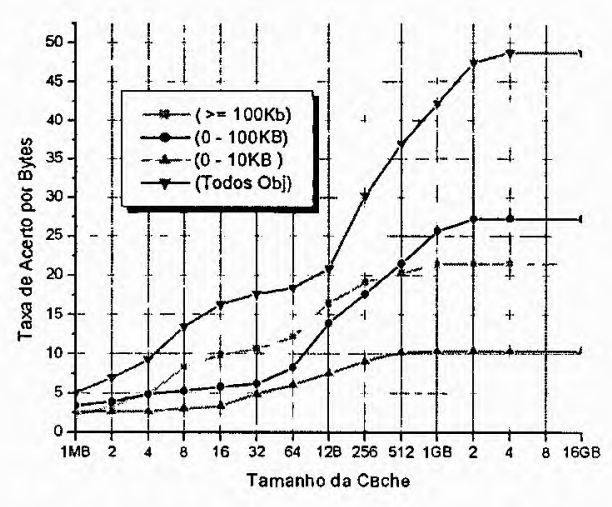

(b) Taxa de Acerto por Bytes (PA) - PESO

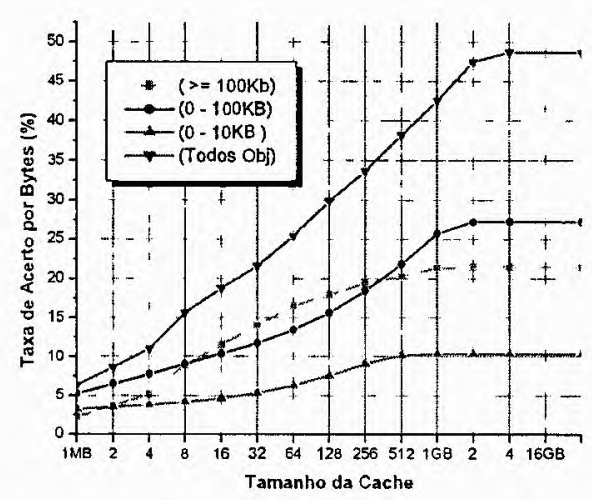

(d) Taxa de Acerto por Bytes (PA) - LRU 


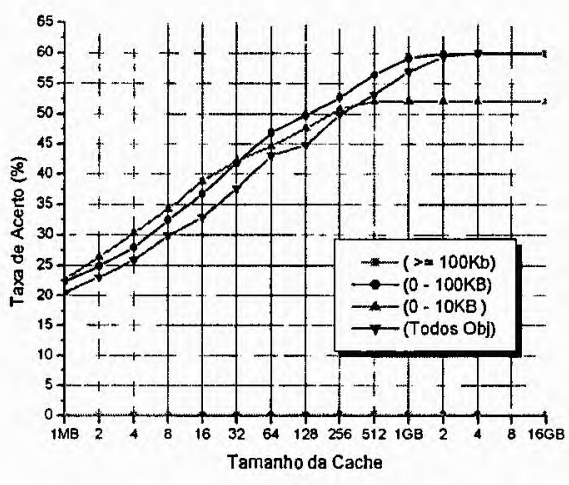

(e) Taxa de Acerto (PA) - FBR

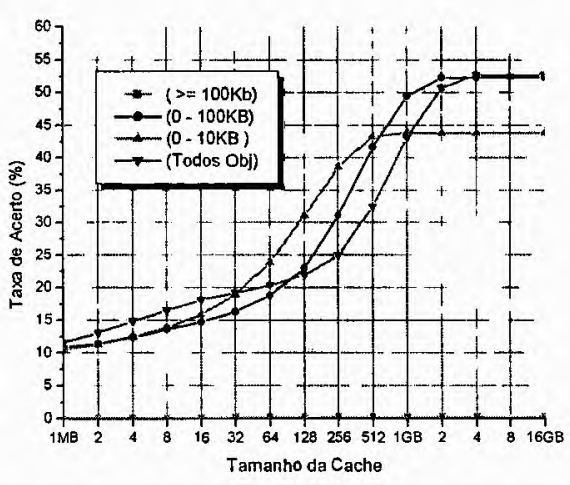

(g) Taxa de Acerto (PA) - LFU

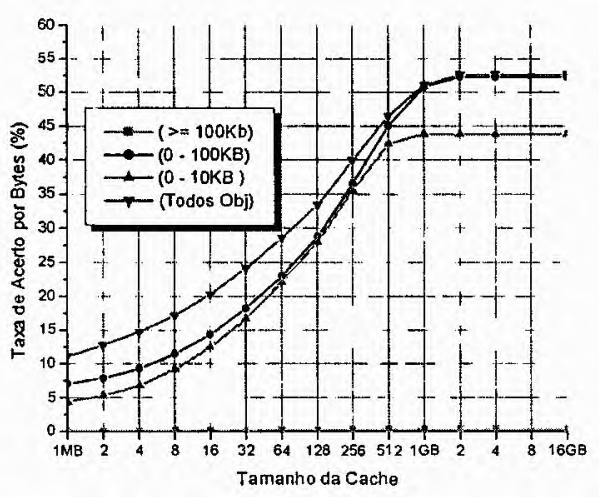

(i) Taxa de Acerto (PA) - SIZE

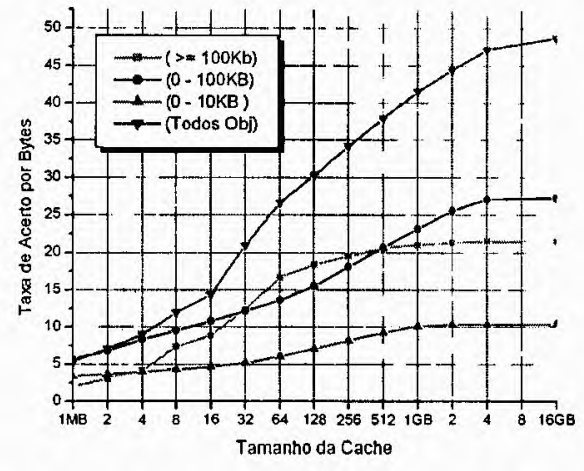

(f) Taxa de Acerto por Bytes (PA) - FBR

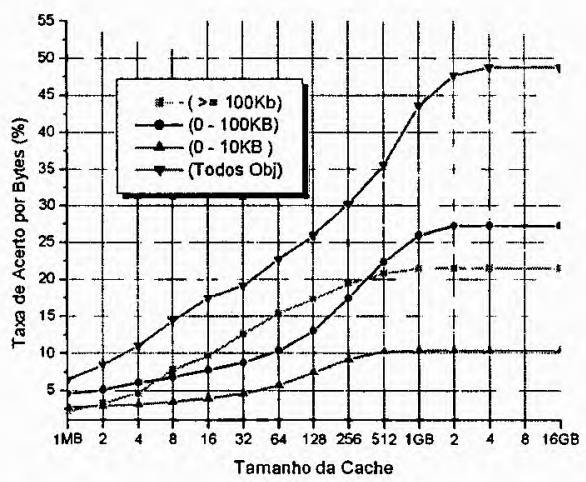

(h) Taxa de Acerto por Bytes (PA) - LFU

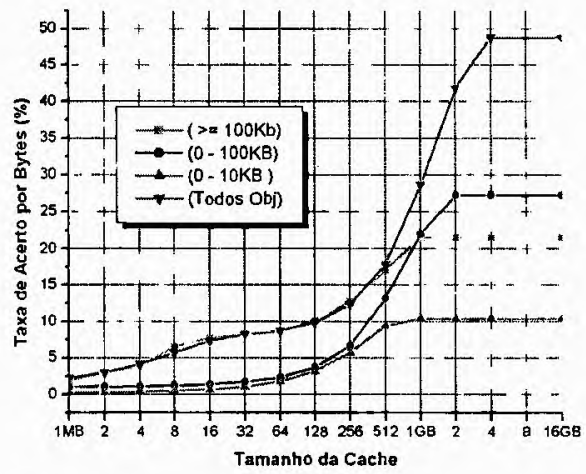

(j) Taxa de Acerto por Bytes (PA) - SIZE

FIGURA 5.11: Comparação de políticas de substituição, considerando um limiar inferior e um superior (PA). 


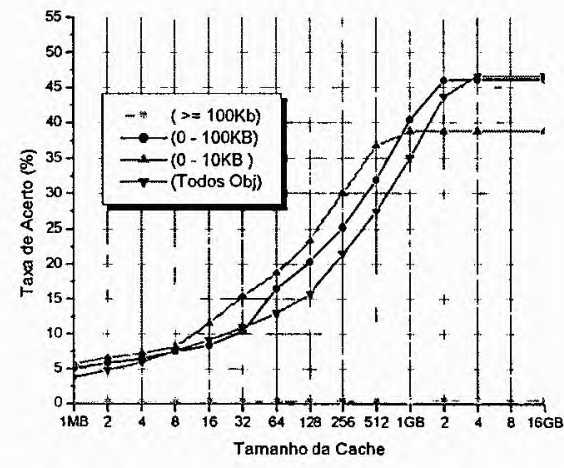

(a) Taxa de Acerto (SV) - PESO

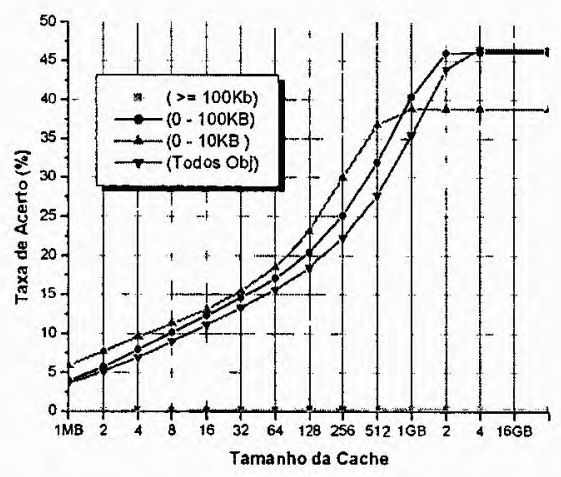

(c) Taxa de Acerto (SV) - LRU

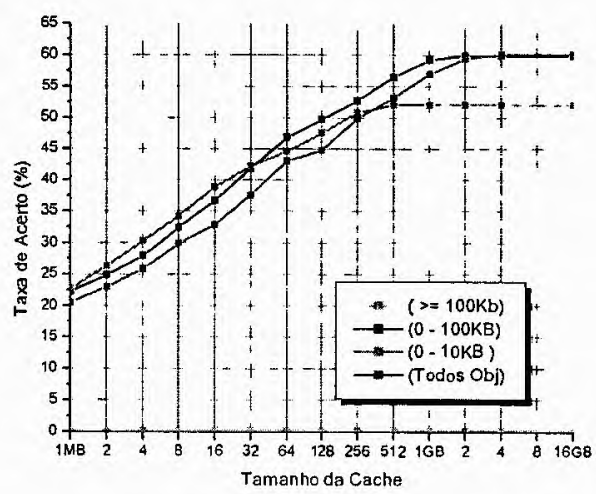

(e) Taxa de Acerto (SV) - FBR

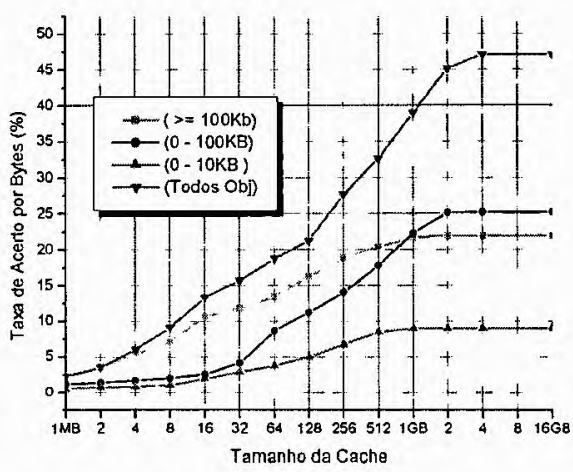

(b) Taxa de Acerto por Bytes (SV) - PESO

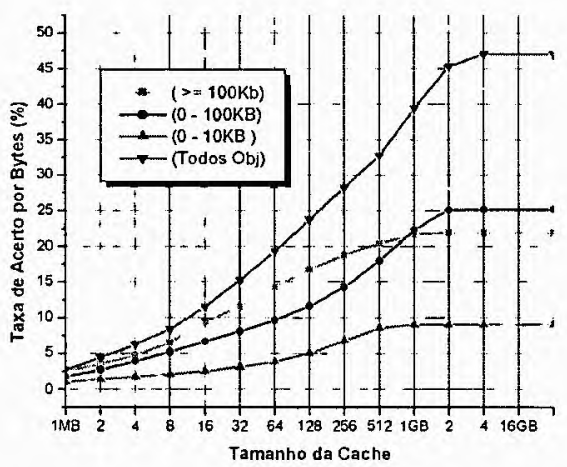

(d) Taxa de Acerto por Bytes (SV) - LRU

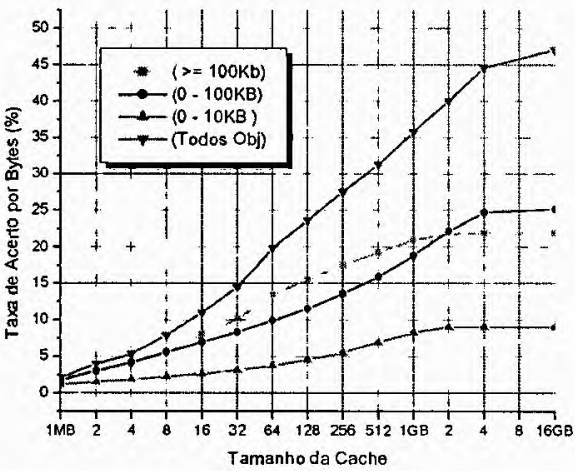

(f) Taxa de Acerto por Bytes (SV) - FBR 


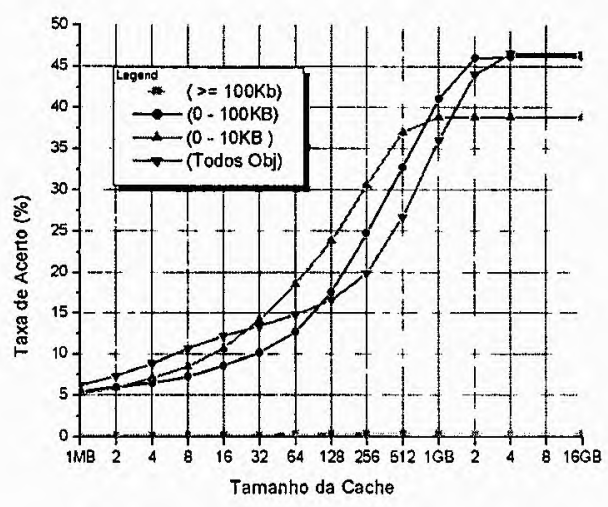

(g) Taxa de Acerto (SV) - LFU

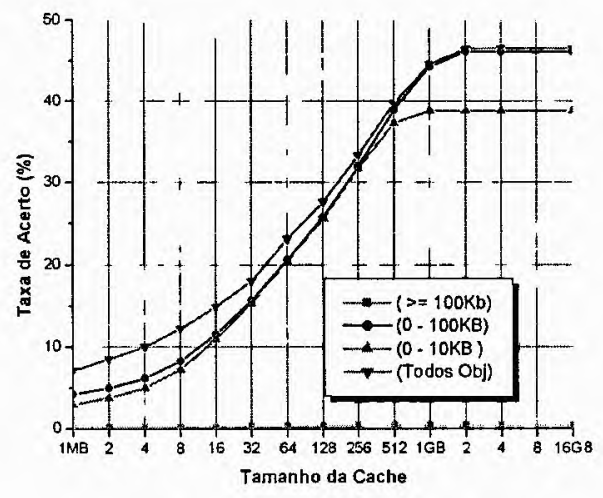

(i) Taxa de Acerto (SV) - SIZE

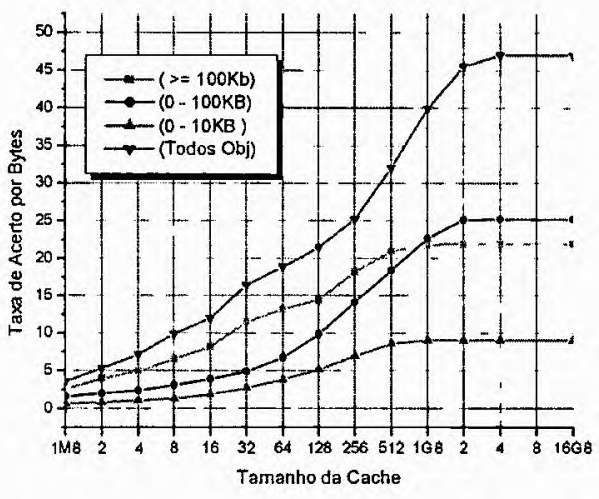

(h) Taxa de Acerto por Bytes (SV) - LFU

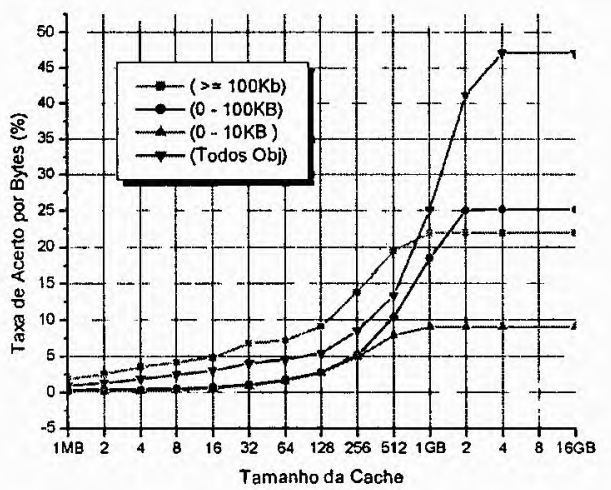

(j) Taxa de Acerto por Bytes (SV) - SIZE

FIGURA 5.12: Comparação de políticas de substituição, considerando um limiar inferior e um superior (SV). 


\subsubsection{Particionamento do Cache por Classes de Objetos}

Nesta seção serão apresentados os resultados da análise de políticas de substituição baseados no particionamento de caches de acordo com classes de objetos, conforme mostrados na Tabela 5.3. Este tipo de particionamento foi proposto anteriormente por Arlitt e Williamson (1996b), na avaliação de desempenho de caches em servidores Web.

Esta análise serve para avaliar se as classes de objetos, que previnem substituições em classes diferentes, têm algum efeito no desempenho de caches.

No estudo de caracterização apresentado no capítulo 4 observou-se que a maioria das requisições foi para objetos da classe "Imagens" e "HTML/XML/TEXTO". Neste estudo as políticas são comparadas considerando-se caches com três partições (Tabela 5.3): "Hipertextos" "Imagens" e "Outros". Nota-se que a partição "Outros" armazena todos os objetos que não são Hipertextos ou Imagens. A porcentagem destinada a cada partição foi baseada nos resultados apresentados na Tabela 4.12.

TABELA 5.3: Definição dos parâmetros para caches com três partições.

\begin{tabular}{|l|c|}
\hline \multicolumn{1}{|c|}{ Partições } & $(\%)$ Tamanho do Cache \\
\hline HTML/XML/TEXTO & $15 \%$ \\
\hline IMAGENS & $35 \%$ \\
\hline OUTROS & $50 \%$ \\
\hline
\end{tabular}

As Figuras 5.13 a 5.16 apresentam os resultados do particionamento por classes de objetos parametrizados de acordo com os valores listados na Tabela 5.3. As seis políticas avaliadas são: PESO, SIZE, LRU, LFU, LFU*-Aging e FBR. As políticas consideradas com melhor desempenho são aquelas que alcançarem melhores HR e BHR.

As políticas FBR e LRU tiveram resultados superiores em todas as cargas analisadas, tanto para HR quanto para BHR, sendo que a política FBR apresentou resultados ligeiramente melhores para HRs em todos os caches com até 256 Mbytes, aproximadamente. A política LRU mostrou BHR melhor em PA para caches com até 64 Mbytes.

A política SIZE apresentou a pior BHR em todas as cargas analisadas. A política PESO apresentou resultados intermediários, tanto na HR quanto na BHR. 

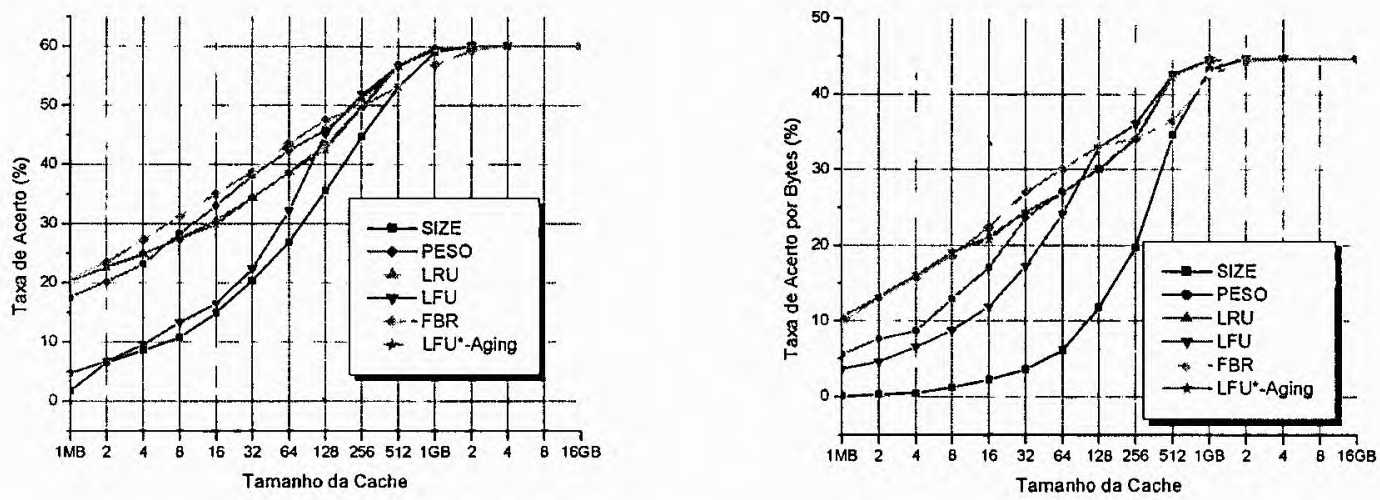

CISC - HR

CISC - BHR

FIGURA 5.13: Comparação de políticas de substituição com 3 partições (CISC).

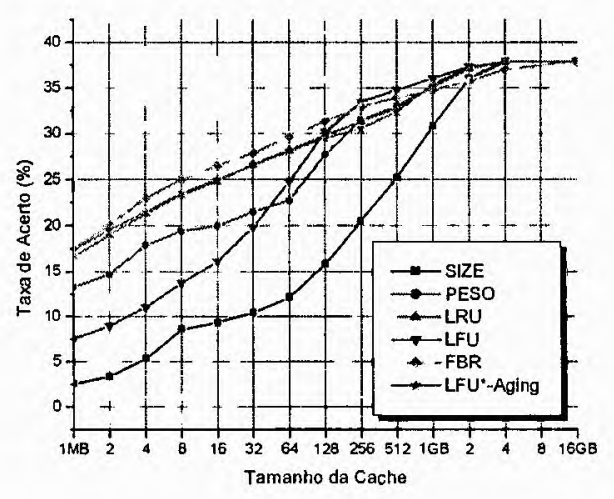

$\mathrm{BO} 2$ - HR

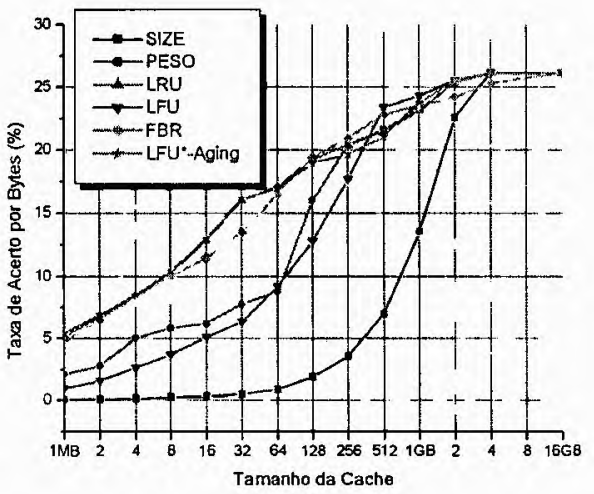

BO2 - BHR

FIGURA 5.14: Comparação de políticas de substituição com 3 partições (BO2).

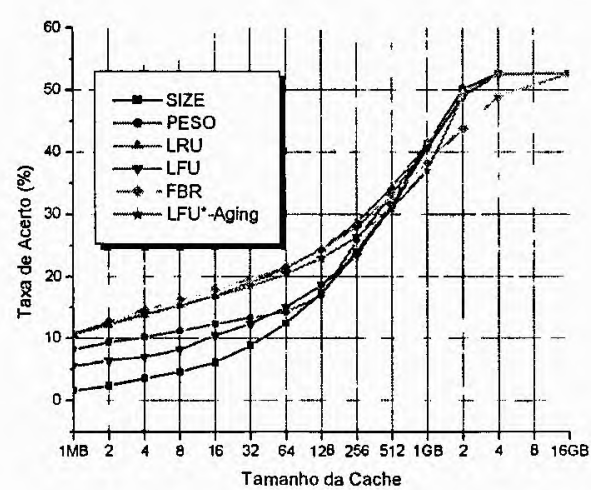

PA - HR

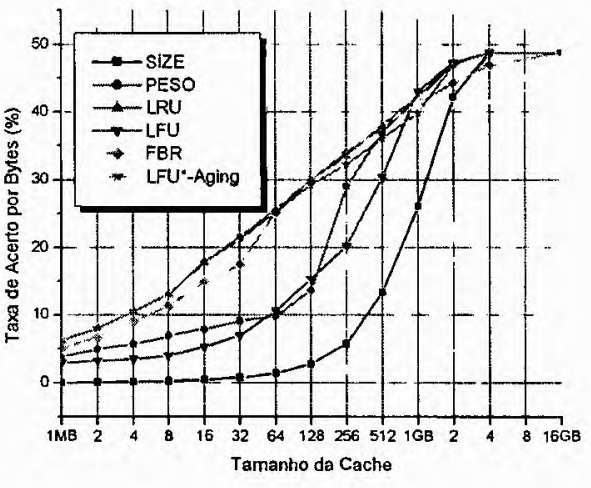

PA - BHR

FIGURA 5.15: Comparação de políticas de substituição com 3 partições (PA). 


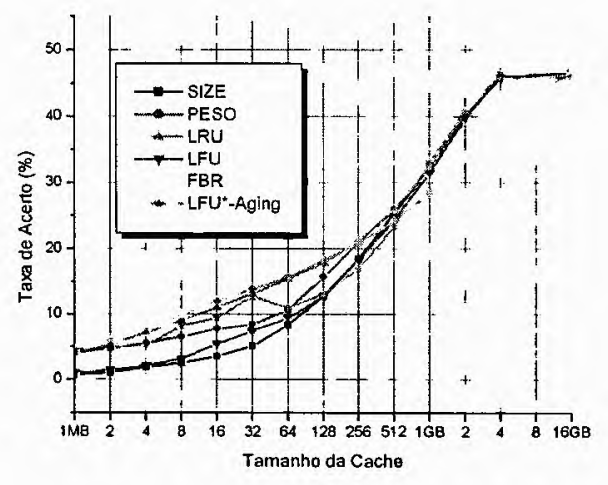

$\mathrm{SV}-\mathrm{HR}$

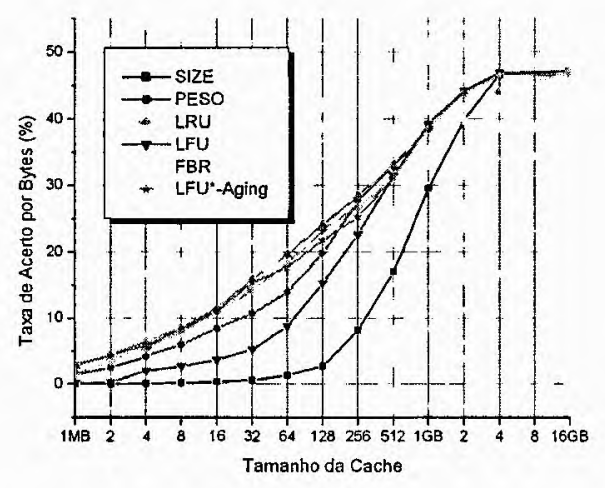

SV - BHR

FIGURA 5.16: Comparação de políticas de substituição com 3 partições (SV).

\subsubsection{Particionamento do Cache por Classes de Tamanho}

Nesta seção são apresentados os resultados da análise das políticas de substituição baseados no particionamento do cache de acordo com o tamanho dos objetos, conforme mostrados nas Tabelas 5.4 e 5.5. Este tipo de particionamento foi proposto em Murta (1999) como uma nova alternativa à gerência de espaços em caches na Web.

São comparados os caches com cinco e três partições, conforme detalhados nas Tabelas 5.4 e 5.5. A escolha da porcentagem de tamanho destinado a cada partição foi baseada nos resultados apresentados na Tabela 4.15 que apresenta a porcentagem de bytes que cada classe é responsável.

TABELA 5.4: Definição dos parâmetros para caches com cinco partições.

\begin{tabular}{|c|c|l|}
\hline Partições & Tamanho do Cache & \multicolumn{1}{|c|}{ Classe } \\
\hline 1 & $5 \%$ & $<1$ Kbyte \\
\hline 2 & $20 \%$ & 1 a 10 Kbytes \\
\hline 3 & $25 \%$ & 10 a 100 Kbytes \\
\hline 4 & $20 \%$ & 100 Kbytes a 1000 Mbytes \\
\hline 5 & $30 \%$ & $>1$ Mbyte \\
\hline
\end{tabular}

TABELA 5.5: Definição dos parâmetros para caches com três partições.

\begin{tabular}{|c|c|l|}
\hline Partições & Tamanho do Cache & \multicolumn{1}{|c|}{ Classe } \\
\hline 1 & $25 \%$ & $<10$ Kbytes \\
\hline 2 & $35 \%$ & 10 a 100 Kbytes \\
\hline 3 & $40 \%$ & $>100$ Kbytes \\
\hline
\end{tabular}




\section{Análise das Políticas de Substituição com 5 Partições}

Esta seção avalia o desempenho de diferentes políticas de substituição de objetos em caches com cinco partições. Os gráficos das Figuras 5.17 a 5.20 apresentam os valores de HR e BHR para as quatro cargas analisadas (CISC, BO2, PA e SV).

Notou-se que as políticas FBR e LRU tiveram resultados superiores em todas as cargas analisadas, tanto para HR quanto para BHR, sendo que a política FBR apresentou resultados melhores para a $\mathrm{HR}$ em todos os caches analisados com até $256 \mathrm{Mbytes}$, com exceção da carga do CISC em que os melhores resultados ficaram com caches de até 64 Mbytes. A política LRU mostrou resultados melhores em BHR para carga PA com tamanho de até 32 Mbytes e maiores que 512 Mbytes.

Notou-se que as políticas que apresentaram os melhores resultados são baseadas em caches tradicionais (Stallings, 2000). Neste caso, as políticas LRU e FBR (que utiliza uma combinação das políticas LRU e LFU na decisão de quais objetos serão removidos do cache). O grande mérito destes resultados está em o particionamento por tamanho de objetos controlar melhor a variabilidade, conforme os resultados apresentados na Tabela 4.14 , que mostrou coeficientes de variação bem menores que os caches não particionados.

A política SIZE apresentou as piores HR e BHR para todas as cargas analisadas. Esta observação ratifica que a utilização da política SIZE não é adequada em cache particionados.

As políticas PESO e LFU apresentaram resultados intermediários, tanto na HR quanto na BHR, sendo que a política LFU mostrou valores bastante satisfatórios nas HR e BHR em caches de tamanhos elevados.

Verificou-se, também, uma semelhança nos gráfico para a HR e a BHR em todas as cargas analisadas, mostrando uma proximidade com os caches tradicionais em que a HR e a BHR são análogas devido ao tamanho dos objetos serem iguais. 


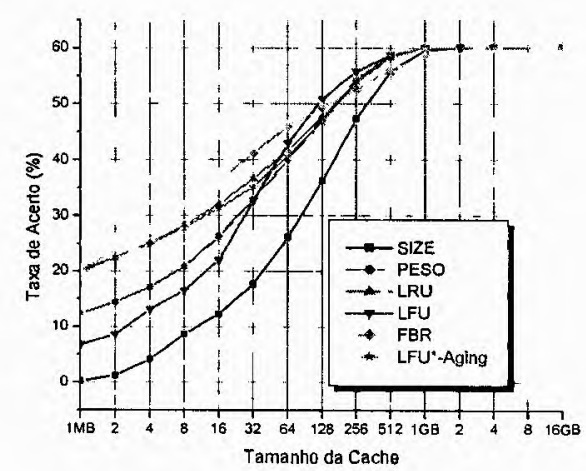

CISC - HR (a)

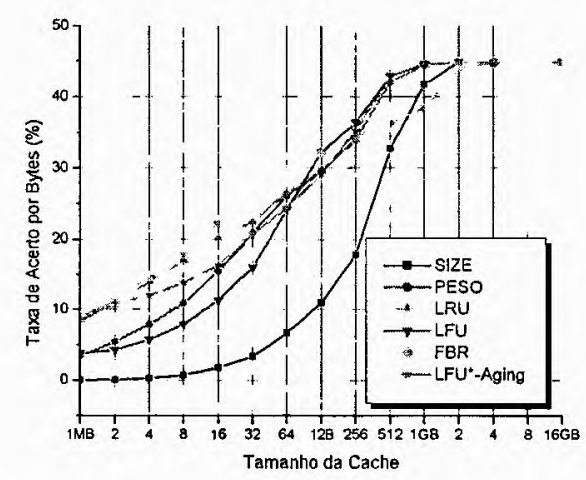

CISC - BHR (b)

FIGURA 5.17: Comparação de políticas de substituição com 5 partições (CISC).

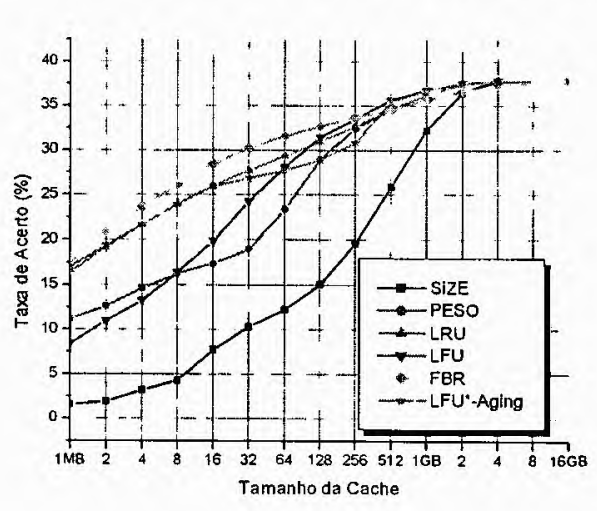

$\mathrm{BO} 2-\mathrm{HR}$ (a)

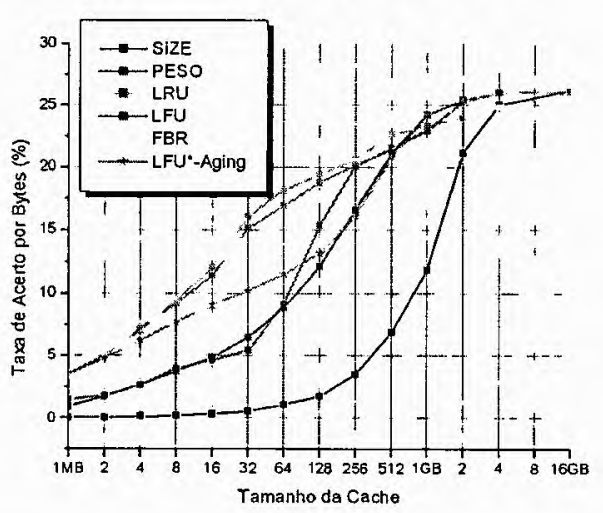

$\mathrm{BO} 2$ - $\mathrm{BHR}$ (b)

FIGURA 5.18: Comparação de políticas de substituição com 5 partições (BO2).

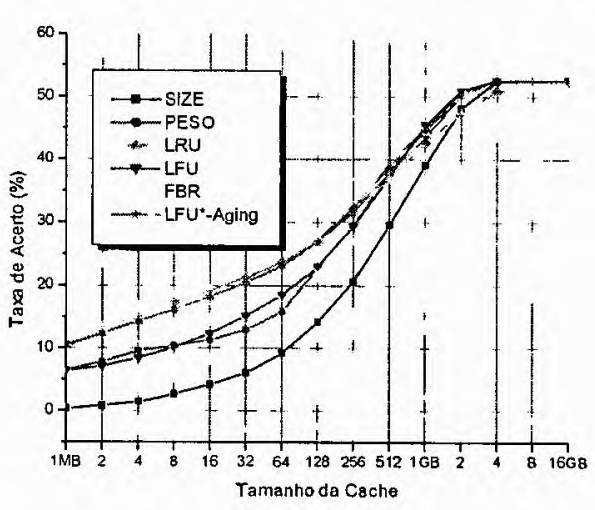

PA - HR (a)

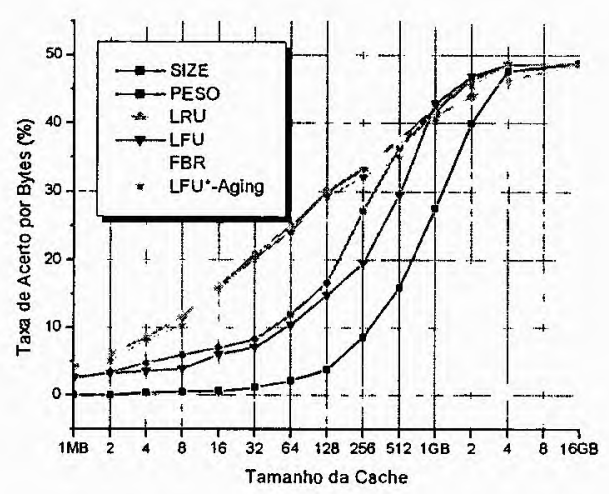

PA - BHR (b)

FIGURA 5.19: Comparação de políticas de substituição com 5 partições (PA). 


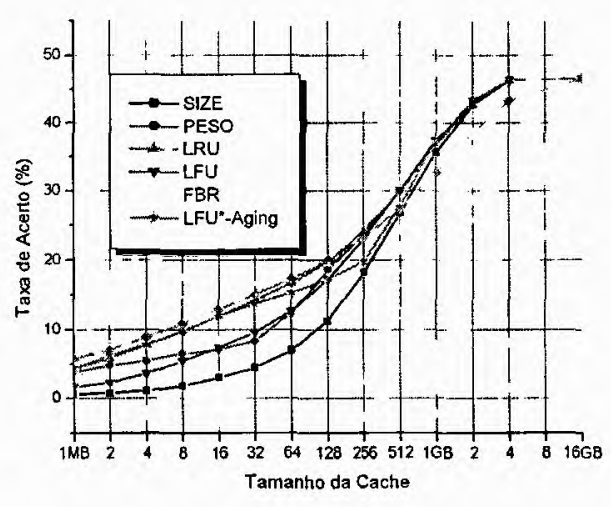

SV - HR (a)

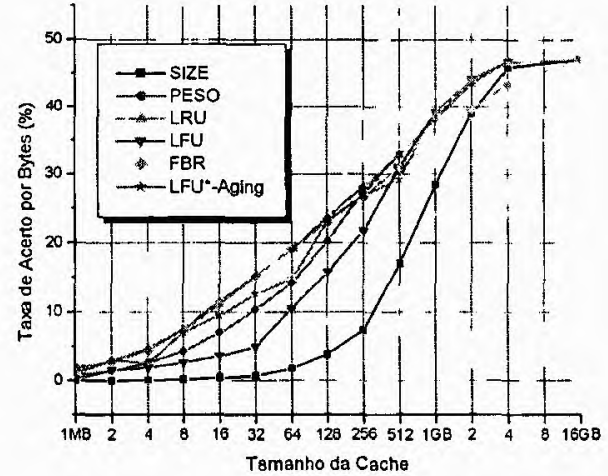

$\mathrm{SV}-\mathrm{BHR}(\mathrm{b})$

FIGURA 5.20: Comparação de políticas de substituição com 5 partições (SV).

\section{Análise das Políticas de Substituição em Cada Partição}

Os gráficos apresentados nas Figuras 5.21 a 5.25 exibem os valores de HR e BHR para cada uma das cinco partições para a carga $\mathrm{BO} 2$. O objetivo de apresentar estes resultados é mostrar que cada partição pode ser tratada como um cache separado, dedicado a classes especificas de objetos, possibilitando a exploração de características particulares em cada partição, como a utilização de políticas de substituição diferentes. A seguir são apresentadas algumas conclusões baseadas na análise dos gráficos.

Os resultados evidenciam que nas partições 1 e 2 a política FBR mostrou os melhores resultados para as HR e BHR. Nas partições 3, 4 e 5, os melhores resultados ficaram com as políticas LRU e FBR para caches com até 256 Mbytes de tamanho. Nas partições 3 e 4 em caches com tamanho variando de 256 Mbytes a 2 Gbytes, a política LFU apresentou resultados ligeiramente melhores. Também, verificou-se, novamente, o desempenho inferior da política SIZE em cada partição, tanto na HR quanto na BHR. 


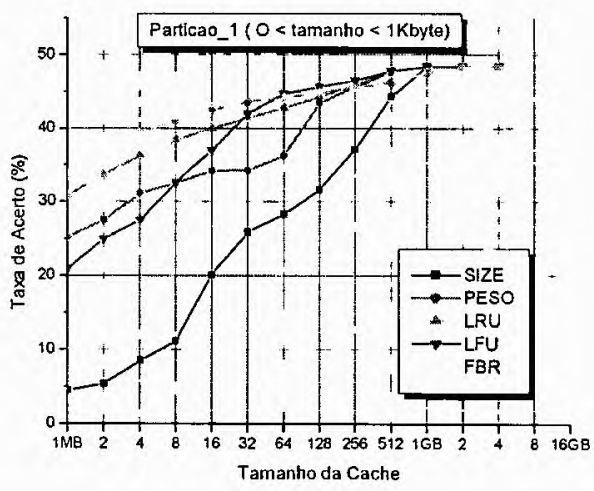

PARTICAO_1 - HR

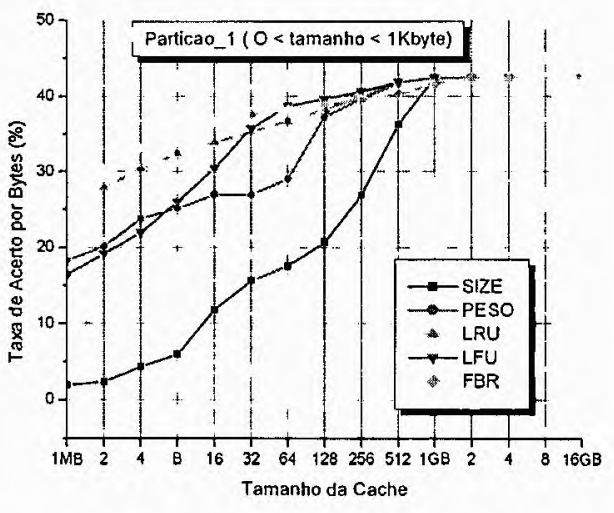

PARTICAO_1-BHR

FIGURA 5.21: Comparação de políticas de substituição de objetos na partição_1.

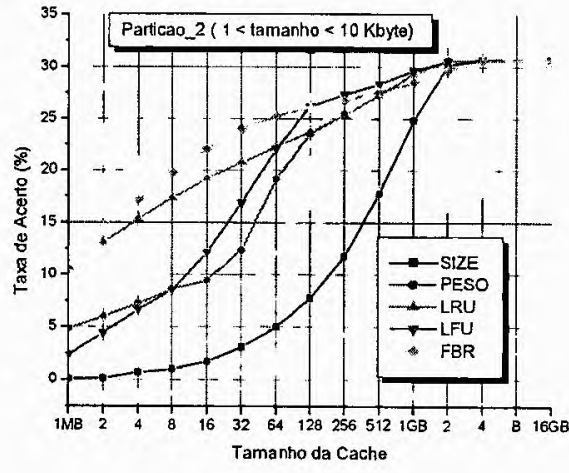

PARTICAO $2-\mathrm{HR}$

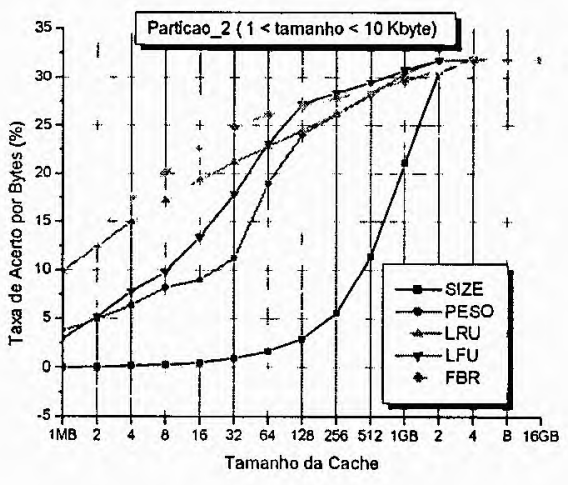

PARTICAO 2 - BHR

FIGURA 5.22: Comparação de políticas de substituição de objetos na partição_1 (BO2).

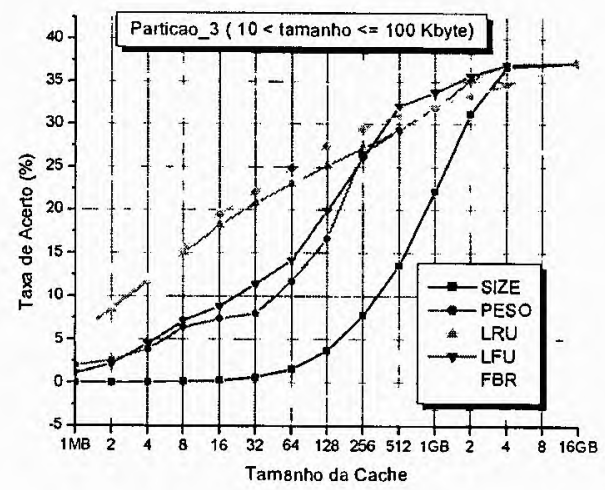

PARTICAO $3-\mathrm{HR}$

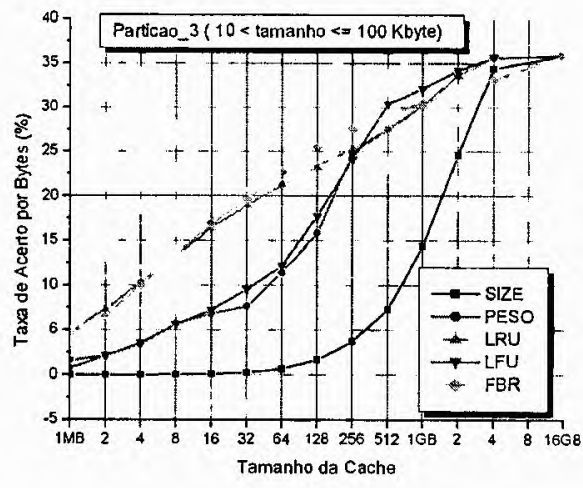

PARTICAO 3 - BHR

FIGURA 5.23: Comparação de políticas de substituição de objetos na partição_3 (BO2). 


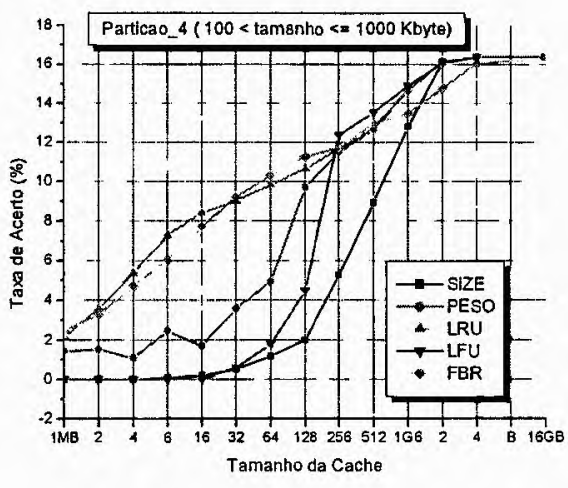

PARTICAO $4-\mathrm{HR}$

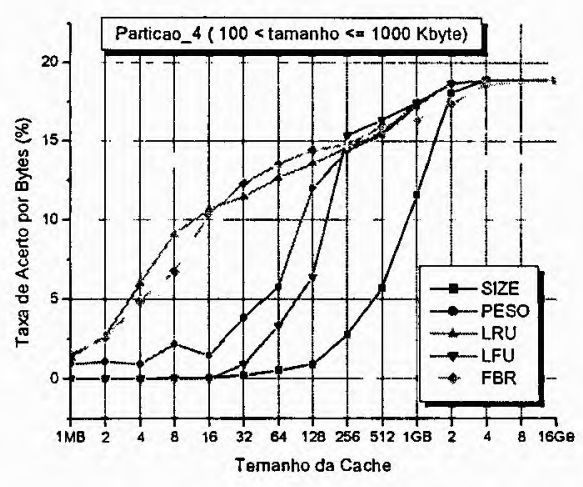

PARTICAO $4-$ - BHR

FIGURA 5.24: Comparação de políticas de substituição de objetos na partição_4 (BO2).

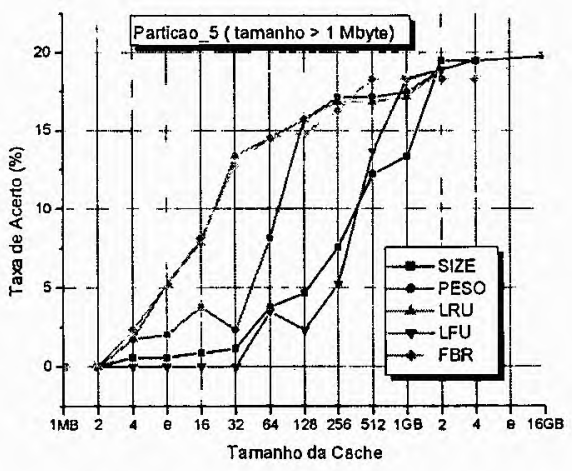

PARTICAO 5-HR

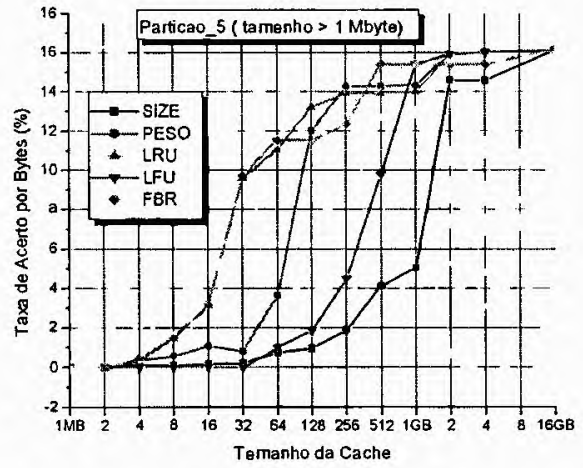

PARTICAO 5 - BHR

FIGURA 5.25: Comparação de políticas de substituição de objetos na partição_5 (BO2).

\subsubsection{Comparação entre Caches não Particionado e Particionado por Classes de Objetos e Tamanho}

Nesta seção são apresentados os resultados do estudo de caracterização de carga, considerando caches não particionado, particionado por classes de objetos e tamanhos. Foram avaliados: o total de objetos presentes no cache ao final da simulação e as medidas de desempenho HR e BHR.

\section{Número de objetos presentes no cache ao final da simulação}

Este estudo tem o objetivo de verificar o efeito do particionamento ao número de objetos presentes no cache ao final da simulação. Foi utilizada a política LRU para todos os casos. Os gráficos apresentam os rótulos PART_5 (particionamento em cinco classes de tamanhos) (Tabela 5.6), PART_3 (particionamento em três classes de tamanhos) (Tabela 
5.7), PART_OBJ (particionamento por classes de objetos) (Tabela 5.5) e NÃO_PART (cache sem particionamento). Os gráficos apresentados na Figura 5.26 mostram os resultados obtidos, quando o número total de objetos armazenados no cache é analisado.

Conforme esperado, em todas as cargas e partições analisadas, o total de objetos aumenta à proporção que o tamanho do cache cresce. No entanto, este número é sempre maior para os caches particionados de acordo com o tamanho dos objetos. No caso de caches com cinco partições, os melhores resultados foram para os caches menores, sendo que no CISC foram para caches com até 512 Mbytes e nas outras cargas até 1 Gbyte. Caches com três partições obtiveram os melhores resultados para caches de tamanho mais elevado.

Os resultados do particionamento por classes de objetos ficaram bem abaixo dos esperados, pois as classes com objetos Hipertextos e Imagens correspondem, em média, a $75 \%$ das referências.

Em média, os caches com cinco partições armazenaram 14,7\% objetos a mais que os cache não particionados, já os caches com três partições armazenaram, em média, 9,9\% objetos a mais do que os caches não particionados, enquanto que os caches particionados por classes de objetos obtiveram resultados piores que os caches não particionados, ficando, em média, com $3,2 \%$ de objetos a menos.

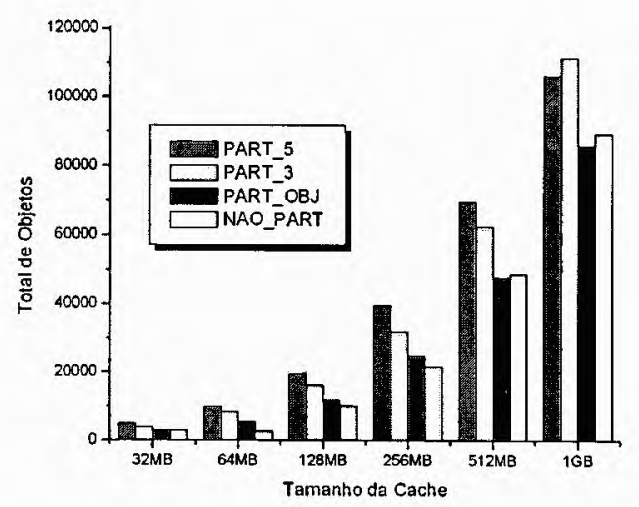

(a) CISC

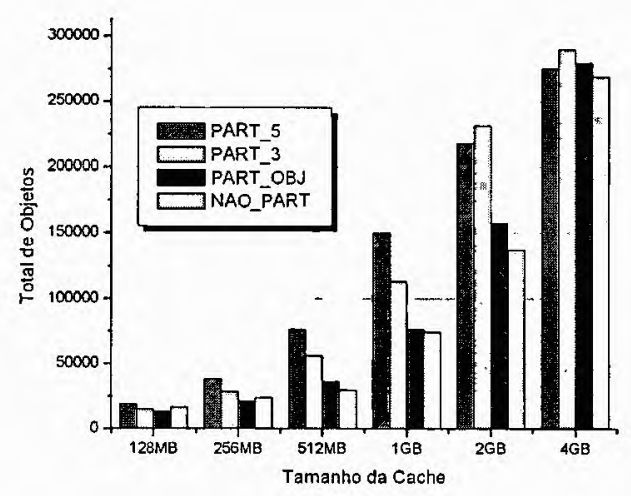

(b) $\mathrm{BO} 2$ 


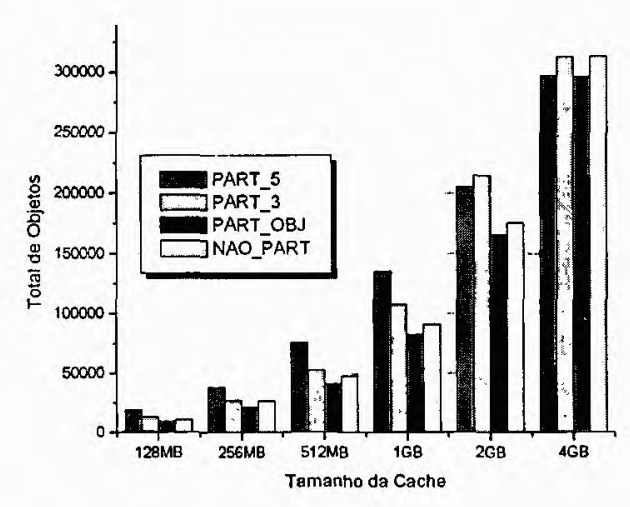

(c) PA

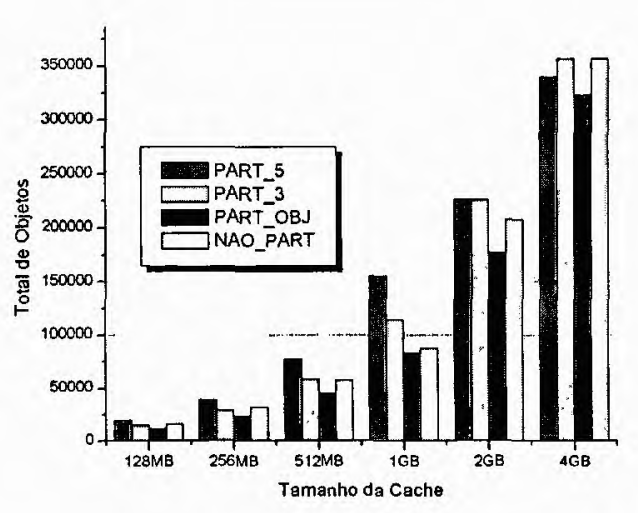

(d) SV

FIGURA 5.26: Total de objetos armazenados no cache ao final da simulação.

\section{HR e BHR}

Os gráficos das Figuras 5.27 a 5.30 mostram os valores de HR e BHR com caches de $16,32,64,128,256$ e 512 Mbytes, 1 e 2 Gbytes para as cargas CISC, BO2, PA e SV. Nesta análise foi utilizada a política FBR, vale destacar que resultados similares foram obtidos por outras políticas de substituição.

Os caches com cinco partições apresentaram, para todas as cargas analisadas, HR melhores em relação aos caches não particionados. $O$ incremento médio foi $5,9 \%$ para o CISC, 4,3\% para $\mathrm{BO} 2,9,83 \%$ para $\mathrm{PA}$ e $9,16 \%$ para $\mathrm{SV}$; enquanto a $\mathrm{BHR}$ se manteve praticamente inalterada, apresentando um decréscimo de, aproximadamente, $1 \%$, para todas as cargas analisadas, em relação aos caches não particionados.

Os caches com três partições apresentaram, em relação a caches não particionados, um aumento médio na $\mathrm{HR}$ de $3,7 \%$ para o CISC, 3,82\% para $\mathrm{BO} 2,5,37 \%$ para $\mathrm{PA}$ e $2,88 \%$ para SV; já a BHR teve um aumento mínimo para o CISC, aproximadamente $0,07 \%$ e $0,38 \%$ para $\mathrm{BO} 2$, enquanto que as cargas $\mathrm{PA}$ e SV apresentaram um decréscimo de $1,14 \%$ e $1,33 \%$, respectivamente.

O particionamento por classes de objetos contribuiu pouco com a $\mathrm{HR}$, em relação a caches não particionados, sendo $1,8 \%$ para o CISC e 0,1\% para BO2 e apresentou um decréscimo de $0,54 \%$ e $2,5 \%$ para as cargas PA e SV, enquanto que a BHR alcançou um aumento sensível de $0,63 \%$ para o CISC e um decréscimo de 3,2\% para $\mathrm{BO} 2,2,21 \%$ para PA e $2,05 \%$ para SV. 
O aumento da HR é bem menor do que a quantidade de objetos mantidos no cache. Este resultado é diretamente influenciado pela quantidade elevada de objetos acessados somente uma vez (Tabela 4.9). Resultados semelhantes foram obtidos em Murta (1999), que concluiu que não há uma relação diretamente proporcional entre o número de objetos armazenados no cache e a HR.

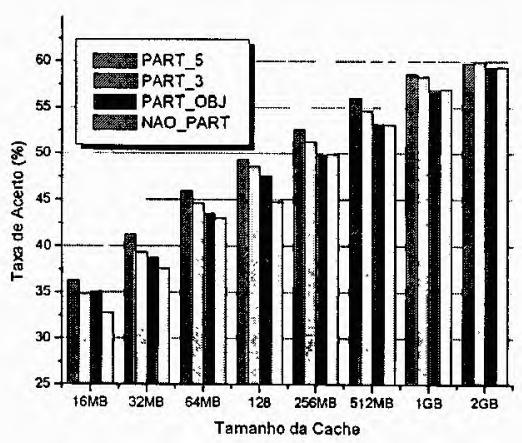

CISC (HR)

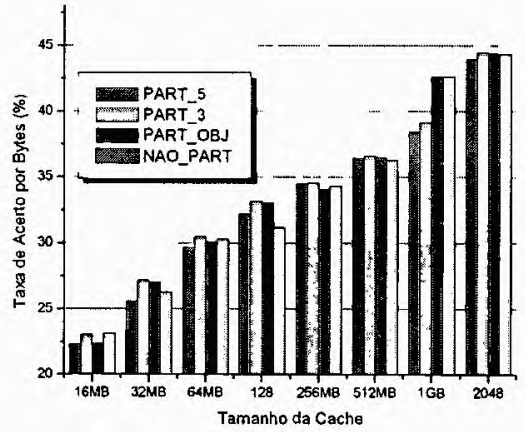

CISC (BHR)

FIGURA 5.27: HR e BHR para quatro configurações no espaço de armazenamento dos caches (CISC).

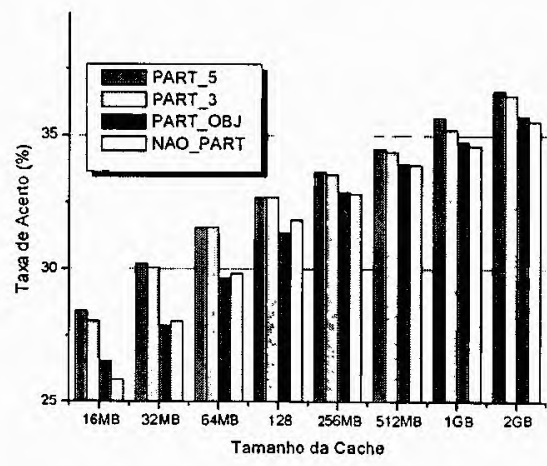

$\mathrm{BO} 2(\mathrm{HR})$

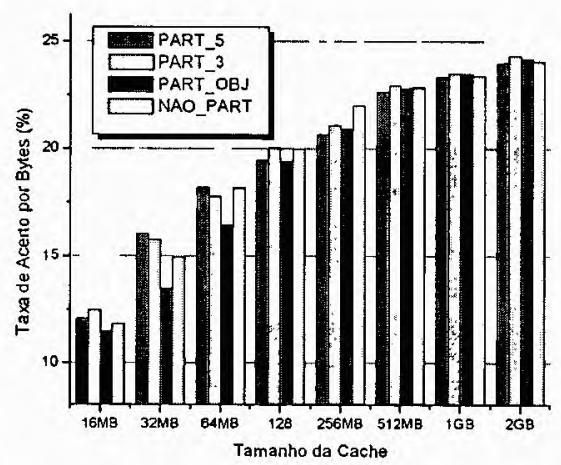

$\mathrm{BO} 2$ (BHR)

FIGURA 5.28: HR e BHR para quatro configurações no espaço de armazenamento dos caches (BO2).

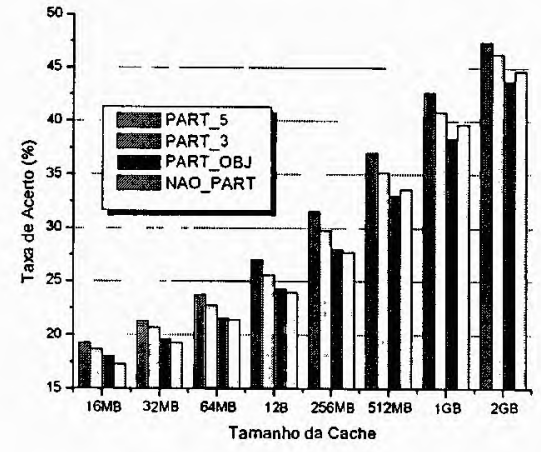

PA (HR)

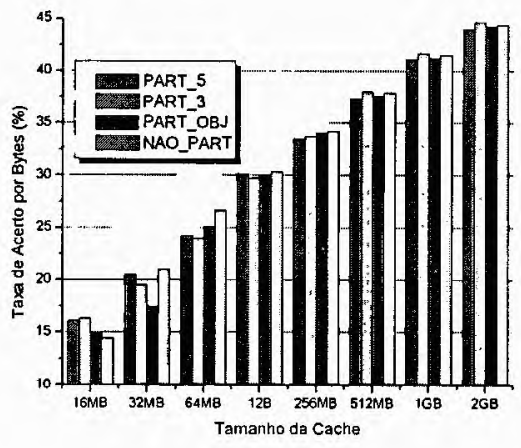

PA (BHR)

FIGURA 5.29: HR e BHR para quatro configurações no espaço de armazenamento dos caches (PA). 


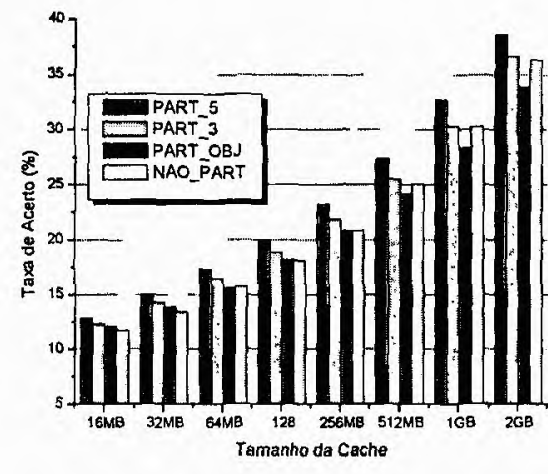

SV (HR)

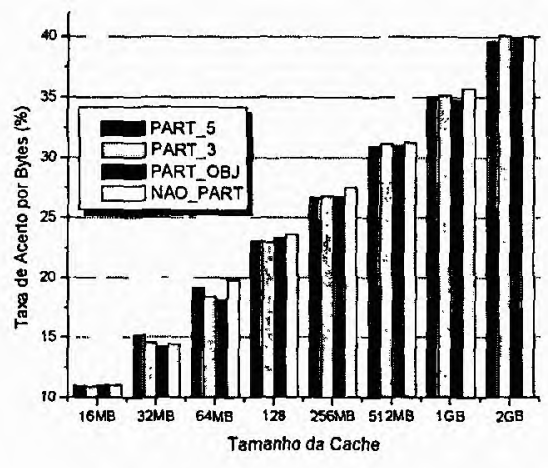

SV (BHR)

FIGURA 5.30: HR e BHR para quatro configuraç̃es no espaço de armazenamento dos caches (SV).

O particionamento do cache em classes de tamanho permite uma melhor utilização do espaço de armazenamento, pois ameniza o problema da variabilidade, em que a chegada de um objeto de tamanho elevado pode gerar a retirada de centenas ou milhares de objetos menores, alterando completamente o estado do cache. Verificou-se, também, que o ganho de desempenho em caches particionados está intrinsecamente relacionado com a escolha adequada dos parâmetros de particionamento.

\subsection{Considerações Finais}

Este capítulo apresentou uma avaliação de desempenho de caches na Web. Foi utilizada uma simulação trace-driven para avaliar o impacto de políticas de substituição, o efeito de atribuir um limiar inferior e um superior no cache, assim como o seu particionamento por classes de objetos e tamanho.

Os resultados apresentados na seção 5.6.4 mostraram que a atribuição de um limiar superior pode melhorar a HR, apesar de degradar a BHR. Na avaliação das políticas de substituição sem particionamento, a política SIZE apresentou a melhor HR e a pior BHR, enquanto que a política $\mathrm{LFU}^{*}$-Aging apresentou desempenho satisfatório em todas as cargas analisadas, tanto para HR quanto para a BHR. Já a política PESO, proposta neste trabalho, obteve resultados intermediários para as duas métricas analisadas.

Em todas as cargas que consideram o particionamento, a política SIZE apresentou HR e BHR inferiores, o que comprova que o seu uso não é adequado em caches particionados. As políticas PESO e LFU apresentaram resultados intermediários, tanto na 
HR quanto na BHR, sendo que na maioria dos casos estas políticas apresentaram valores bastante satisfatórios nas HR e BHR em caches de tamanhos elevados.

Caches com cinco partições apresentaram HR melhor, enquanto a BHR se manteve praticamente inalterada. Caches com três partições tiveram um aumento menor na HR e uma melhora moderada na BHR. Já a utilização de particionamento por classes de objetos não foi proveitosa em relação aos caches não particionados. Em todos os modelos de partição as políticas que alcançaram melhores desempenhos foram baseadas em caches tradicionais, neste caso, as políticas LRU e FBR. O grande mérito destes resultados está em o particionamento de caches controlar melhor a variabilidade no tamanho dos objetos, conforme os resultados apresentados na Tabela 4.15, que mostrou coeficientes de variação bem menores que os caches não particionados. Nota-se que o particionamento traz o problema dos caches na Web um tanto afim de caches tradicionais.

Verificou-se que a política PESO em quase todos os casos apresentou resultados intermediários, sendo que a latência, devido a grande variabilidade observada nas cargas de trabalho analisadas, contribuiu significativamente para que os resultados não fossem melhores. Cao e Irani (1997) constataram que a variância para recuperar o mesmo objeto variou de 5 a 500\% para as cargas analisadas; este resultado revela que a latência não é um parâmetro adequado.

É importante frisar que a escolha adequada do número de partições e o espaço destinado a cada uma destas partições necessita de um conhecimento detalhado das características de carga, sendo que todas as escolhas realizadas neste estudo foram baseadas nos resultados apresentados no capítulo 4 . 
Capitulo 6

\section{Conclusões, Contribuições e Propostas para Trabalhos Futuros}

\subsection{Considerações Sobre a Revisão Bibliográfica}

Este trabalho apresentou uma avaliação de desempenho dos caches na Web, com o objetivo de ponderar sobre o impacto ocasionado por políticas de substituição de objetos por meio de diversas organizações de espaço nos caches.

Inicialmente, apresentou-se uma visão geral sobre a Web, destacando-se seus principais componentes: o cliente, o servidor e o proxy e seu paradigma de interação cliente-servidor.

Em seguida, foi apresentado o estado da arte dos caches na Web, frisando as suas principais diferenças com caches tradicionais. Foi mostrado, também, um panorama das principais estratégias de implementação de caches na Web, assim como vantagens e desvantagens em sua utilização. Comentou-se sobre o problema de consistência de caches e suas topologias hierárquica e cooperativa. Também, fez-se um mapa das principais políticas, categorizando-as de acordo com a quantidade de parâmetros considerados nos algoritmos de substituição. Finalmente, foi apresentada a proposta de uma nova política de substituição de objetos, denominada PESO. 
O crescimento da Web tem motivado pesquisas que buscam explorar técnicas para nela fornecer desempenho; em virtude disso, foi realizada uma revisão bibliográfica sobre trabalhos relacionados com a caracterização de carga da Web. Também foi mostrado um estudo de caracterização de carga, com objetivo de adquirir uma melhor percepção e entendimento das cargas de servidores proxy estudadas, assim como retratar o seu padrão de acesso, o impacto dos objetos acessados uma única vez e a concentração das referências e dos bytes transferidos, para possibilitar um melhor planejamento e parametrização na avaliação de desempenho de caches na Web.

Foi avaliado o impacto das políticas de substituição de objetos, o efeito de atribuir um limiar inferior e superior aos objetos aceitos no cache, assim como o seu particionamento por classes de objeto e tamanho.

\subsection{Resultados, Contribuições e Conclusões}

As contribuições mais importantes deste trabalho apresentam-se em dois grupos: (1) estudo de caracterização de carga da Web e (2) avaliação de desempenho de políticas de substituição, considerando diversas organizações de espaço de caches na Web.

O primeiro grupo de contribuições deste trabalho é a caracterização de carga desenvolvida com quatro cargas de servidores proxy que implementam caches na Web. Este estudo traz subsídios, apontando direções e limitações na implementação de sistemas de caches na Web. Algumas características relevantes para o conjunto de cargas analisadas e que têm influência direta nos sistemas de caches na Web, são:

- mais de $70 \%$ dos objetos são acessados somente uma vez, o que corresponde a uma fração considerável da cardinalidade do conjunto de objetos;

- a metade dos objetos acessados é menor que 3 Kbytes e o tamanho médio dos objetos ficou abaixo de 13,4 Kbytes; o coeficiente de variação variou de 12,7 a 32,4 revelando a grande variabilidade em todas as cargas analisadas;

- $20 \%$ dos objetos correspondem de 50 a $65 \%$ das requisições e $10 \%$ dos objetos correspondem a $80 \%$ dos bytes transferidos; 
- um aumento significativo para as requisições dinâmicas em relação a trabalhos anteriores, entre $8 \%$ e $25,8 \%$, acarretado principalmente por scripts que executam no lado servidor;

- $\quad 99,3 \%$ das requisições compreendem objetos menores que 100 Kbytes;

- objetos acima de $1 \mathrm{Mbyte}$, apesar de ter, em média, somente 0,07\% das referências, correspondem a $33,22 \%$ dos bytes transferidos;

- imagens correspondem à maioria das requisições, entre 52,23\% e 74,37\%. Estes resultados são semelhantes a estudos anteriores, porém houve uma diminuição na quantidade de bytes transferidos.

No segundo grupo de contribuições, destaca-se a avaliação de desempenho de políticas de substituição de caches na Web, simuladas neste trabalho, considerando diversas configurações diferentes. Os resultados observados são:

- em caches sem particionamento a política SIZE apresentou a melhor HR e a pior $\mathrm{BHR}$, enquanto que a política LFU*-Aging apresentou desempenho satisfatório em todas as cargas analisadas, tanto para HR quanto para a BHR. Esta política trata diretamente o problema apresentado no estudo de caracterização de carga, que é a quantidade elevada de objetos acessados somente uma vez. Vale destacar que o parâmetro $A_{\max }$ desta política precisa de uma parametrização cuidadosa para apresentar desempenho satisfatório;

- a atribuição de um limiar superior para os objetos aceitos no cache pode melhorar a HR, apesar de degradar a BHR;

- constatou-se que a política SIZE em caches particionados tanto por classes de objetos quanto por classes de tamanho, não apresentou desempenho satisfatório. As políticas PESO e LFU apresentaram resultados intermediários, tanto na $\mathrm{HR}$ quanto na BHR;

- caches com cinco partições apresentaram HR melhor, enquanto a BHR se manteve praticamente inalterada em relação aos caches não particionados; enquanto caches com três partições apresentaram um aumento menor na HR e uma melhora moderada na BHR; 
- a utilização de particionamento por classes de objetos não foi vantajosa em relação aos caches não particionados;

- em todos os modelos de partição as políticas que tiveram melhor desempenho foram baseadas em caches tradicionais (LRU e FBR);

- verificou-se que a política PESO apresentou resultados intermediários na maioria dos resultados apresentados;

- a escolha adequada do total de partições e do espaço destinado a cada uma destas partições necessita de um conhecimento aprofundado das características de carga.

O presente trabalho conseguiu atingir seus objetivos, fornecendo um entendimento melhor das cargas de trabalho atuais, como forma de embasamento à implementação de caches na Web e suas políticas de substituição. Algumas diretrizes a serem seguidas para o particionamento de caches na Web foram delineadas e o desempenho de políticas de substituição com diversas organizações de seu espaço de armazenamento foram avaliadas.

\subsection{Trabalhos Futuros}

O trabalho desenvolvido nesta dissertação poderá ter continuidade para melhoramentos ou trabalhos futuros:

- o desenvolvimento de um ambiente gráfico que permita a descrição gráfica em tempo de execução das HR e BHR das políticas de substituições analisadas;

- a inclusão de maneira explicita de técnicas de admissão em caches na Web, devido à proporção elevada de objetos acessados somente uma vez;

- expandir o simulador para tratar diversas questões relevantes em caches na Web, como a implantação de novas políticas e o problema de consistência;

- introduzir o prefetching de objetos com objetivo de avaliar o seu impacto na poluição do cache e na melhora das métricas HR e BHR.

- acrescentar as políticas analisadas e o particionamento por classes de tamanho ao servidor proxy Squid. 
Como é possível constatar, são várias as direções em que se pode expandir e melhorar o trabalho apresentado, o que, é um objetivo que se tinha em mente ao iniciá-lo, pois este trabalho é o primeiro a tratar o uso de caches na Web no Laboratório de Sistemas Distribuídos e Programação Concorrente do ICMC - USP. 


\section{Referências Bibliográficas}

(Abdulla et al., 1997) Abdulla, G.; Fox, E.; Abrams, M.; Williams, S. WWW Proxy Traffic Characterization with Application to Caching. Technical Report TR97-03, Departamento de Ciência da Computação, Virginia Tech, Março, 1997.

Disponível em: http://www.cs.vt.edu/ chitra/work.html, 03/2001.

(Aggarwal, \& Yu, Aggarwal, C. C.; Yu, P. On Disk Caching of Web Objects in Proxy 1997) Servers. Proc. 6th International Conference on Information and Knowledge Management, 1997.

(Aggarwal et al., 1997)

Aggarwal, C. C.; Wolf, J.; Yu, P. e Epelman, M. On Caching Policies for Web Objects. Research Report RC 20619, Divisão de Pesquisas da IBM, T.J.Watson Research Center, Yorktown Heights, NY, Março, 1997.

(Arlitt \& Williamson, Arlitt, M.; Williamson, C. Web Server Workload Characterization. Proc. 1996a) of 1996 SIGMETRICS Conference on Measurement and Modeling of Computer Systems, Maio, 1996.

(Arlitt \& Williamson, Arlitt, M.; Williamson, C. Trace-Driven Simulation of Document Caching 1996b)

Strategies for Internet Web Server. Proc. of 1996Departamento de Ciência da Computação, Universidade de Saskatchewan, SK, Canadá, Setembro, 1996.

(Arlitt et al., 2000) Arlitt, M.; Friedrich, Rich; Jin, Tai. Performance Evaluation of Web Proxy Cache Replacement Policies. Performance Evaluation Vol. 39, pp 149-164, 2000.

(Barish \& Obraczka, Barish, G.; Obraczka, K;. World Wide Web Caching: Trends and 2000) techniques. IEEE Communications Magazine, Vol. 38, pp 178 - 184, Maio, 2000.

(Berners-Lee et al., 1994a)

Berners-Lee, T.; Cailliau, R.; Luotonen, H.; Frystyck, Nielson e Secret, A. The World Wide Web. Communications of the ACM, Vol. 37, No. 8, pp. 76-82, Agosto, 1994. 
(Berners-Lee et al., 1994b)

(Bolot \& Hoschka, 1996)

(Brandão \& Anido, 2001)

(CacheNow, 2001)

(Cao \& Irani, 1997)

(Cesário et al., 1997)

(Chankhunthod, et al., 1996)

(Crovella \& Bestavros 1996)

(Dilley et al., 1999)
Berners-Lee, T.; Masinter, L. e Mccahil, M. Uniform Resource Locators. RFC 1738, Dezembro, 1994.

Bolot, J, C \& Hoschka, P. Performance engineering of the world wide web: Application to dimensioning and cache design. Proc. of the 5th WWW Conference, Paris, Maio, 1996.

Brandão, Roberto Ferreira; Anido, Ricardo de Oliveira. Um simulador paralelo para sistemas de caches para Web. Simpósio Brasileiro de Redes de Computadores, Florianópolis, Santa Catarina, maio, 2001.

Campanha Cache Now.

Disponível em: http://vancouver-webpages.com/CacheNow/, 05/2001.

Cao, P.; Irani, S. Cost-Aware WWW Proxy Caching Algorithms. Proceedings of USENLX Symposium on Internet Technologies and Systems (USITS), Monterey, CA, pp. 193-206, Dezembro, 1997.

Cesário, M. A. G.; Pinto, L. M.; Monteiro, M. S. Cache: Melhor Aproveitamento dos Recursos na Internet. RNP News Generation, 1(2), Junho, 1997.

Chankhunthod, Anawat; Schwartz, Michael; Danzig, Peter; Worrell, Kurt; Neerdaels, Chuck. A Hierarchical Internet Object Cache. Proceedings of Usenix, Technical Conference, 1996.

Crovella, Mark E.; Bestavros, Azer. Self-Similarity in WWW - Evidence and Possible Causes. Proceedings of the 1996 ACM SIGMETRICS Conference, Philadelphia, PA, Maio, 1996.

Dilley, John; Arlitt, Martin; Perret, Stéphane. Enhancement and Validation of Squid's Cache Replacement Policy. HP Laboratories, Palo Alto, Maio, 1999.

(Fielding et al., 1998) Fielding, R.; Gettys, J.; Mogul, J.; Frystyk, H.; Masinter, L.; Leach, P.; Berners-Lee, T. Hypertext Transfer Protocol - HTTP/1.1, HTTP Working Group. Internet Draft, Novembro, 1998.

Disponível em: http://www.w3.org/Protocols/HTTP/1.1/ draft-ietf-httpv11- spec-rev-06.txt, 03/2001.

(Fonseca et al., 1998) Fonseca, E. L. S.; Almeida, Virgílio A. F. e Meira, Wagner Jr. Análise de Desempenho de Servidores Proxy Cache WWW. Universidade 
(Gwertzman \&

Seltzer, 1996)

(Jain, 1991)

(Mahanti \& Williamson, 1999)

(Markatos, 1996)

(Murta, 1999)

(Murta \& Almeida, 2000)

(NLANR, 2001)

(Rizzo \& Vicisano, 1998)

(Rodriguez et al., 1999)

(Stallings, 2000)
Federal de Minas Gerais, 1998.

Disponível em:

http://www.dcc.ufmg.br/pos/html/spg98/anais/erik/erik.html. 08/2001.

Gwertzman, J.; Seltzer, M. World-Wide Web Cache Consistency. Proceedings of the 1996 USENIX Technical Conference, San Diego, CA, pp. 141-151, Janeiro, 1996.

Jain, R. The Art of Computer Systems Performance Analysis: Techniques for Experimental Design, Measurement, Simulation, and Modeling, New York, NY, 1991.

Mahanti, Anirban; Williamson, Carey. Web Proxy Workload Characterization. Departamento de Ciência da Computação, Universidade de Saskatchewan, SK, Canadá, Fevereiro, 1999.

Markatos, Evangelos, P. Main Memory Caching of Web Documents, Computer Networks and ISDN Systems, Proceedings of the Fifth International WWW Conference, Maio, 1996.

Murta, C. D. Modelo de Particionamento de Espaço para Caches da World Wide Web. Tese de Doutorado, Universidade Federal de Minas Gerais, 1999.

Murta, C. D.; Almeida, V. A. F. Modelo de Particionamento de Espaço para Caches da World Wide Web. Universidade Federal de Minas Gerais, 2000.

National Laboratoty for Applied Network Research, NLANR sanitized access logs.

Disponivel em: ftp://ircache.nlanr.net/Traces, junho, 2001.

Rizzo, L.; Vicisano, L. Replacement Policies for a Proxy Cache. IEEE/ACM Transactions on Networking, Vol. 8, No. 2, pp. 158-170, 1998 .

Rodriguez, Pablo; Spanner, Christian; e Biersack, Ernst, W. Web Caching Architectures: Hierarchical and distributed caching. In 4th International Caching Workshop, Março, 1999.

Stalling, W. Computer Organization and Architecture. $5^{\mathrm{a}}$ Edição, Prentice Hall, 2000. 
(Tanenbaum, 1995) Tanenbaum, A. S. Sistemas Operacionais Modernos. Prentice Hall Inc, 1995.

(Tanenbaum, 1997) Tanembaum, A. S. Computer Networks, Prentice Hall Inc, 1997.

(Vass et al., 1998) Vass, J.; Harwell, J.; Bharadvaj, H.; Joshi, A. The World Wide Web: Everything you never wanted to know about its servers, IEEE Potentials, Vol. 17, No. 4, pp. 33-34, Novembro, 1998.

(Wang, 1999)

Wang, Jia. A survey of web caching schemes for the Internet. $A C M$ Computer Communication Review. Vol. 29, N 5, pp. 36-46, Outubro, 1999.

(Wessels \& Claffy, Wessels, D; Claffy, K. RFC 2187: Application of internet cache protocol 1997) (ICP), versão 2" Setembro, 1997. Disponível em: http://www.squid-cache.org/Doc/rfc2186.txt, Junho, 2001.

(Williams et al., 1996)

Williams, S., Abrams, M., Standbridge, C.R., Abdulla, G., Fox,E.A.. Removal Policies in Network Caches for World-Wide Web Documents. In Proceedings of the ACM Sigcomm96, Agosto, 1996, Stanford University.

(Wooster \& Abrams, Wooster, R.; Abrams, M. Proxy caching that estimates page load delays. 1997) Proceedings of the 6th World Wide Web Conference, Santa Clara, California, 1997. 